\title{
The Discrete Agglomeration Model: Equivalent Problems
}

\author{
James L. Moseley \\ West Virginia University, Morgantown, USA \\ Email: moseley@math.wvu.edu
}

Received July 22, 2011; revised October 11, 2012; accepted October 18, 2012

\begin{abstract}
In this paper we develop equivalent problems for the Discrete Agglomeration Model in the continuous context.
\end{abstract}

Keywords: Agglomeration; Coagulation; Smoluchowski; Differential Equations

\section{Introduction}

Agglomeration of particles in a fluid environment (e.g., a chemical reactor or the atmosphere) is an integral part of many industrial processes (e.g., Goldberger [1]) and has been the subject of scientific investigation (e.g., Siegell [2]). A fundamental mathematical problem is the determination of the number of particles of each particle-type as a function of time for a system of particles that may agglutinate during two particle collisions. Little analytical work has been done for systems where particle-type requires several variables. Efforts have focused on particle size (or mass). This allows use of what is often called the coagulation equation which has been well studied in aerosol research (Drake [3]). Original work on this equation was done by Smoluchowski [4]) and it is also referred to as Smoluchowski's equation. The agglomeration equation is perhaps more descriptive since the term coagulation implies a process carried out until solidification whereas we focus on the agglomeration process; that is, on the determination of a time-varying particle-size distribution even if coagulation is never reached.

In his original work Smoluchowski considered the agglomeration equation in a discrete form. Later it was considered in a continuous form by Muller [5]). In either case, an initial particle-size distribution to specify the initial number of particles for each particle size is needed to complete the initial value problem (IVP). We refer to these as the Discrete Agglomeration Model and the Continuum Agglomeration Model respectively. Solution of either model yields an updated particle-size distribution giving number densities as time progresses. For various conditions, studies of these and more general models include Morganstern [6], Melzak [7], Mcleod [8], Marcus [9], White [10], Spouge [11], Treat [12], McLaughlin, Lamb, and McBride [13], Moseley [14], and Moseley [15].

Let $\mathbf{R}$ be the real numbers, $\operatorname{Int}_{\mathrm{o}}=\{\mathrm{I} \subseteq \mathbf{R}: \mathrm{I}$ is a finite, infinite, or semi-infinite open interval $\}$, and for $\mathrm{I} \in \mathrm{Int}_{\mathrm{o}}$, $\mathscr{A}(\mathrm{I}, \mathbf{R})=\{\mathrm{f} ; \mathrm{I} \rightarrow \mathbf{R} ; \mathrm{f}$ is analytic on $\mathrm{I}\}$ $\subseteq \mathrm{C}^{1}(\mathrm{I}, \mathbf{R})=\{\mathrm{f}: \mathrm{I} \rightarrow \mathbf{R}: \mathrm{f}$ is continuously differential on $\mathrm{I}\}$ $\subseteq \mathrm{C}(\mathrm{I}, \mathrm{R})=\{\mathrm{f}: \mathrm{I} \rightarrow \mathrm{R}: \mathrm{f}$ is continuous on $\mathrm{I}\}$ $\subseteq \mathscr{F}(\mathrm{I}, \mathbf{R})=\{\mathrm{f}: \mathrm{I} \rightarrow \mathbf{R}: \mathrm{f}$ is a function on $\mathrm{I}\}$

If $A$ is a subspace of a vector space $B$ we write $\mathrm{A} \subseteq_{\mathrm{vs}} \mathrm{B}$. These function spaces are vector spaces and $\mathscr{A}(\mathrm{I}, \mathbf{R}) \subseteq_{\mathrm{vs}} \mathrm{C}^{1}(\mathrm{I}, \mathbf{R}) \subseteq_{\mathrm{vs}} \mathrm{C}(\mathrm{I}, \mathbf{R}) \subseteq_{\mathrm{vs}} \mathrm{F}(\mathrm{I}, \mathbf{R})$

To develop the discrete model, assume that all particles are a multiple of a particle of smallest size (volume), say $\Delta \mathrm{v}$. Thus a particle made up of $\mathrm{i}$ smallest-sized particles has size $\mathrm{i} \Delta \mathrm{v}$. In polymer chemistry, the particle is called an i-mer. The initial time is $\mathrm{t}_{0} \in \mathrm{I}_{0} \in \mathrm{Int}_{\mathrm{o}}$ where $\mathrm{I}_{0}$ is the largest time interval of interest. We indicate this by the extended interval notation $I_{0}=\left(t_{0-}, t_{0}, t_{0+}\right)$. We also let $\operatorname{Int}_{\mathrm{o}}\left(\mathrm{I}_{0}\right)=\left\{\mathrm{I} \in \mathrm{Int}_{\mathrm{o}}: \mathrm{I} \subseteq \mathrm{I}_{0}\right\}$ and Int $_{\mathrm{o}}\left(\mathrm{t}_{0}, \mathrm{I}_{0}\right)=\left\{\mathrm{I} \in \mathrm{Int}_{\mathrm{o}}: \mathrm{t}_{0} \in \mathrm{I} \subseteq \mathrm{I}_{0}\right\}$. Unless otherwise specified, we assume $I \in \operatorname{Int}_{\mathrm{o}}\left(\mathrm{I}_{0}\right)$. Now for each $\mathrm{i} \in \mathbf{N}=\{1,2,3, \cdots\}$ let $\mathrm{n}_{\mathrm{i}}(\mathrm{t})$ be a real-valued function (either in $\mathrm{C}^{1}(\mathrm{I}, \mathbf{R})$ or $\left.\mathscr{A}(\mathrm{I}, \mathbf{R})\right)$ that approximates the number of $\mathrm{i}$-mers in the reactor at time $t$. Since there are an infinite number of sizes, initially, we take the state (or phase) space to be $\mathbf{R}^{\infty}=\left\{\left\{a_{i}\right\}_{i=1}^{\infty}: a_{i} \in \mathbf{R}\right\}$. Assume the initial number density $\boldsymbol{n}_{0}=\left\{\mathrm{n}_{\mathrm{i}}^{0}\right\}_{\mathrm{i}=1}^{\infty} \in \mathbf{R}^{\infty}$ is known. As time passes, particles collide, agglutinations occur, and larger particles result. The net rate of increase in $n_{i}(t)$ with time, $\mathrm{dn}_{\mathrm{i}} / \mathrm{dt}$, is the rate of formation minus the rate of depletion (conservation of mass). For $I \in \operatorname{Int}_{\mathrm{o}}\left(\mathrm{t}_{0}, \mathrm{I}_{0}\right)$ we consider as a possible $\Sigma$ space (i.e., the designated space where we look for solutions) either $\mathscr{A}_{\mathrm{cw}}\left(\mathrm{I}, \mathbf{R}^{\infty}\right)$ for the analytic context or $\boldsymbol{C}_{\mathrm{cw}}^{1}\left(\mathrm{I}, \mathbf{R}^{\infty}\right)$ for the continuous context where 


$$
\begin{aligned}
& \mathscr{A}_{\mathrm{cw}}\left(\mathrm{I}, \mathbf{R}^{\infty}\right)=\left\{\boldsymbol{n}=\left\{\mathrm{n}_{\mathrm{i}}(\mathrm{t})\right\}_{\mathrm{i}=1}^{\infty}: \mathrm{n}_{\mathrm{i}}(\mathrm{t}) \in \mathscr{A}(\mathrm{I}, \mathbf{R})\right\} \\
& \subseteq_{\mathrm{vs}} \boldsymbol{C}_{\mathrm{cw}}^{1}\left(\mathrm{I}, \mathbf{R}^{\infty}\right)=\left\{\boldsymbol{n}=\left\{\mathrm{n}_{\mathrm{i}}(\mathrm{t})\right\}_{\mathrm{i}=1}^{\infty}: \mathrm{n}_{\mathrm{i}}(\mathrm{t}) \in \mathrm{C}^{1}(\mathrm{I}, \mathbf{R})\right\} \\
& \subseteq_{\mathrm{vs}} \boldsymbol{C}_{\mathrm{cw}}^{1}\left(\mathrm{I}, \mathbf{R}^{\infty}\right)=\left\{\boldsymbol{n}=\left\{\mathrm{n}_{\mathrm{i}}(\mathrm{t})\right\}_{\mathrm{i}=1}^{\infty}: \mathrm{n}_{\mathrm{i}}(\mathrm{t}) \in \mathrm{C}(\mathrm{I}, \mathbf{R})\right\} \\
& \subseteq_{\mathrm{vs}} \mathscr{F}_{\mathrm{cw}}\left(\mathrm{I}, \mathbf{R}^{\infty}\right)=\left\{\boldsymbol{n}=\left\{\mathrm{n}_{\mathrm{i}}(\mathrm{t})\right\}_{\mathrm{i}=1}^{\infty}: \mathrm{n}_{\mathrm{i}}(\mathrm{t}) \in \mathscr{F}(\mathrm{I}, \mathbf{R})\right\}
\end{aligned}
$$

Functions in $\mathrm{C}(\mathrm{I}, \mathbf{R})$ are continuous, but functions in $\boldsymbol{C}_{\mathrm{cw}}\left(\mathrm{I}, \mathbf{R}^{\infty}\right)$ are not as we have not established a topology on $\mathbf{R}^{\infty}$. They are componentwise continuous.

For $\boldsymbol{n}=\left\{\mathrm{n}_{\mathrm{i}}(\mathrm{t})\right\}_{\mathrm{i}=1}^{\infty} \in \boldsymbol{C}_{\mathrm{cw}}^{1}\left(\mathrm{I}, \mathbf{R}^{\infty}\right)$ we may define $\mathrm{d} \boldsymbol{n} / \mathrm{dt}=\left\{\mathrm{dn}_{\mathrm{i}} / \mathrm{dt}^{\infty}\right\}_{i=1}^{\infty}$. The derivatives $\mathrm{dn}_{\mathrm{i}} / \mathrm{dt}$ exist and are in $C(I, R)$. However, we can not assert that $\mathrm{d} \boldsymbol{n} / \mathrm{dt}=\lim _{\mathrm{h} \rightarrow 0}[(\boldsymbol{n}(\mathrm{t}+\mathrm{h})-\boldsymbol{n}(\mathrm{t})) / \mathrm{h}]$ as we have no topology on $\mathbf{R}^{\infty}$.

Let $\mathbf{R}^{\infty \times \infty}=\left\{\left\{a_{i, j}\right\}_{i, j=1}^{\infty}: a_{i, j} \in \mathbf{R}\right\}$ be the set of "infinite matrices". The kernel (which measures adhesion or "stickiness"), $\mathbf{K}(\mathbf{t})=\left\{\mathrm{K}_{\mathrm{i}, \mathrm{j}}(\mathrm{t})\right\}_{\mathrm{i}, \mathrm{j}=1}^{\infty}$, is a doubly infinite array of real-valued functions of time either in

$$
\begin{aligned}
\mathscr{A}_{\mathrm{cw}}\left(\mathrm{I}_{0}, \mathbf{R}^{\infty \times \infty}\right)= & \left\{\mathrm{K}(\mathrm{t})=\left\{\mathrm{K}_{\mathrm{ij}}(\mathrm{t})\right\}_{\mathrm{i}, \mathrm{j}=1}^{\infty} \text { : for all } \mathrm{i}, \mathrm{j} \in \mathbf{N},\right. \\
& \left.\mathrm{K}_{\mathrm{i}, \mathrm{j}}(\mathrm{t}) \in \mathscr{A}\left(\mathrm{I}_{0}, \mathbf{R}\right)\right\}
\end{aligned}
$$

(analytic context) or in

$$
\begin{aligned}
\mathrm{C}_{\mathrm{cw}}\left(\mathrm{I}_{0}, \mathbf{R}^{\infty \times \infty}\right)= & \left\{\mathrm{K}(\mathrm{t})=\left\{\mathrm{K}_{\mathrm{ij}}(\mathrm{t})\right\}_{\mathrm{i}, \mathrm{j}=1}^{\infty} \text { : for all } \mathrm{i}, \mathrm{j} \in \mathbf{N},\right. \\
& \left.\mathrm{K}_{\mathrm{i}, \mathrm{j}}(\mathrm{t}) \in \mathrm{C}\left(\mathrm{I}_{0}, \mathbf{R}\right)\right\}
\end{aligned}
$$

(continuous context). As with $\mathbf{R}^{\infty}$, we establish no topology on $\mathbf{R}^{\infty \times \infty}$.

The resultant Discrete Agglomeration Model or Discrete Agglomeration Problem (DAP) is an IVP consisting of an infinite system of Ordinary Differential Equations (ODE's) each with an Initial Condition (IC) that may be written in scalar (componentwise) form as:

$$
\begin{array}{r}
\text { ODE's } \frac{d n_{i}}{d t}=\frac{1}{2} \sum_{j=i}^{i-1} K_{i-j, j}(t) n_{i-j} n_{j}-n_{i} \sum_{j=1}^{\infty} K_{i, j}(t) n_{j}, \\
t \in I_{0}=\left(t_{0-}, t_{0}, t_{0+}\right)
\end{array}
$$

IVP

$$
\text { IC's : } \quad n_{i}\left(t_{0}\right)=n_{i}^{0} \quad t_{0} \in I_{0}=\left(t_{0-}, t_{0}, t_{0+}\right)
$$

where for $\mathrm{i}=1$ the empty sum on the right hand side of (1) is assumed to be zero. The first sum in the scalar (componentwise) discrete agglomeration Equation (1) is the (average) rate of formation of $i$-mers by agglutinations of $(i-j)$-mers with $j$-mers. The $1 / 2$ avoids double counting. The second sum is the (average) rate of depletion of i-mers by the agglutinations of i-mers with all particle sizes. We model a stochastic process as deterministic. The physical system is often stationary so that each $K_{i, j}$ is time independent and the model is said to be autonomous. In a physical context, we require $\mathrm{K}_{\mathrm{i}, \mathrm{j}}(\mathrm{t})>0, \mathrm{n}_{1}^{0}>0$, and $\mathrm{n}_{\mathrm{i}}^{0} \geq 0$ for $\mathrm{i}>1$. However, we will address DAP as a mathematical problem where we allow the initial number of particles $\mathrm{n}_{\mathrm{i}}^{0}$, the components of the kernel $\mathrm{K}_{\mathrm{i}, \mathrm{j}}(\mathrm{t})$, and the components of the solution, $\mathrm{n}_{\mathrm{i}}(\mathrm{t})$, to be negative. The physical context will be a special case.

Smoluchowski found in the physical context that when $\mathrm{K}_{\mathrm{i}, \mathrm{j}}(\mathrm{t})=\mathrm{A}_{0}>0$ is a constant, that

$$
\begin{aligned}
\mathrm{n}_{\mathrm{i}}^{\mathrm{A}_{0}}(\mathrm{t})= & {\left[\mathrm{n}_{\mathrm{i}}^{0}+\sum_{\mathrm{n}=1}^{\mathrm{i}-1} \frac{\mathrm{k}_{\mathrm{i}}^{(\mathrm{n}+1)}}{2^{\mathrm{n}}}\left[\frac{\mathrm{A}_{0}\left(\mathrm{t}-\mathrm{t}_{0}\right)}{1+\frac{1}{2} \mathrm{M}_{\mathbf{n}_{0}} \mathrm{~A}_{0}\left(\mathrm{t}-\mathrm{t}_{0}\right)}\right]^{\mathrm{n}}\right] } \\
& \times \frac{1}{\left(1+\frac{1}{2} \mathrm{M}_{\mathbf{n}_{0}} \mathrm{~A}_{0}\left(\mathrm{t}-\mathrm{t}_{0}\right)\right)^{2}}, \mathrm{i} \in \mathbf{N}
\end{aligned}
$$

where

$$
\begin{aligned}
& \mathrm{k}_{\mathrm{i}}^{(\mathrm{n}+1)}=\sum_{\mathrm{i}_{1}+\mathrm{i}_{2}+\cdots+\mathrm{i}_{\mathrm{n}+1}=\mathrm{i}} \mathrm{n}_{\mathrm{i}_{1}}^{0} \mathrm{n}_{\mathrm{i}_{2}}^{0} \cdots \mathrm{n}_{\mathrm{i}_{\mathrm{n}+1}}^{0} \\
& \text { and } \mathrm{M}_{\boldsymbol{n}_{0}}=\sum_{\mathrm{i}=1}^{\infty} \mathrm{n}_{\mathrm{i}}^{0}
\end{aligned}
$$

uniquely satisfies DAP on its interval of validity $\mathrm{I}_{\mathrm{IV}}\left(\mathrm{I}_{0}, \mathrm{t}_{0}, \boldsymbol{n}_{0}, \mathrm{~A}_{0}\right) \in \mathrm{Int}_{\mathrm{o}}\left(\mathrm{t}_{0}, \mathrm{I}_{0}\right)$. If we assume $\mathrm{I}_{0} \supseteq\left[\mathrm{t}_{0}, \infty\right)$, then $\left[\mathrm{t}_{0}, \infty\right) \subseteq \mathrm{I}_{\mathrm{IV}}\left(\mathrm{I}_{0}, \mathrm{t}_{0}, \boldsymbol{n}_{0}, \mathrm{~A}_{0}\right)$.

The requirement on $M_{n_{0}}$ in (4) and the infinite sum in (1.1) motivate consideration of the Banach spaces $\ell^{\mathrm{p}}=\left\{\boldsymbol{n}=\left\{\mathrm{n}_{\mathrm{i}}\right\}_{\mathrm{i}=1}^{\infty} \in \mathbf{R}^{\infty}: \sum_{\mathrm{i}=1}^{\infty}\left|\mathrm{n}_{\mathrm{i}}\right|^{\mathrm{p}}<\infty\right\} \subseteq_{\mathrm{vs}} \mathbf{R}^{\infty}$ where $\mathrm{p} \geq 1$ (Martin [16, p. 3]) with norm $\|\boldsymbol{n}\|_{\mathrm{p}}=\left(\sum_{\mathrm{i}=1}^{\infty}\left|\mathrm{n}_{\mathrm{i}}\right|^{\mathrm{p}}\right)^{1 / \mathrm{p}}$ (and hence a metric and a topology). Equality of two vectors in $\ell^{\mathrm{p}}$ requires the metric (the norm of their difference) to be zero. This is equivalent to both vectors being in $\ell^{\mathrm{p}}$ and being componentwise equal. If

$(\mathrm{t}, \mathrm{n}) \in \mathrm{I} \times \ell^{\mathrm{p}}$, then $\|(\mathrm{t}, \mathrm{n})\|_{1, \mathrm{p}}=\left(|\mathrm{t}|+\|\mathrm{n}\|_{\mathrm{p}}\right)^{1 / \mathrm{p}}$ defines a norm on $\mathrm{I} \times \ell^{\mathrm{p}} \quad$ (Naylor and Sell $\left.[17, \mathrm{p} .58]\right)$. To insure that $M_{\mathbf{n}_{0}}$ exists (even for negative initial conditions), we will require $\boldsymbol{n}_{0}=\left\{\mathrm{n}_{\mathrm{i}}^{0}\right\}_{\mathrm{i}=1}^{\infty} \in \ell^{1} \subseteq_{\mathrm{vs}} \mathbf{R}^{\infty}$ so that $\mathrm{M}_{\boldsymbol{n}_{0}}=\sum_{\mathrm{i}=1}^{\infty}\left|\mathrm{n}_{\mathrm{i}}^{0}\right|<\infty$.

We are particularly interested in the time-varying kernel $\mathrm{K}_{\mathrm{i}, \mathrm{j}}(\mathrm{t})=\mathrm{A}(\mathrm{t})$ which depends on time, but not on 
particle size. In the continuous context where

$$
\begin{aligned}
& \mathbf{K}(\mathbf{t}) \in \mathbf{M}_{\mathrm{CT}}\left(\mathrm{I}_{0}, \mathbf{R}^{\infty \times \infty}\right)=\left\{\mathbf{K}(\mathrm{t})=\left\{\mathrm{K}_{\mathrm{i}, \mathrm{j}}(\mathrm{t})\right\}_{\mathrm{i}, \mathrm{j}=1}^{\infty} \in\right. \\
& \left.\mathrm{C}_{\mathrm{cw}}\left(\mathrm{I}_{0}, \mathrm{R}^{\infty \times \infty}\right): \mathrm{K}_{\mathrm{i}, \mathrm{j}}(\mathrm{t})=\mathrm{A}(\mathrm{t}) \in \mathrm{C}\left(\mathrm{I}_{0}, \mathbf{R}\right)\right\}
\end{aligned}
$$

the problem parameters are

$\left(\mathrm{I}_{0}, \mathrm{t}_{0}, \mathrm{n}_{0}, \mathrm{~A}(\mathrm{t})\right) \in \mathrm{Int}_{0} \times \mathrm{I}_{0} \times \ell^{1} \times \mathrm{C}\left(\mathrm{I}_{0}, \mathbf{R}\right)$. In the analytic context where

$$
\begin{aligned}
& \mathbf{K}(\mathbf{t}) \in \mathbf{M}_{\mathrm{AT}}\left(\mathrm{I}_{0}, \mathbf{R}^{\infty \times \infty}\right)=\left\{\mathbf{K}(\mathrm{t})=\left\{\mathrm{K}_{\mathrm{i}, \mathrm{j}}(\mathrm{t})\right\}_{\mathrm{i}, \mathrm{j}=1}^{\#}\right. \\
& \left.\in \mathscr{A}_{\mathrm{cw}}\left(\mathrm{I}_{0}, \mathbf{R}^{\infty \times \infty}\right): \mathrm{K}_{\mathrm{i}, \mathrm{j}}(\mathrm{t})=\mathrm{A}(\mathrm{t}) \in \mathscr{A}\left(\mathrm{I}_{0}, \mathbf{R}\right)\right\}
\end{aligned}
$$

the problem parameters are

$\left(\mathrm{I}_{0}, \mathrm{t}_{0}, \mathrm{n}_{0}, \mathrm{~A}(\mathrm{t})\right) \in \mathrm{Int}_{\mathrm{o}} \times \mathrm{I}_{0} \times \ell^{1} \times \mathscr{A}\left(\mathrm{I}_{0}, \mathbf{R}\right)$. For any kernel, solution requires that both sides of (1) are continuous in the continuous context and analytic in the analytic context.

The $\mathbf{i}^{\text {th }}$ depletion coefficient associated with $t \in I_{0}$ and the distribution $\boldsymbol{n}=\left\{\mathrm{n}_{\mathrm{j}}\right\}_{\mathrm{j}=1}^{\infty} \in \mathbf{R}^{\infty}$ is defined formally by the infinite series

$$
\mathrm{f}_{\mathrm{i}}^{\mathrm{d}}(\mathrm{t}, \mathbf{n} ; \mathbf{K})=\sum_{\mathrm{j}=1}^{\infty} \mathrm{K}_{\mathrm{i}, \mathrm{j}}(\mathrm{t}) \mathrm{n}_{\mathrm{j}}, \mathrm{i} \in \mathbf{N}=\{1,2,3, \cdots\}
$$

The only direct dependence of $f_{i}^{d}(t, n ; \mathbf{K})$ on $t$ is through $\mathbf{K}(\mathrm{t})$. If (5) converges for all $(\mathrm{t}, \boldsymbol{n}) \in \mathrm{I}_{0} \times \mathbf{R}^{\infty}$, then $f_{i}^{d}(t, n ; K)$ maps $I_{0} \times \mathbf{R}^{\infty}$ to $\mathbf{R}$. We may view $f_{i}^{d}(t, \boldsymbol{n} ; \mathbf{K})$ as a function of an infinite number of real variables or as a function of time and a size distribution. Regardless, if $\boldsymbol{n}(\mathrm{t}) \in \mathscr{T}\left(\mathrm{I}, \mathbf{R}^{\infty}\right)$, and we have convergence, the composition $\mathrm{f}_{\mathrm{i}}^{\mathrm{d}}(\mathrm{t}, \boldsymbol{n}(\mathrm{t}) ; \mathbf{K})$ maps I to $\mathbf{R}$.

Implicit in (1) is that for solution in the continuous context, we must have for all $I \in \operatorname{Int}_{\mathrm{o}}\left(\mathrm{t}_{0}, \mathrm{I}_{0}\right)$, that

$\mathrm{f}_{\mathrm{i}}^{\mathrm{d}}(\mathrm{t}, \boldsymbol{n}(\mathrm{t}) ; \mathbf{K}) \in \mathrm{C}(\mathrm{I}, \mathbf{R})$. That is, DAP requires us to first find $\boldsymbol{n}(\mathrm{t}) \in \boldsymbol{C}_{\mathrm{cw}}\left(\mathrm{I}, \mathbf{R}^{\infty}\right)$ such that for all $\mathrm{i} \in \mathbf{N}$ and $\mathrm{t} \in \mathrm{I}, \mathrm{f}_{\mathrm{i}}^{\mathrm{d}}(\mathrm{t}, \boldsymbol{n}(\mathrm{t}) ; \mathbf{K})$ exists (i.e., converges) and defines a function in $\mathrm{C}(\mathrm{I}, \mathbf{R})$. If, in addition,

$\boldsymbol{n}(\mathrm{t}) \in \boldsymbol{C}_{\mathrm{cw}}^{\mathrm{l}}\left(\mathrm{I}, \mathbf{R}^{\infty}\right)$ (the $\Sigma$ space) and satisfies (1) on I and (2), then it solves DAP on I. This formulation of DAP does not require mathematics beyond calculus and is often used by engineers and scientists.

For DAP with a time varying kernel, $\mathrm{K}_{\mathrm{i}, \mathrm{j}}(\mathrm{t})=\mathrm{A}(\mathrm{t})$, in the analytic context, Moseley [14] established that the more general formula

$$
\begin{aligned}
\mathrm{n}_{\mathrm{i}}^{\mathrm{A}}(\mathrm{t})= & {\left[\mathrm{n}_{\mathrm{i}}^{0}+\sum_{\mathrm{n}=1}^{\mathrm{i}-1} \frac{\mathrm{k}_{\mathrm{i}}^{(\mathrm{n}+1)}}{2^{\mathrm{n}}}\left[\frac{\mathscr{A}(\mathrm{t})}{1+(1 / 2) \mathrm{M}_{\mathrm{n}_{0}} \mathscr{A}(\mathrm{t})}\right]^{\mathrm{n}}\right] } \\
& \times \frac{1}{\left(1+(1 / 2) \mathrm{M}_{\mathrm{n}_{0}} \mathscr{A}(\mathrm{t})\right)^{2}}
\end{aligned}
$$

where $\mathscr{A}(\mathrm{t})=\int_{\tau=\mathrm{t}_{0}}^{\tau=\mathrm{t}} \mathrm{A}(\tau) \mathrm{d} \tau$, satisfies DAP uniquely on its interval of validity $\mathrm{I}_{\mathrm{IV}}\left(\mathrm{I}_{0}, \mathrm{t}_{0}, \boldsymbol{n}_{0}, \mathrm{~A}\left(\mathrm{t}_{0}\right)\right) \in \operatorname{Int}_{\mathrm{o}}\left(\mathrm{I}_{0}\right)$. or the physical context where $\mathrm{n}_{\mathrm{i}}^{0} \geq 0, \mathrm{~A}(\mathrm{t})>0$, again we have $\left[\mathrm{t}_{0}, \infty\right) \subseteq \mathrm{I}_{\mathrm{IV}}\left(\mathrm{I}_{0}, \mathrm{t}_{0}, \boldsymbol{n}_{0}, \mathrm{~A}(\mathrm{t})\right) \subseteq \mathrm{I}_{0}$ and require $0 \leq \mathrm{M}_{\mathrm{n}_{0}}=\sum_{\mathrm{i}=1}^{\infty} \mathrm{n}_{\mathrm{i}}^{0}=\sum_{\mathrm{i}=1}^{\infty}\left|\mathrm{n}_{\mathrm{i}}^{0}\right|<\infty$. The formula (6) satisfies (1) on I and (2) in the continuous context as well where we now allow $A(t) \in C\left(I_{0}, R\right)$ However, since (6) was not derived using equivalent equation operations, uniqueness has not been proved rigorously for $\mathbf{K} \in \mathrm{M}_{\mathrm{CT}}\left(\mathrm{I}_{0}, \mathbf{R}^{\infty \times \infty}\right)$. Unless otherwise stated, for the rest of the paper, we focus on the continuous context.

Moseley [14] divided DAP into several problems which could be considered separately. Under certain conditions, a reasonably complicated change of (both the independent and dependent) variables transforms DAP with a time varying kernel (Moseley, [14]) into another IVP which Moseley later referred to as the Fundamental Agglomeration Problem (FAP). The solution process for FAP is fully documented in Moseley [15]. For FAP, Moseley established existence and uniqueness for both the analytic and continuous contexts by using a sequential solution. To facilitate further progress, in this paper we develop equivalent problems for DAP in the continuous context. Analogs for the analytic context can be obtained.

To rearrange terms in infinite series we will need

$$
\sum_{i=1}^{\infty} \sum_{j=1}^{\infty} a_{i, j}=\sum_{i=1}^{\infty} \sum_{j=1}^{i-1} a_{i-j, j}=\sum_{i=2}^{\infty} \sum_{j=1}^{i-1} a_{i-j, j}
$$

If all sums exist, we add all of the elements in $A=\left\{a_{i j}\right\}_{i, j=1}^{\infty} \in \mathbf{R}^{\infty \times \infty}$ in two different ways. Since we use them often, we will use $\forall$ to mean "for all" and $\exists$ to mean "there exists" (with apologies to the logicians). If y $=n(t)$, we use any of $n, n(t), y(t)$ and $n(\cdot)$ to denote the function. Also, we denote the restriction of a function to a smaller domain by the same symbol. The context will make it clear.

\section{Mathematical Problem Solving}

Often, a mathematical problem is specified by giving a condition (or conditions) (e.g., an algebraic equation or an ODE with an initial condition) on elements in a $\boldsymbol{\Sigma}$ set (the designated set where we look for solutions, e.g., $\mathbf{R}$ or $\left.\mathrm{C}^{1}(\mathrm{I}, \mathbf{R})\right)$. If the $\Sigma$ set is a vector space, we say $\Sigma$ space. A problem is (set-theoretically) well-posed if it has exactly one solution in its $\Sigma$ set. (In this paper, we will not consider continuity with respect to problem parameters.) A well-developed model of dynamics using an IVP is well-posed (exactly one event happens). As mod- 
elers, we expect our models to be well-posed. As mathematicians, we require rigorous proof. Often, we solve equations by using equivalent equation operations to isolate the unknown(s). This yields uniqueness, and, as all steps are reversible, existence. (Squaring both sides of an equation is not an equivalent equation operation and may lead to extraneous roots.) For linear ODE's, we may guess the form of a solution and prove existence and uniqueness by using the linear theory. For nonlinear problems, we may prove existence by substituting back into the equation. Uniqueness then becomes an issue.

Let $\mathrm{A} \subseteq \mathrm{B}$. If a solution is unique in $\mathrm{B}$, and it is in $\mathrm{A}$, then it is unique in $\mathrm{A}$. If $\mathrm{A}$ is the $\Sigma$ set for the problem and contains only one solution, then the solution is unique in B. Being in A is a requirement for existence. In the continuous context, for $I \subseteq \operatorname{Int}_{\mathrm{o}}\left(\mathrm{t}_{0}, \mathrm{I}_{0}\right)$, we look for solutions to

$$
\begin{aligned}
& \text { IVP ODE dy/dt }=\mathrm{f}(\mathrm{t}, \mathrm{y}) \\
& \text { IC } \mathrm{y}\left(\mathrm{t}_{0}\right)=\mathrm{y}_{0}, \mathrm{t} \in \mathrm{I}_{0}
\end{aligned}
$$

in the $\Sigma$ space $\mathrm{C}^{1}(\mathrm{I}, \mathbf{R})$. Thus, as is usually done, we require solutions to (8) to not only exist, but to also have continuous derivatives. We also require $\mathrm{f} \in \mathrm{C}(\mathrm{I} \times \mathrm{U}, \mathbf{R})$ where $\mathrm{U} \subseteq \mathbf{R}$ and the range of $\mathrm{y}(\mathrm{t})$ is in $\mathrm{U}$ for $\mathrm{y}(\mathrm{t})$ in the $\Sigma$ space. Placing these additional constraints avoids dealing with pathology, but narrows the space where a known solution is to be shown to be unique. There may be (pathological) solutions to (8) where the derivative exists, but is not continuous.

Also, as is usually done, we allow I to vary. If we show that there exists a solution for some I, then we say that we have local existence on I. The largest

$I \in \operatorname{Int}_{0}\left(t_{0}, I_{0}\right)$ where a solution exists is the interval of validity for the solution (i.e., the domain). We say that we have shown global existence on $\mathrm{I}$ if, given

$\mathrm{I} \in \mathrm{Int}_{\mathrm{o}}\left(\mathrm{t}_{0}, \mathrm{I}_{0}\right)$, we prove that there exists a solution on I (i.e., a solution in $\left.\mathrm{C}^{1}(\mathrm{I}, \mathbf{R})\right)$. Suppose a solution on $I \in \operatorname{Int}_{\mathrm{o}}\left(\mathrm{t}_{0}, \mathrm{I}_{0}\right)$ goes through the point where $\mathrm{t}=\mathrm{t}_{1}$. It is said to be locally unique at $t_{1}$ if there exists

$\mathrm{I}_{1} \in \operatorname{Int}_{\mathrm{o}}\left(\mathrm{t}_{1}, \mathrm{I}_{0}\right)$ such that it is the only solution on $\mathrm{I}_{1}$. It is locally unique on $I$ if it is locally unique at every point in I. Obviously, if a solution exists globally on

$\mathrm{I} \in \operatorname{Int}_{\mathrm{o}}\left(\mathrm{t}_{0}, \mathrm{I}_{0}\right)$, and is locally unique on $\mathrm{I}$, then it is globally unique on $\mathrm{I}$. That is, it is the only solution in the $\Sigma$ space $\left.\mathrm{C}^{1}(\mathrm{I}, \mathbf{R})\right)$.

For DAP in the continuous context we start with the large $\Sigma$ space $\mathbf{C}_{\mathrm{cw}}^{1}\left(\mathrm{I}, \mathbf{R}^{\infty}\right)$ and say that $\boldsymbol{n}(\mathrm{t})=\left\{\mathrm{n}_{\mathrm{i}}(\mathrm{t})\right\}_{\mathrm{i}=1}^{\infty}$ satisfies (1) on I if $\forall \mathrm{i} \in \mathbf{N}$, the composition $\mathrm{f}_{\mathrm{i}}^{\mathrm{d}}(\mathrm{t}, \boldsymbol{n}(\mathrm{t}) ; \mathbf{K})$ exists (converges) and is in $C(I, R)$ and $n_{i}(t)$ satisfies (1) on I. Since composition of continuous functions is continuous, we expect

$\mathrm{f}_{\mathrm{i}}^{\mathrm{d}}(\mathrm{t}, \boldsymbol{n}(\mathrm{t}) ; \mathbf{K}) \in \mathrm{C}(\mathrm{I}, \mathbf{R})$ if in some sense $\mathrm{f}_{\mathrm{i}}^{\mathrm{d}}(\mathrm{t}, \boldsymbol{n} ; \mathbf{K})$ from $\mathrm{I} \times \mathbf{R}^{\infty}$ to $\mathbf{R}$ given by (5) is continuous. But we do not have a topology on $\mathbf{R}^{\infty}$ and hence not one on $\mathrm{I} \times \mathbf{R}^{\infty} \subseteq \mathrm{I}_{0} \times \mathbf{R}^{\infty}$. Instead of requiring $\forall \mathrm{i} \in \mathbf{N}$, $\mathrm{f}_{\mathrm{i}}^{\mathrm{d}}(\mathrm{t}, \boldsymbol{n}(\mathrm{t}) ; \mathbf{K}) \in \mathrm{C}\left(\mathrm{I}, \mathbf{R}^{\infty}\right)$ as a separate condition for solution, we may incorporate it into the $\Sigma$ space. We refer to DAP with the $\Sigma$ space

$$
\begin{aligned}
& \boldsymbol{C}_{\mathrm{cw}, \mathrm{d}}^{1}\left(\mathrm{I}, \mathbf{R}^{\infty}\right)=\left\{\boldsymbol{n}(\mathrm{t}) \in \boldsymbol{C}_{\mathrm{cw}}^{1}\left(\mathrm{I}, \mathbf{R}^{\infty}\right):\right. \\
& \left.\forall \mathrm{i} \in \mathbf{N}, \mathrm{f}_{\mathrm{i}}^{\mathrm{d}}(\mathrm{t}, \boldsymbol{n}(\mathrm{t}) ; \mathbf{K}(\mathrm{t})) \in \mathrm{C}(\mathrm{I}, \mathbf{R})\right\}
\end{aligned}
$$

as the Scalar Discrete Agglomeration Problem (SDAP). Obviously, this may be formulated in an analytic context as well.

Recalling the constraint

$\mathrm{M}_{n_{0}}=\sum_{\mathrm{i}=1}^{\infty}\left|\mathrm{n}_{\mathrm{i}}^{0}\right| \in \ell^{1} \quad\left(\mathrm{M}_{\boldsymbol{n}_{0}}<\infty\right)$, instead of $\mathbf{R}^{\infty}$, we may choose the state space as $\ell^{1} \subseteq_{\mathrm{vs}} \mathbf{R}^{\infty}$ which has a norm (and hence a metric and a topology). A solution on $\mathrm{I}$ is then a time-varying infinite-dimensional "state vector" $\boldsymbol{n}(\mathrm{t})=\left\{\mathrm{n}_{\mathrm{i}}(\mathrm{t})\right\}_{\mathrm{i}=1}^{\infty}$. Later we will choose an appropriate $\Sigma$ space and write DAP in vector form. We refer to this formulation of DAP as the Vector Discrete Agglomeration Problem (VDAP). As with SDAP, VDAP may be in the continuous or analytic context. If SDAP is well-posed, and its solution is in the (smaller) $\Sigma$ space for VDAP, then SDAP and VDAP are equivalent except for the space where local uniqueness is proved. That is, by choosing a smaller $\Sigma$ space, VDAP requires proving local uniqueness in a smaller space than does SDAP. If we do not worry about pathology, and redefine the $\Sigma$ space for SDAP to be the same as for VDAP, the two problems are equivalent. The question is: How do we choose an appropriate (smaller) $\Sigma$ space? But first we consider an equivalent scalar problem and $\ell^{\mathrm{p}}$ spaces.

\subsection{Equivalent Scalar Problems}

Again assume for $\mathrm{i} \in \mathbf{N}$ that $\mathrm{f}_{\mathrm{i}}^{\mathrm{d}}(\mathrm{t}, \boldsymbol{n} ; \mathbf{K})$ converges $\forall(\mathrm{t}, \boldsymbol{n}) \in \mathrm{I}_{0} \times \mathbf{R}^{\infty}$ where $\boldsymbol{n}=\left\{\mathrm{n}_{\mathrm{i}}\right\}_{i=1}^{\infty}$. Now define the functions

$$
\begin{aligned}
\mathrm{f}_{\mathrm{i}}^{1}(\mathrm{t}, \boldsymbol{n} ; \mathbf{K}) & =\frac{1}{2} \sum_{\mathrm{j}=\mathrm{i}}^{\mathrm{i}-1} \mathrm{~K}_{\mathrm{i}-\mathrm{j}, \mathrm{j}}(\mathrm{t}) \mathrm{n}_{\mathrm{j}} \mathrm{n}_{\mathrm{i}-\mathrm{j}} \\
\mathrm{f}_{\mathrm{i}}^{2}(\mathrm{t}, \boldsymbol{n} ; \mathbf{K}) & =\mathrm{n}_{\mathrm{i}} \sum_{\mathrm{j}=1}^{\infty} \mathrm{K}_{\mathrm{i}, \mathrm{j}}(\mathrm{t}) \mathrm{n}_{\mathrm{j}} \\
& =\mathrm{n}_{\mathrm{i}} \mathrm{f}_{\mathrm{i}}^{\mathrm{d}}(\mathrm{t}, \boldsymbol{n} ; \mathbf{K}) \\
\mathrm{f}_{\mathrm{i}}(\mathrm{t}, \boldsymbol{n} ; \mathbf{K}) & =\mathrm{f}_{\mathrm{i}}^{1}(\mathrm{t}, \boldsymbol{n} ; \mathbf{K})-\mathrm{f}_{\mathrm{i}}^{2}(\mathrm{t}, \boldsymbol{n} ; \mathbf{K})
\end{aligned}
$$

which also map $\mathrm{I}_{0} \times \mathbf{R}^{\infty}$ to $\mathbf{R}$. For these functions, as with $\mathrm{f}_{\mathrm{i}}^{\mathrm{d}}(\mathrm{t}, \boldsymbol{n} ; \mathbf{K})$, the only explicit dependence on $\mathrm{t}$ is through $\mathbf{K}(\mathrm{t})$. For $(\mathrm{t}, \boldsymbol{n}) \in \mathrm{I}_{0} \times \mathbf{R}^{\infty}$ we may now write (1) as the system of ODE's 


$$
\begin{aligned}
& \frac{\mathrm{dn}_{\mathrm{i}}}{\mathrm{dt}}=\mathrm{f}_{\mathrm{i}}(\mathrm{t}, \boldsymbol{n} ; \mathbf{K}), \mathrm{t} \in \mathrm{I}_{0}=\left(\mathrm{t}_{0-}, \mathrm{t}_{0}, \mathrm{t}_{0+}\right), \\
& \mathrm{i} \in \mathbf{N}=\{1,2,3, \cdots\}
\end{aligned}
$$

If the restriction of $\mathrm{f}_{\mathrm{i}}^{\mathrm{d}}(\mathrm{t}, \boldsymbol{n} ; \mathbf{K})$ to $\mathrm{I} \times \ell^{1}$ (which we denote by the same symbol) converges $\forall(\mathrm{t}, \boldsymbol{n}) \in \mathrm{I} \times \ell^{1}$ and is continuous on $\mathrm{I} \times \ell^{1}$ with respect to the norm topology, we write $\mathrm{f}_{\mathrm{i}}^{\mathrm{d}}(\mathrm{t}, \boldsymbol{n} ; \mathbf{K}) \in \mathrm{C}\left(\mathrm{I} \times \ell^{1}, \mathbf{R}\right)$. That is, $\mathrm{C}\left(\mathrm{I}_{0} \times \ell^{1}, \mathbf{R}\right)=\left\{\mathrm{f}: \mathrm{I}_{0} \times \ell^{1} \rightarrow \mathbf{R} \mid \mathrm{f}(\mathrm{t}, \boldsymbol{n})\right.$ is continuous $\}$.

Initially, we assume $\mathrm{f}_{\mathrm{i}}^{\mathrm{d}}(\mathrm{t}, \boldsymbol{n} ; \mathbf{K}) \in \mathrm{C}\left(\mathrm{I} \times \ell^{1}, \mathbf{R}\right)$ and investigate $\mathrm{f}_{\mathrm{i}}^{1}(\mathrm{t}, \boldsymbol{n} ; \mathbf{K}) \mathrm{f}_{\mathrm{i}}^{2}(\mathrm{t}, \boldsymbol{n} ; \mathbf{K})$, and $\mathrm{f}_{\mathrm{i}}(\mathrm{t}, \boldsymbol{n} ; \mathbf{K})$. Note $\mathrm{f}_{\mathrm{i}}^{1}(\mathrm{t}, \boldsymbol{n} ; \mathbf{K})$ is just a finite sum involving $\mathrm{K}_{\mathrm{i}, \mathrm{j}}(\mathrm{t})$ and components of $\boldsymbol{n}, \mathrm{f}_{\mathrm{i}}^{2}(\mathrm{t}, \boldsymbol{n} ; \mathbf{K})$ is just the product of $\mathrm{f}_{\mathrm{i}}^{\mathrm{d}}(\mathrm{t}, \boldsymbol{n} ; \mathbf{K})$ with a component of $\boldsymbol{n}$, and $\mathrm{f}_{\mathrm{i}}(\mathrm{t}, \boldsymbol{n} ; \mathbf{K})$ is just the difference of $\mathrm{f}_{\mathrm{i}}^{1}(\mathrm{t}, \boldsymbol{n} ; \mathbf{K})$ and $\mathrm{f}_{\mathrm{i}}^{2}(\mathrm{t}, \boldsymbol{n} ; \mathbf{K})$.

Theorem 2.1. Let $\mathbf{K}(\mathrm{t}) \in \mathrm{C}_{\mathrm{cw}}\left(\mathrm{I}_{0}, \mathbf{R}^{\infty \times \infty}\right)$ and

$\mathrm{f}_{\mathrm{i}}^{\mathrm{d}}(\mathrm{t}, \boldsymbol{n} ; \mathbf{K}) \in \mathrm{C}\left(\mathrm{I}_{0}, \ell^{1}, \mathbf{R}\right)$. Then $\mathrm{f}_{\mathrm{i}}^{1}(\mathrm{t}, \boldsymbol{n} ; \mathbf{K})$,

$\mathrm{f}_{\mathrm{i}}^{2}(\mathrm{t}, \boldsymbol{n} ; \mathbf{K})$, and $\mathrm{f}_{\mathrm{i}}(\mathrm{t}, \boldsymbol{n} ; \mathbf{K})$ are all in $\mathrm{C}\left(\mathrm{I}_{0} \times \ell^{1}, \mathbf{R}\right)$.

Proof. Sums, products, and compositions of continuous functions involving $\ell^{1}$ are continuous.

Detailed $\varepsilon-\delta$ proofs follow proofs in an elementary real analysis course. All functions map to R. We must choose $\left\|(\mathrm{t}, \boldsymbol{n})-\left(\mathrm{t}_{1}, \boldsymbol{n}_{1}\right)\right\|_{1,1}=\left|\mathrm{t}-\mathrm{t}_{1}\right|+\left\|\mathrm{n}-\boldsymbol{n}_{1}\right\|_{1}$ sufficiently small so that $\left|\mathrm{f}(\mathrm{t}, \boldsymbol{n})-\mathrm{f}\left(\mathrm{t}_{1}, \boldsymbol{n}_{1}\right)\right|<\varepsilon$. For example, if $\boldsymbol{n}=\left\{\mathrm{n}_{\mathrm{i}}\right\}_{\mathrm{i}=1}^{\infty}$, then the projection function $\mathrm{f}(\boldsymbol{n})=\mathrm{n}_{\mathrm{i}}$ is continuous since if $\boldsymbol{n}_{1}=\left\{\mathrm{n}_{\mathrm{i}}^{1}\right\}_{\mathrm{i}=1}^{\infty}$, then $\left|\mathrm{f}(\boldsymbol{n})-\mathrm{f}\left(\boldsymbol{n}_{1}\right)\right|=\left|\mathrm{n}_{\mathrm{i}}-\mathrm{n}_{\mathrm{i}}^{1}\right| \leq\left\|\boldsymbol{n}-\boldsymbol{n}_{1}\right\|$ satisfies a Lipschitz condition (Bartle $[18$, p. 161]) and hence is continuous on $\ell^{1}$ i.e., is in $\mathrm{C}\left(\ell^{1}, \mathbf{R}\right)$. Since it is a constant function of $\mathrm{t}$, it is in $\mathrm{C}\left(\mathrm{I}_{0} \times \ell^{1}, \mathbf{R}\right)$. We investigate continuity and differentiability in $\ell^{\mathrm{p}}$ in more detail in the next section.

Let $\boldsymbol{n}(\mathrm{t}) \in \boldsymbol{C}_{\mathrm{cw}}\left(\mathrm{I}, \mathbf{R}^{\infty}\right)$. If the composition

$\mathrm{f}_{\mathrm{i}}^{\mathrm{d}}(\mathrm{t}, \boldsymbol{n} ; \mathbf{K})$ converges $\forall \mathrm{t} \in \mathrm{I}$ and is continuous on $\mathrm{I}$, we write $\mathrm{f}_{\mathrm{i}}^{\mathrm{d}}(\mathrm{t}, \boldsymbol{n}(\mathrm{t}) ; \mathbf{K}) \in \mathrm{C}(\mathrm{I}, \mathbf{R})$. Previewing the next section, we define the function spaces

$\boldsymbol{C}\left(\mathrm{I}, \ell^{1}\right)=\left\{\boldsymbol{n}(\cdot): \mathrm{I} \rightarrow \ell^{1} \mid \boldsymbol{n}(\cdot)\right.$ is continuous $\}$ and

$\boldsymbol{C}_{\mathrm{cw}}\left(\mathrm{I}, \ell^{1}\right)$ as the componentwise continuous functions that have codomain $\ell^{1}$, and claim that

$$
\boldsymbol{C}\left(\mathrm{I}, \ell^{1}\right) \subseteq_{\mathrm{vs}} \boldsymbol{C}_{\mathrm{cw}}\left(\mathrm{I}, \ell^{1}\right) \subseteq_{\mathrm{vs}} \boldsymbol{C}_{\mathrm{cw}}\left(\mathrm{I}, \mathbf{R}^{\infty}\right) .
$$

Corollary 2.2. Let $\mathbf{K}(\mathrm{t}) \in \mathrm{C}_{\mathrm{cw}}\left(\mathrm{I}_{0}, \mathbf{R}^{\infty \times \infty}\right)$ and $\mathrm{f}_{\mathrm{i}}^{\mathrm{d}}(\mathrm{t}, \boldsymbol{n} ; \mathbf{K}) \in \mathrm{C}\left(\mathrm{I} \times \ell^{1}, \mathbf{R}\right)$. If $\boldsymbol{n}(\mathrm{t}) \in \mathbf{C}\left(\mathrm{I}, \ell^{1}\right)$, then the compositions

$$
\begin{aligned}
& \mathrm{f}_{\mathrm{i}}^{\mathrm{d}}(\mathrm{t}, \boldsymbol{n}(\mathrm{t}) ; \mathbf{K}), \mathrm{f}_{\mathrm{i}}^{1}(\mathrm{t}, \boldsymbol{n}(\mathrm{t}) ; \mathbf{K}), \mathrm{f}_{\mathrm{i}}^{2}(\mathrm{t}, \boldsymbol{n}(\mathrm{t}) ; \mathbf{K}) \text {, and } \\
& \mathrm{f}_{\mathrm{i}}(\mathrm{t}, \boldsymbol{n}(\mathrm{t}) ; \mathbf{K}) \text { are all in } \mathrm{C}(\mathrm{I}, \mathbf{R}) .
\end{aligned}
$$

Proof. Sums, products, and compositions of continuous functions involving $\ell^{1}$ are continuous.

We now show that in the continuous context if $\mathrm{f}_{\mathrm{i}}(\mathrm{t}, \boldsymbol{n} ; \mathbf{K}) \in \mathrm{C}\left(\mathrm{I}_{0} \times \ell^{1}, \mathbf{R}\right)$, then SDAP given by (12) and (2) with the $\Sigma$ space $C_{\mathrm{cw}}^{1}\left(\mathrm{I}, \mathbf{R}^{\infty}\right)$ is equivalent to the infinite system of scalar (componentwise) Voltera integral equations

$$
\mathrm{n}_{\mathrm{i}}(\mathrm{t})=\mathrm{n}_{\mathrm{i}}^{0}+\int_{\mathrm{t}_{0}}^{\mathrm{t}} \mathrm{f}_{\mathrm{i}}(\mathrm{s}, \boldsymbol{n}(\mathrm{s}) ; \mathbf{K}) \mathrm{ds}
$$

where $\boldsymbol{n}(\mathrm{t})=\left\{\mathrm{n}_{\mathrm{i}}(\mathrm{t})\right\}_{\mathrm{i}=1}^{\infty}$ is a solution to (13) if it is in the $\Sigma$ space

$$
\begin{aligned}
& \mathrm{C}_{\mathrm{cw}, \mathrm{d}}\left(\mathrm{I}, \mathbf{R}^{\infty}\right) \\
& =\left\{\boldsymbol{n}(\mathrm{t}) \in \boldsymbol{C}_{\mathrm{cw}}\left(\mathrm{I}, \mathbf{R}^{\infty}\right): \forall \mathrm{i} \in \mathbf{N}, \mathrm{f}_{\mathrm{i}}^{\mathrm{d}}(\mathrm{t}, \boldsymbol{n}(\mathrm{t}) ; \mathbf{K}) \in \mathrm{C}(\mathrm{I}, \mathbf{R})\right\}
\end{aligned}
$$

and $\forall \mathrm{i} \in \mathbf{N}, \mathrm{n}_{\mathrm{i}}(\mathrm{t})$ satisfies (6). (We require $\boldsymbol{n}(\mathrm{t}) \in \boldsymbol{C}_{\mathrm{cw}}\left(\mathrm{I}, \mathbf{R}^{\infty}\right)$ and not just that the integral in (6) exists.) We refer to this problem as the Integral Scalar Discrete Agglomeration Problem (ISDAP) in the continuous context. A formulation in the analytic context can also be established.

Theorem 2.3. In the continuous context, a distribution $\boldsymbol{n}(\mathrm{t})$ is a solution of SDAP in $\boldsymbol{C}_{\mathrm{cw}, \mathrm{d}}^{1}\left(\mathrm{I}, \mathbf{R}^{\infty}\right)$ if and only if it is a solution of ISDAP in $\boldsymbol{C}_{\mathrm{cw}, \mathrm{d}}^{1}\left(\mathrm{I}, \mathbf{R}^{\infty}\right)$.

Proof. First assume that $\boldsymbol{n}(\mathrm{t})=\left\{\mathrm{n}_{\mathrm{i}}(\mathrm{t})\right\}_{\mathrm{i}=1}^{\infty}$ is a solution of SDAP in $C_{\mathrm{cw}, \mathrm{d}}^{1}\left(\mathrm{I}, \mathbf{R}^{\infty}\right)$. We have by the definition of a solution of SDAP, that

$\boldsymbol{n}(\mathrm{t})=\left\{\mathrm{n}_{\mathrm{i}}(\mathrm{t})\right\}_{\mathrm{i}=1}^{\infty} \in \boldsymbol{C}_{\mathrm{cw}, \mathrm{d}}^{1}\left(\mathrm{I}, \mathbf{R}^{\infty}\right)$, that

$\forall \mathrm{i} \in \mathbf{N}, \mathrm{f}_{\mathrm{i}}^{\mathrm{d}}(\mathrm{t}, \boldsymbol{n}(\mathrm{t}) ; \mathbf{K}) \in \mathrm{C}(\mathrm{I}, \mathbf{R})$, that (13) is satisfied on $\mathrm{I}$, and that (2) is satisfied. Since both sides of (13) are continuous, we may integrate from $t_{0}$ to $t \in I$ to obtain

$$
\mathrm{n}_{\mathrm{i}}(\mathrm{t})=\mathrm{c}_{\mathrm{i}}+\int_{\mathrm{t}_{0}}^{\mathrm{t}} \mathrm{f}_{\mathrm{i}}(\mathrm{s}, \boldsymbol{n}(\mathrm{s}) ; \mathbf{K}(\mathrm{s})) \mathrm{ds}
$$

Applying the initial condition we obtain (13). Similarly, let us assume that $\boldsymbol{n}(\mathrm{t})=\left\{\mathrm{n}_{\mathrm{i}}(\mathrm{t})\right\}_{\mathrm{i}=1}^{\infty}$ is a solution of (13) in $\boldsymbol{C}_{\mathrm{cw}, \mathrm{d}}\left(\mathrm{I}, \mathbf{R}^{\infty}\right)$. Substituting in $\mathrm{t}_{0}$ we obtain (2). Since $\boldsymbol{n}(\mathrm{t}) \in \boldsymbol{C}_{\mathrm{cw}, \mathrm{d}}\left(\mathrm{I}, \mathbf{R}^{\infty}\right)$, we have $\forall \mathrm{i} \in \mathbf{N}$ that $\mathrm{f}_{\mathrm{i}}^{\mathrm{d}}(\mathrm{t}, \boldsymbol{n}(\mathrm{t}) ; \mathbf{K}) \in \mathrm{C}(\mathrm{I}, \mathbf{R})$ so that the integrand, $\mathrm{f}_{\mathrm{i}}(\mathrm{s}, \boldsymbol{n}(\mathrm{s}) ; \mathbf{K})$, is continuous. Since $\mathrm{n}_{\mathrm{i}}(\mathrm{t})$ is written as an integral, it is differentiable so that $\boldsymbol{n}(\mathrm{t}) \in \boldsymbol{C}_{\mathrm{cw}, \mathrm{d}}^{1}\left(\mathrm{I}, \mathbf{R}^{\infty}\right)$. Differentiating we see that (11) is satisfied.

For the scalar Equation (2.1), it is the integral formulation that is used to obtain existence (Picard iterations) and uniqueness using a Lipschitz condition. If we choose to specify $C_{\mathrm{cw}, \mathrm{d}}^{1}\left(\mathrm{I}, \mathbf{R}^{\infty}\right)$ as the $\Sigma$ space for both prob- 
lems, the problems remain equivalent as any solution to (13) in $\boldsymbol{C}_{\mathrm{cw}}\left(\mathrm{I}, \mathbf{R}^{\infty}\right)$ is in fact in $\boldsymbol{C}_{\mathrm{cw}, \mathrm{d}}^{1}\left(\mathrm{I}, \mathbf{R}^{\infty}\right)$. That is, there are no solutions to (13) in $\boldsymbol{C}_{\mathrm{cw}}\left(\mathrm{I}, \mathbf{R}^{\infty}\right)-\boldsymbol{C}_{\mathrm{cw}, \mathrm{d}}^{1}\left(\mathrm{I}, \mathbf{R}^{\infty}\right)$. These results can also be established in the analytic context.

\subsection{Continuity and Differentiability for $\boldsymbol{\ell}^{\mathrm{p}}$ Spaces}

Since $\ell^{\mathrm{p}}$ has a norm (and hence a metric) we have a topology on the subspace $\ell^{\mathrm{p}}$ of $\mathbf{R}^{\infty}$. Many of the limit laws can be extended to $\ell^{\mathrm{p}}$. For example, if

$\lim _{\mathrm{t} \rightarrow \mathrm{t}_{0}} \boldsymbol{n}_{1}(\mathrm{t})=\mathrm{L}_{1}$ and $\lim _{\mathrm{t} \rightarrow \mathrm{t}_{0}} \boldsymbol{n}_{2}(\mathrm{t})=\mathrm{L}_{2}$, then

$\lim _{\mathrm{t} \rightarrow \mathrm{t}_{0}}\left[\boldsymbol{n}_{1}(\mathrm{t})+\boldsymbol{n}_{2}(\mathrm{t})\right]=\mathrm{L}_{1}+\mathrm{L}_{2}$. We also have if

$\lim _{\mathrm{t} \rightarrow \mathrm{t}_{0}} \mathrm{f}(\mathrm{t})=\mathrm{L}_{1}$ and $\lim _{\mathrm{t} \rightarrow \mathrm{t}_{0}} \boldsymbol{n}(\mathrm{t})=\mathrm{L}_{2}$, then

$\lim _{\mathrm{t} \rightarrow \mathrm{t}_{0}} \mathrm{f}(\mathrm{t}) \boldsymbol{n}(\mathrm{t})=\mathrm{L}_{1} \mathrm{~L}_{2}$

Definition 2.1. A function $\boldsymbol{n}(\cdot): \mathrm{I} \rightarrow \ell^{\mathrm{p}}$ is continuous at $t_{1} \in I$ with respect to the norm topology if $\lim _{\mathrm{t} \rightarrow \mathrm{t}_{1}} \boldsymbol{n}(\mathrm{t})=\boldsymbol{n}\left(\mathrm{t}_{1}\right)$ in $\ell^{\mathrm{p}}$; that is, given $\varepsilon>0, \exists \delta>0$ such that $0<\left|\mathrm{t}-\mathrm{t}_{1}\right|<\delta$ implies

$\left\|\boldsymbol{n}(\mathrm{t})-\boldsymbol{n}\left(\mathrm{t}_{1}\right)\right\|_{\mathrm{p}}=\left(\sum_{\mathrm{i}=1}^{\infty}\left|\mathrm{n}_{\mathrm{i}}(\mathrm{t})-\mathrm{n}_{\mathrm{i}}\left(\mathrm{t}_{1}\right)\right|^{\mathrm{p}}\right)^{1 / p}<\varepsilon$. If it is continuous $\forall \mathrm{t} \in \mathrm{I}$, it is continuous on I. Similarly, a function $\mathrm{M}(\cdot): \ell^{\mathrm{p}} \rightarrow \mathbf{R}$ is continuous at $\boldsymbol{n}_{1} \in \ell^{\mathrm{p}}$ with respect to the norm topology if $\lim _{n \rightarrow n_{1}} \mathrm{M}(\boldsymbol{n})=\mathrm{M}\left(\boldsymbol{n}_{1}\right)$ in I; that is, given $\varepsilon>0, \exists \delta>0$ such that

$0<\left\|\boldsymbol{n}-\boldsymbol{n}_{1}\right\|_{\mathrm{p}}=\left(\sum_{\mathrm{i}=1}^{\infty}\left|\mathrm{n}_{\mathrm{i}}(\mathrm{t})-\mathrm{n}_{\mathrm{i}}\left(\mathrm{t}_{1}\right)\right|^{\mathrm{p}}\right)^{1 / \mathrm{p}}<\delta$ implies

$\left|\mathrm{M}(\boldsymbol{n})-\mathrm{M}\left(\boldsymbol{n}_{1}\right)\right|<\varepsilon$. If it is continuous $\forall \boldsymbol{n} \in \ell^{\mathrm{p}}$, it is continuous on $\ell^{\mathrm{p}}$. Similarly for the functions $\boldsymbol{f}(\cdot): \ell^{\mathrm{p}} \rightarrow \ell^{\mathrm{p}}, \mathrm{f}(\cdot, \cdot): \mathrm{I} \times \ell^{\mathrm{p}} \rightarrow \mathbf{R}$, and

$\boldsymbol{f}(\cdot, \cdot): \mathrm{I} \times \ell^{\mathrm{p}} \rightarrow \ell^{\mathrm{p}}$.

Hence we can define the function spaces

$\boldsymbol{C}\left(\mathrm{I}, \ell^{\mathrm{p}}\right)=\left\{\boldsymbol{n}(\cdot): \mathrm{I} \rightarrow \ell^{\mathrm{p}} \mid \boldsymbol{n}(\cdot)\right.$ is continuous $\}$ and

$\boldsymbol{C}\left(\ell^{\mathrm{p}}, \mathbf{R}\right)=\left\{\mathrm{M}(\cdot): \ell^{\mathrm{p}} \rightarrow \mathbf{R} \mid \mathrm{M}(\cdot)\right.$ is continuous $\}$ as well as $\boldsymbol{C}\left(\ell^{\mathrm{p}}, \ell^{\mathrm{p}}\right), \boldsymbol{C}\left(\mathrm{I} \times \ell^{\mathrm{p}}, \mathbf{R}\right)$ and $\boldsymbol{C}\left(\mathrm{I} \times \ell^{\mathrm{p}}, \ell^{\mathrm{p}}\right)$. If

$\mathrm{B} \subseteq \mathrm{C}$, then we may assume $\mathscr{F}(\mathrm{A}, \mathrm{B}) \subseteq \mathscr{F}(\mathrm{A}, \mathrm{C})$. For $\mathscr{F}(\mathrm{A}, \mathrm{B})$, the range is restricted to the set $\mathrm{B}$ whereas, for $\mathscr{F}(\mathrm{A}, \mathrm{C})$, it is allowed to be in the larger set $\mathrm{C}$. Since $\ell^{\mathrm{p}} \subseteq \mathbf{R}^{\infty}, \boldsymbol{C}\left(\mathrm{I}, \ell^{\mathrm{p}}\right) \subseteq_{\mathrm{vs}} \boldsymbol{C}\left(\mathrm{I}, \mathbf{R}^{\infty}\right)$. However, $\ell^{\mathrm{p}}$ has a norm (and hence a metric and a topology), but $\mathbf{R}^{\infty}$ does not. (We could establish a topology for $\mathbf{R}^{\infty}$, but this is not necessary if the system states are all in $\ell^{\mathrm{p}}$.) We will use $\boldsymbol{C}_{\mathrm{cw}}\left(\mathrm{I}, \ell^{\mathrm{p}}\right)$ for functions that are componentwise continuous with codomain $\ell^{\mathrm{p}}$ and write $\boldsymbol{n}(\cdot) \in \boldsymbol{C}_{\mathrm{cw}}\left(\mathrm{I}, \ell^{\mathrm{p}}\right) \subseteq \boldsymbol{C}_{\mathrm{cw}}\left(\mathrm{I}, \mathbf{R}^{\infty}\right)$,

$\boldsymbol{f}(\cdot) \in \boldsymbol{C}_{\mathrm{cw}}\left(\ell^{\mathrm{p}}, \ell^{\mathrm{p}}\right) \subseteq \boldsymbol{C}_{\mathrm{cw}}\left(\ell^{\mathrm{p}}, \mathbf{R}^{\infty}\right)$, and

$\boldsymbol{f}(\cdot, \cdot) \in \boldsymbol{C}_{\mathrm{cw}}\left(\mathrm{I} \times \ell^{\mathrm{p}}, \ell^{\mathrm{p}}\right) \subseteq \boldsymbol{C}_{\mathrm{cw}}\left(\mathrm{I} \times \ell^{\mathrm{p}}, \mathbf{R}^{\infty}\right)$. Also, if

$\mathrm{A} \subseteq \mathrm{B}$, we write $\mathrm{f}(\cdot) \in \mathscr{F}(\mathrm{A}, \mathrm{C})$ if $\mathrm{f}(\cdot) \in \mathscr{F}(\mathrm{B}, \mathrm{C})$; that is, we use the same symbol for the restriction of a function to a smaller domain.

We give necessary and sufficient conditions for $\mathbf{n}(\cdot)$ to be in $\boldsymbol{C}\left(\mathrm{I}, \ell^{\mathrm{p}}\right)$.

Theorem 2.4. $\boldsymbol{C}\left(\mathrm{I}, \ell^{\mathrm{p}}\right) \subseteq_{\mathrm{vs}} \boldsymbol{C}_{\mathrm{cw}}\left(\mathrm{I}, \ell^{\mathrm{p}}\right) \subseteq_{\mathrm{vs}} \boldsymbol{C}_{\mathrm{cw}}\left(\mathrm{I}, \mathbf{R}^{\infty}\right)$. Proof. We show that $\boldsymbol{C}\left(\mathrm{I}, \ell^{\mathrm{p}}\right) \subseteq \boldsymbol{C}_{\mathrm{cw}}\left(\mathrm{I}, \ell^{\mathrm{p}}\right)$. That is, if $\boldsymbol{n}(\cdot) \in \boldsymbol{C}\left(\mathrm{I}, \ell^{\mathrm{p}}\right)$, then $\boldsymbol{n}(\mathrm{t})$ is componentwise continuous. As $\boldsymbol{C}\left(\mathrm{I}, \ell^{\mathrm{p}}\right)$ is a vector space, by our previous comments $\boldsymbol{C}\left(\mathrm{I}, \ell^{\mathrm{p}}\right) \subseteq_{\mathrm{vs}} \boldsymbol{C}_{\mathrm{cw}}\left(\mathrm{I}, \ell^{\mathrm{p}}\right) \subseteq_{\mathrm{vs}} \boldsymbol{C}_{\mathrm{cw}}\left(\mathrm{I}, \mathbf{R}^{\infty}\right)$ follows. Let $\boldsymbol{n}(\cdot)=\left\{\mathrm{n}_{\mathrm{i}}(\cdot)\right\}_{i=1}^{\infty} \in \boldsymbol{C}\left(\mathrm{I}, \ell^{\mathrm{p}}\right)$ and $\mathrm{t}_{1} \in \mathrm{I}$. Then $\lim _{\mathrm{t} \rightarrow \mathrm{t}_{1}} \boldsymbol{n}(\mathrm{t})=\boldsymbol{n}\left(\mathrm{t}_{1}\right)$ in $\ell^{\mathrm{p}}$. That is, given $\varepsilon>0, \exists \delta>0$ such that $0<\left|\mathrm{t}-\mathrm{t}_{1}\right|<\delta$ implies

$\left\|\boldsymbol{n}(\mathrm{t})-\boldsymbol{n}\left(\mathrm{t}_{1}\right)\right\|_{\mathrm{p}}=\left(\sum_{\mathrm{i}=1}^{\infty}\left|\mathrm{n}_{\mathrm{i}}(\mathrm{t})-\mathrm{n}_{\mathrm{i}}\left(\mathrm{t}_{1}\right)\right|^{\mathrm{p}}\right)^{1 / \mathrm{p}}<\varepsilon$. Since

$\left|\mathrm{n}_{\mathrm{i}}(\mathrm{t})-\mathrm{n}_{\mathrm{i}}\left(\mathrm{t}_{1}\right)\right| \leq\left(\sum_{\mathrm{i}=1}^{\infty}\left|\mathrm{n}_{\mathrm{i}}(\mathrm{t})-\mathrm{n}_{\mathrm{i}}\left(\mathrm{t}_{1}\right)\right|^{\mathrm{p}}\right)^{1 / \mathrm{p}}$, given

$\varepsilon>0, \exists \delta>0$ such that $0<\left|\mathrm{t}-\mathrm{t}_{1}\right|<\delta$ implies

$\left|\mathrm{n}_{\mathrm{i}}(\mathrm{t})-\mathrm{n}_{\mathrm{i}}\left(\mathrm{t}_{\mathrm{i}}\right)\right|<\varepsilon$. Hence $\forall \mathrm{i} \in \mathbf{N}, \lim _{\mathrm{t} \rightarrow \mathrm{t}_{1}} \mathrm{n}_{\mathrm{i}}(\mathrm{t})=\mathrm{n}_{\mathrm{i}}\left(\mathrm{t}_{1}\right)$

in $\mathbf{R}$ so that $\boldsymbol{n}(\cdot) \in \boldsymbol{C}\left(\mathrm{I}, \ell^{\mathrm{p}}\right)$. Hence

$\boldsymbol{C}\left(\mathrm{I}, \ell^{\mathrm{p}}\right) \subseteq \boldsymbol{C}_{\mathrm{cw}}\left(\mathrm{I}, \ell^{\mathrm{p}}\right) \subseteq \boldsymbol{C}_{\mathrm{cw}}\left(\mathrm{I}, \mathbf{R}^{\infty}\right)$

Theorem 2.5. If $\boldsymbol{n}(\cdot) \in \boldsymbol{C}\left(\mathrm{I}, \ell^{\mathrm{p}}\right)$, then $\|\boldsymbol{n}(\cdot)\|_{\mathrm{p}} \in \mathrm{C}(\mathrm{I}, \mathbf{R})$.

If $\boldsymbol{n}=\left\{\mathrm{n}_{\mathrm{i}}\right\}_{\mathrm{i}=1}^{\infty} \in \ell^{1}$, then $\mathrm{M}_{0}(\boldsymbol{n})=\sum_{\mathrm{j}=1}^{\infty} \mathrm{n}_{\mathrm{j}} \in \boldsymbol{C}\left(\ell^{1}, \mathbf{R}\right)$. If $\boldsymbol{n}(\cdot)=\left\{\mathrm{n}_{\mathrm{i}}(\cdot)\right\}_{i=1}^{\infty} \in \boldsymbol{C}\left(\mathrm{I}, \ell^{1}\right)$, then

$\mathrm{M}_{0}(\boldsymbol{n}(\cdot))=\sum_{\mathrm{j}=1}^{\infty} \mathrm{n}_{\mathrm{j}}(\cdot) \in \mathrm{C}(\mathrm{I}, \mathbf{R})$.

Proof. If $\boldsymbol{n}_{1}, \boldsymbol{n}_{2} \in \ell^{\mathrm{p}}$ (or any normed linear space), then the triangle inequality $\left\|\mathrm{n}_{1}+\mathrm{n}_{2}\right\|_{\mathrm{p}} \leq\left\|\mathrm{n}_{1}\right\|_{\mathrm{p}}+\left\|\mathrm{n}_{2}\right\|_{\mathrm{p}}$ implies $\left|\left\|\boldsymbol{n}_{2}\right\|_{\mathrm{p}}-\left\|\boldsymbol{n}_{1}\right\|_{\mathrm{p}}\right| \leq\left\|\boldsymbol{n}_{2}-\boldsymbol{n}_{1}\right\|_{\mathrm{p}}$ so the norm function $\|\cdot\|_{\mathrm{n}}: \ell^{\mathrm{p}} \rightarrow \mathbf{R}$ satisfies a Lipschitz condition on $\ell^{\mathrm{p}}$ and hence is continuous on $\ell^{\mathrm{p}}$ i.e., is in $\mathrm{C}\left(\ell^{\mathrm{p}}, \mathbf{R}\right)$. We say it is Lipschitz continuous on $\ell^{\mathrm{p}}$. Now let $\boldsymbol{n}(\cdot) \in \boldsymbol{C}\left(\mathrm{I}, \ell^{\mathrm{p}}\right)$. Since $\|\boldsymbol{n}(\cdot)\|_{\mathrm{p}}$ is the composition of the norm function with $\boldsymbol{n}(\cdot), \boldsymbol{n}(\cdot) \in \boldsymbol{C}\left(\mathrm{I}, \ell^{\mathrm{p}}\right)$ implies $\|\boldsymbol{n}(\cdot)\|_{\mathrm{p}} \in \mathrm{C}(\mathrm{I}, \mathbf{R})$. For $\boldsymbol{n}=\left\{\mathrm{n}_{\mathrm{i}}\right\}_{i=1}^{\infty} \in \ell^{1} \subseteq \mathbf{R}^{\infty}$, let 
$\mathrm{M}_{0}(\boldsymbol{n})=\sum_{\mathrm{j}=1}^{\infty} \mathrm{n}_{\mathrm{j}}$. Since

$\left|\mathrm{M}_{0}(\boldsymbol{n})\right|=\left|\sum_{\mathrm{j}=1}^{\infty} \mathrm{n}_{\mathrm{j}}\right| \leq \sum_{\mathrm{j}=1}^{\infty}\left|\mathrm{n}_{\mathrm{j}}\right|=\|\boldsymbol{n}\|_{1}<\infty, \quad \mathrm{M}_{0}(\boldsymbol{n})=\sum_{\mathrm{j}=1}^{\infty} \mathrm{n}_{\mathrm{j}}$

exists (converges absolutely). If

$\boldsymbol{n}=\left\{\mathrm{n}_{\mathrm{i}}\right\}_{i=1}^{\infty}, \boldsymbol{n}_{1}=\left\{\mathrm{n}_{\mathrm{i}}^{1}\right\}_{i=1}^{\infty} \in \ell^{1}$, then so that $\mathrm{M}_{0}(\mathrm{~A})$ is

Lipschitz continuous on $\ell^{1}$ so that $\mathrm{M}_{0}(\cdot) \in \mathrm{C}\left(\ell^{1}, \mathbf{R}\right)$.

Since the composition of continuous functions (to and from $\left.\ell^{1}\right)$ is continuous, $\mathrm{M}_{0}(\boldsymbol{n}(\cdot))=\sum_{\mathrm{j}=1}^{\infty} \mathrm{n}_{\mathrm{j}}(\cdot) \in \boldsymbol{C}(\mathrm{I}, \mathbf{R})$

Example 2.1. Let $I=(-1,2)$ and for $t \in I$ let

$$
\begin{aligned}
& n_{i}(t) \\
& =\left\{\begin{array}{ccc}
0 & \text { if } & t \leq 1 /(i+3) \\
(i+2)(i+3) t-(i+2) & \text { if } & 1 /(i+3) \leq t \leq 1 /(i+2) \\
1 & \text { if } & 1 /(i+2) \leq t \leq 1 /(i+1) \\
-i(i+1) t+(i+1) & \text { if } & 1 /(i+1) \leq t \leq 1 / i \\
0 & \text { if } & 1 / i \leq t
\end{array}\right.
\end{aligned}
$$

Then $\boldsymbol{n}(\mathrm{t})=\left\{\mathrm{n}_{\mathrm{i}}(\mathrm{t})\right\}_{i=1}^{\infty} \in \boldsymbol{C}_{\mathrm{cw}}\left(\mathrm{I}, \ell^{\mathrm{p}}\right)$ as each $\mathrm{n}_{\mathrm{i}}(\mathrm{t})$ is continuous and $\forall \mathrm{t} \in \mathrm{I}, \quad\|\boldsymbol{n}(\mathrm{t})\|_{\mathrm{p}}=\left(\sum_{\mathrm{i}=1}^{\infty}\left|\mathrm{n}_{\mathrm{i}}(\mathrm{t})\right|^{\mathrm{p}}\right)^{1 / \mathrm{p}} \leq 3$. However, $\quad \boldsymbol{n}(0)=\boldsymbol{0}=\{0\}_{\mathrm{i}=1}^{\infty}, \quad \lim _{\mathrm{t} \rightarrow 0^{-}}\|\boldsymbol{n}(\mathrm{t})-\boldsymbol{0}\|_{\mathrm{p}}=0 \quad$ but for $0<\mathrm{t}<1 / 2, \quad\|\boldsymbol{n}(\mathrm{t})\|_{\mathrm{p}} \geq 1$. Hence $\lim _{\mathrm{t} \rightarrow 0^{+}}\|\boldsymbol{n}(\mathrm{t})-\boldsymbol{0}\|_{\mathrm{p}}$ either does not exist or is greater then or equal to 1 . Hence $\|\boldsymbol{n}(\mathrm{t})\|_{\mathrm{p}}$ in not contiuous at $\mathrm{t}=0$ as $\lim _{t \rightarrow 0}\|\boldsymbol{n}(\mathrm{t})\|_{p}$ does not exist. Hence $\lim _{t \rightarrow 0} \boldsymbol{n}(\mathrm{t})$ does not exist in $\ell^{\mathrm{p}}$. Hence $\boldsymbol{n}(\mathrm{t}) \notin \boldsymbol{C}\left(\mathrm{I}, \ell^{\mathrm{p}}\right)$. Hence the relations $\boldsymbol{C}\left(\mathrm{I}, \ell^{\mathrm{p}}\right) \subseteq_{\mathrm{vs}} \boldsymbol{C}_{\mathrm{cw}}\left(\mathrm{I}, \ell^{\mathrm{p}}\right) \subseteq_{\mathrm{vs}} \boldsymbol{C}_{\mathrm{cw}}\left(\mathrm{I}, \mathbf{R}^{\infty}\right)$ are proper.

Example 2.2. Let $\mathrm{I} \supseteq[-1,1]$ and for any $\mathrm{t}$ let $\mathrm{n}_{1}(\mathrm{t})=\left\{\begin{array}{ccc}-1 & \text { for } & \mathrm{t} \leq 0 \\ 1 & \text { for } & \mathrm{t}>0\end{array}\right.$ and $\mathrm{n}_{\mathrm{i}}(\mathrm{t})=0$ otherwise.

Then $\forall \mathrm{t}, \mathrm{p}$, we have $\boldsymbol{n}(\mathrm{t}) \in \ell^{\mathrm{p}}$ and $\|\boldsymbol{n}(\mathrm{t})\|_{\mathrm{p}}=1 . \mathrm{Ob}-$ viously $\boldsymbol{n}(\cdot) \notin \mathrm{C}_{\mathrm{cw}}\left(\mathrm{I}, \ell^{\mathrm{p}}\right) \quad$ so $\quad \boldsymbol{n}(\cdot) \notin \mathrm{C}\left(\mathrm{I}, \ell^{\mathrm{p}}\right) \quad$ even though $\|\boldsymbol{n}(\cdot)\|_{\mathrm{p}} \in \mathrm{C}(\mathrm{I}, \mathbf{R})$ as $\forall \mathrm{t},\|\boldsymbol{n}(\mathrm{t})\|_{\mathrm{p}}=1$.

Although not sufficient individually for $\boldsymbol{n}(\cdot): \mathrm{I} \rightarrow \mathbf{R}^{\infty}$ to be in $\mathrm{C}\left(\mathrm{I}, \ell^{\mathrm{p}}\right)$, we need its range to be in $\ell^{\mathrm{p}}$, $\boldsymbol{n}(\cdot) \in \boldsymbol{C}_{\mathrm{cw}}\left(\mathrm{I}, \ell^{\mathrm{p}}\right)$, and $\|\boldsymbol{n}(\cdot)\|_{\mathrm{p}} \in \mathrm{C}(\mathrm{I}, \mathbf{R})$. However, all of these do force $\boldsymbol{n}(\cdot)$ to be in $\boldsymbol{C}\left(\mathrm{I}, \ell^{\mathrm{p}}\right)$.

\section{Theorem 2.6.}

$$
\boldsymbol{C}\left(\mathrm{I}, \ell^{\mathrm{p}}\right)=\left\{\boldsymbol{n}(\cdot) \in \boldsymbol{C}_{\mathrm{cw}}\left(\mathrm{I}, \ell^{\mathrm{p}}\right):\|\boldsymbol{n}(\cdot)\|_{\mathrm{p}} \in \mathrm{C}(\mathrm{I}, \mathbf{R})\right\}
$$

Proof. Let

$$
\boldsymbol{n}(\cdot)=\left\{\mathrm{n}_{\mathrm{i}}(\cdot)\right\}_{\mathrm{i}=1}^{\infty} \in \boldsymbol{C}_{\mathrm{cw}}\left(\mathrm{I}, \ell^{\mathrm{p}}\right),\|\boldsymbol{n}(\cdot)\|_{\mathrm{p}} \in \mathrm{C}(\mathrm{I}, \mathbf{R}), \in,
$$

and

$$
\boldsymbol{n}^{\mathrm{N}+}(\mathrm{t})=\left\{\begin{array}{ll}
0 & \text { for } \mathrm{i} \leq \mathrm{N} \\
\mathrm{n}_{\mathrm{i}}(\mathrm{t}) & \text { for } \mathrm{i}>\mathrm{N}
\end{array} .\right.
$$

Since $\boldsymbol{n}(\cdot) \in \boldsymbol{C}_{\mathrm{cw}}\left(\mathrm{I}, \ell^{\mathrm{p}}\right), \forall \mathrm{i} \in \mathbf{N}, \mathrm{n}_{\mathrm{i}}(\cdot) \in \mathrm{C}(\mathrm{I}, \mathbf{R})$ and $\forall \mathrm{t} \in \mathrm{I}, \boldsymbol{n}(\mathrm{t}) \in \ell^{\mathrm{p}} \quad$. Also, $\quad\left\|\boldsymbol{n}^{\mathrm{N}}(\cdot)\right\|_{\mathrm{p}}=\left(\sum_{\mathrm{i}=1}^{\mathrm{N}}\left|\mathrm{n}_{\mathrm{i}}(\cdot)\right|^{\mathrm{p}}\right)^{1 / \mathrm{p}}$, $\left(\|\boldsymbol{n}(\cdot)\|_{\mathrm{p}}\right)^{\mathrm{p}}$

$$
\begin{aligned}
\left(\left\|\boldsymbol{n}^{\mathrm{N}+}(\cdot)\right\|_{\mathrm{p}}\right)^{\mathrm{p}} & =\sum_{\mathrm{i}=\mathrm{N}+1}^{\infty}|\mathrm{n}(\cdot)|^{\mathrm{p}}=\sum_{\mathrm{i}=1}^{\infty}|\mathrm{n}(\cdot)|^{\mathrm{p}}-\sum_{\mathrm{i}=1}^{\mathrm{N}}|\mathrm{n}(\cdot)|^{\mathrm{p}} \\
& =\left(\|\boldsymbol{n}(\cdot)\|_{\mathrm{p}}\right)^{\mathrm{p}}-\left(\left\|\boldsymbol{n}^{\mathrm{N}}(\cdot)\right\|_{\mathrm{p}}\right)^{\mathrm{p}}
\end{aligned}
$$

and $\left\|\boldsymbol{n}^{\mathrm{N}+}(\cdot)\right\|_{\mathrm{p}}$ are all in $\mathrm{C}(\mathrm{I}, \mathbf{R})$. Let $\mathrm{t}, \mathrm{t}_{1} \in \mathrm{I}$. Then

$$
\begin{aligned}
& \left\|\boldsymbol{n}(\mathrm{t})-\boldsymbol{n}\left(\mathrm{t}_{1}\right)\right\|_{\mathrm{p}} \\
= & \left\|\boldsymbol{n}^{\mathrm{N}}(\mathrm{t})+\boldsymbol{n}^{\mathrm{N}+}(\mathrm{t})-\boldsymbol{n}^{\mathrm{N}}\left(\mathrm{t}_{1}\right)-\boldsymbol{n}^{\mathrm{N}+}\left(\mathrm{t}_{1}\right)\right\|_{\mathrm{p}} . \\
\leq & \left\|\boldsymbol{n}^{\mathrm{N}}(\mathrm{t})-\boldsymbol{n}^{\mathrm{N}}\left(\mathrm{t}_{1}\right)\right\|_{\mathrm{p}}+\left\|\boldsymbol{n}^{\mathrm{N}+}(\mathrm{t})\right\|_{\mathrm{p}}+\left\|\boldsymbol{n}^{\mathrm{N}+}\left(\mathrm{t}_{1}\right)\right\|_{\mathrm{p}}
\end{aligned}
$$

Now let $\varepsilon>0$. Since $\left(\|\boldsymbol{n}(\cdot)\|_{\mathrm{p}}\right)^{\mathrm{p}}=\sum_{\mathrm{i}=1}^{\infty}\left|\mathrm{n}_{\mathrm{i}}\left(\mathrm{t}_{1}\right)\right|^{\mathrm{p}}<\infty$, we can choose $\mathrm{N}$ sufficiently large so that $\left(\left\|\boldsymbol{n}^{\mathrm{N}+}\left(\mathrm{t}_{1}\right)\right\|_{\mathrm{p}}\right)^{\mathrm{p}}=\sum_{\mathrm{i}=\mathrm{N}+1}^{\infty}\left|\mathrm{n}_{\mathrm{i}}\left(\mathrm{t}_{1}\right)\right|^{\mathrm{p}}<(\varepsilon / 6)^{\mathrm{p}}$. Since $\left\|\boldsymbol{n}^{\mathrm{N}+}(\cdot)\right\|_{\mathrm{p}} \in \mathrm{C}(\mathrm{I}, \mathbf{R}), \quad \exists \delta_{\mathrm{N}+}$ such that $0<\left|\mathrm{t}-\mathrm{t}_{1}\right|<\delta_{\mathrm{N}+}$ implies $\left\|\boldsymbol{n}^{\mathrm{N}+}\left(\mathrm{t}_{1}\right)\right\|_{\mathrm{p}}-\left\|\boldsymbol{n}^{\mathrm{N}+}(\mathrm{t})\right\|_{\mathrm{p}} \mid<\varepsilon / 6$ so that $\left\|\boldsymbol{n}^{\mathrm{N}+}(\mathrm{t})\right\|_{\mathrm{p}}<\left\|\boldsymbol{n}^{\mathrm{N}+}\left(\mathrm{t}_{1}\right)\right\|_{\mathrm{p}}+\varepsilon / 6<\varepsilon / 3$. Since $\boldsymbol{n}(\cdot) \in \boldsymbol{C}_{\mathrm{cw}}\left(\mathrm{I}, \ell^{\mathrm{p}}\right), \forall \mathrm{i}$ choose $\delta_{\mathrm{i}}$ so that $0<\left|\mathrm{t}-\mathrm{t}_{1}\right|<\delta_{\mathrm{i}}$ implies $\left|\mathrm{n}_{\mathrm{i}}(\mathrm{t})-\mathrm{n}_{\mathrm{i}}\left(\mathrm{t}_{1}\right)\right|^{\mathrm{p}}<(\varepsilon / 2)^{\mathrm{p}} / \mathrm{N}$. Hence

$$
\begin{aligned}
\left(\left\|\boldsymbol{n}^{\mathrm{N}}(\mathrm{t})-\boldsymbol{n}^{\mathrm{N}}\left(\mathrm{t}_{1}\right)\right\|_{\mathrm{p}}\right)^{\mathrm{p}} & =\sum_{\mathrm{i}=1}^{\mathrm{N}}\left|\mathrm{n}_{\mathrm{i}}(\mathrm{t})-\mathrm{n}_{\mathrm{i}}\left(\mathrm{t}_{1}\right)\right|^{\mathrm{p}} \\
& \leq \mathrm{N}\left(\frac{\varepsilon}{2}\right)^{\mathrm{p}} \frac{1}{\mathrm{~N}}=(\varepsilon / 2)^{\mathrm{p}}
\end{aligned}
$$

Now choose $\delta=\min \left(\delta_{1}, \cdots, \delta_{\mathrm{N}}, \delta_{\mathrm{N}+}\right)$. Hence $0<\left|\mathrm{t}-\mathrm{t}_{1}\right|<\delta$ implies 


$$
\begin{aligned}
&\left\|\boldsymbol{n}(\mathrm{t})-\boldsymbol{n}\left(\mathrm{t}_{1}\right)\right\|_{\mathrm{p}} \\
& \leq\left\|\boldsymbol{n}^{\mathrm{N}}(\mathrm{t})-\boldsymbol{n}^{\mathrm{N}}\left(\mathrm{t}_{1}\right)\right\|_{\mathrm{p}}+\left\|\boldsymbol{n}^{\mathrm{N}+}(\mathrm{t})\right\|_{\mathrm{p}}+\left\|\boldsymbol{n}^{\mathrm{N}+}\left(\mathrm{t}_{1}\right)\right\|_{\mathrm{p}} . \\
&<\varepsilon / 2+\varepsilon / 3+\varepsilon / 6=\varepsilon
\end{aligned}
$$

Hence $\boldsymbol{n}(\cdot) \in \mathbf{C}\left(\mathrm{I}, \ell^{\mathrm{p}}\right)$.

Rather than check directly that $\boldsymbol{n}(\cdot) \in \boldsymbol{C}\left(\mathrm{I}, \ell^{\mathrm{p}}\right)$, it may be easier to check that for each $\mathrm{t} \in \mathrm{I}, \boldsymbol{n}(\mathrm{t}) \in \ell^{\mathrm{p}}$, $\boldsymbol{n}(\cdot) \in \boldsymbol{C}_{\mathrm{cw}}\left(\mathrm{I}, \mathbf{R}^{\infty}\right)$ and $\|\boldsymbol{n}(\cdot)\|_{\mathrm{p}} \in \mathrm{C}(\mathrm{I}, \mathbf{R})$ since $\mathrm{n}_{\mathrm{i}}(\cdot)$ and $\|\boldsymbol{n}(\cdot)\|_{\mathrm{p}}$ map from I to R. Similarly,

\section{Corollary 2.7.}

$$
\boldsymbol{C}\left(\ell^{\mathrm{p}}, \ell^{\mathrm{p}}\right)=\left\{\boldsymbol{f}(\cdot) \in \boldsymbol{C}_{\mathrm{cw}}\left(\ell^{\mathrm{p}}, \ell^{\mathrm{p}}\right):\|\boldsymbol{f}(\cdot)\|_{\mathrm{p}} \in \mathrm{C}\left(\ell^{\mathrm{p}}, \mathbf{R}\right)\right\},
$$

and

$$
\begin{aligned}
& \boldsymbol{C}\left(\mathrm{I} \times \ell^{\mathrm{p}}, \ell^{\mathrm{p}}\right) \\
& =\left\{\boldsymbol{f}(\cdot, \cdot) \in \boldsymbol{C}_{\mathrm{cw}}\left(\mathrm{I} \times \ell^{\mathrm{p}}, \ell^{\mathrm{p}}\right):\|\boldsymbol{f}(\cdot, \cdot)\|_{\mathrm{p}} \in \mathrm{C}\left(\mathrm{I} \times \ell^{\mathrm{p}}, \mathbf{R}\right)\right\}
\end{aligned}
$$

Following the standard proof for products, we also have

Theorem 2.8. If $\mathrm{A}(\cdot) \in \mathrm{C}(\mathrm{I}, \mathbf{R})$ and $\boldsymbol{n}(\cdot) \in \boldsymbol{C}\left(\mathrm{I}, \ell^{\mathrm{p}}\right)$, then $\mathrm{A}(\cdot) \boldsymbol{n}(\cdot) \in \boldsymbol{C}\left(\mathrm{I}, \ell^{\mathrm{p}}\right)$.

Proof. Let $0<\varepsilon<1$ and $\mathrm{t}_{1} \in \mathrm{I}$. Choose $\delta_{1}$ such that $0<\left|\mathrm{t}-\mathrm{t}_{1}\right|<\delta_{1}$ implies $\left|\mathrm{A}(\mathrm{t})-\mathrm{A}\left(\mathrm{t}_{1}\right)\right|<\frac{\varepsilon}{2\left(\left\|\boldsymbol{n}\left(\mathrm{t}_{1}\right)\right\|+1\right)}$ and $\delta_{2}$ such that $0<\left|\mathrm{t}-\mathrm{t}_{1}\right|<\delta_{2}$ implies $\left\|\boldsymbol{n}(\mathrm{t})-\boldsymbol{n}\left(\mathrm{t}_{1}\right)\right\|_{\mathrm{p}}<\frac{\varepsilon}{2\left(\mathrm{~A}\left(\mathrm{t}_{1}\right)+1\right)}$. Let $\delta=\min \left(\delta_{1}, \delta_{2}\right)$. Then $0<\left|\mathrm{t}-\mathrm{t}_{1}\right|<\delta$ implies

$$
\begin{aligned}
& \left\|\mathrm{A}(\mathrm{t}) \boldsymbol{n}(\mathrm{t})-\mathrm{A}\left(\mathrm{t}_{1}\right) \boldsymbol{n}\left(\mathrm{t}_{1}\right)\right\|_{\mathrm{p}} \\
& =\left\|\left(\mathrm{A}(\mathrm{t})-\mathrm{A}\left(\mathrm{t}_{1}\right)\right) \boldsymbol{n}(\mathrm{t})+\mathrm{A}\left(\mathrm{t}_{1}\right)\left(\boldsymbol{n}(\mathrm{t})-\boldsymbol{n}\left(\mathrm{t}_{1}\right)\right)\right\|_{\mathrm{p}} \\
& \leq\left\|\left(\mathrm{A}(\mathrm{t})-\mathrm{A}\left(\mathrm{t}_{1}\right)\right) \boldsymbol{n}(\mathrm{t})\right\|_{\mathrm{p}}+\left\|\mathrm{A}\left(\mathrm{t}_{1}\right)\left(\boldsymbol{n}(\mathrm{t})-\boldsymbol{n}\left(\mathrm{t}_{1}\right)\right)\right\|_{\mathrm{p}} \\
& \leq\left|\mathrm{A}(\mathrm{t})-\mathrm{A}\left(\mathrm{t}_{1}\right)\|\boldsymbol{n}(\mathrm{t})\|_{\mathrm{p}}+\right| \mathrm{A}\left(\mathrm{t}_{1}\right) \mid\left\|\boldsymbol{n}(\mathrm{t})-\boldsymbol{n}\left(\mathrm{t}_{1}\right)\right\|_{\mathrm{p}} \\
& <\frac{\varepsilon}{2\left(\left\|\boldsymbol{n}\left(\mathrm{t}_{1}\right)\right\|+1\right)}\|\boldsymbol{n}(\mathrm{t})\|_{\mathrm{p}}+\left|\mathrm{A}\left(\mathrm{t}_{1}\right)\right| \frac{\varepsilon}{2\left(\left|\mathrm{~A}\left(\mathrm{t}_{1}\right)\right|+1\right)} \leq \varepsilon
\end{aligned}
$$

\section{Similarly,}

Corollary 2.9. If $\mathrm{A}(\cdot) \in \mathrm{C}(\mathrm{I}, \mathbf{R})$ and $\mathrm{M}(\cdot) \in \mathrm{C}\left(\ell^{\mathrm{p}}, \mathbf{R}\right)$, then $\mathrm{A}(\cdot) \mathrm{M}(\cdot) \in \mathrm{C}\left(\mathrm{I} \times \ell^{\mathrm{p}}, \mathbf{R}\right)$. If $\mathrm{A}(\cdot) \in \mathrm{C}(\mathrm{I}, \mathbf{R})$ and $\boldsymbol{f}(\cdot) \in \boldsymbol{C}\left(\ell^{\mathrm{p}}, \ell^{\mathrm{p}}\right)$, then $\mathrm{A}(\cdot) \boldsymbol{f}(\cdot) \in \boldsymbol{C}\left(\mathrm{I} \times \ell^{\mathrm{p}}, \ell^{\mathrm{p}}\right)$. If $\mathrm{A}(\cdot) \in \mathrm{C}(\mathrm{I}, \mathbf{R})$ and $\mathrm{f}(\cdot, \cdot) \in \boldsymbol{C}\left(\mathrm{I} \times \ell^{\mathrm{p}}, \ell^{\mathrm{p}}\right)$, then $\mathrm{A}(\cdot) \mathrm{f}(\cdot, \cdot) \in \boldsymbol{C}\left(\mathrm{I} \times \ell^{\mathrm{p}}, \ell^{\mathrm{p}}\right)$.
We say $\boldsymbol{n}(\cdot)=\left\{\mathrm{n}_{\mathrm{i}}(\cdot)\right\}_{\mathrm{i}=1}^{\infty} \in \boldsymbol{C}\left(\mathrm{I}, \ell^{\mathrm{p}}\right)$ is differentiable (with respect to the norm topology) at $\mathrm{t}_{1} \in \mathrm{I}$, if $\frac{\mathrm{d} \boldsymbol{n}}{\mathrm{dt}}=\lim _{\mathrm{t} \rightarrow \mathrm{t}_{1}} \frac{\boldsymbol{n}(\mathrm{t})-\boldsymbol{n}\left(\mathrm{t}_{1}\right)}{\mathrm{t}-\mathrm{t}_{1}}$ exists in $\ell^{\mathrm{p}}$. If $\frac{\mathrm{d} \boldsymbol{n}(\mathrm{t})}{\mathrm{dt}}$ exists $\forall \mathrm{t} \in \mathrm{I}$ and is in $\boldsymbol{C}\left(\mathrm{I}, \ell^{\mathrm{p}}\right)$, then $\boldsymbol{n}(\cdot) \in \boldsymbol{C}^{1}\left(\mathrm{I}, \ell^{\mathrm{p}}\right)$. We define integration componentwise. Following Theorem 2.6, we have

Theorem 2.10. If $\boldsymbol{n}(\cdot)=\left\{\mathrm{n}_{\mathrm{i}}(\cdot)\right\}_{\mathrm{i}=1}^{\infty} \in \boldsymbol{C}\left(\mathrm{I}, \ell^{\mathrm{p}}\right)$, then $\mathrm{d} \boldsymbol{n} / \mathrm{dt}=\left\{\mathrm{dn}_{\mathrm{i}}(\mathrm{t}) / \mathrm{dt}\right\}_{\mathrm{i}=1}^{\infty} \in \boldsymbol{C}\left(\mathrm{I}, \ell^{\mathrm{p}}\right)$. Also,

$$
\boldsymbol{C}^{1}\left(\mathrm{I}, \ell^{\mathrm{p}}\right)=\left\{\boldsymbol{n}(\cdot) \in \boldsymbol{C}_{\mathrm{cw}}^{1}\left(\mathrm{I}, \ell^{\mathrm{p}}\right):\left\|\frac{\mathrm{d} \boldsymbol{n}(\cdot)}{\mathrm{dt}}\right\|_{1} \in \mathrm{C}(\mathrm{I}, \mathbf{R})\right\} .
$$

Proof. That $\mathrm{d} \boldsymbol{n} / \mathrm{dt}=\left\{\mathrm{d} \boldsymbol{n}_{\mathrm{i}}(\mathrm{t}) / \mathrm{dt}\right\}_{\mathrm{i}=1}^{\infty}$ follows from considering the limit for components. A proof of $\mathrm{d} \boldsymbol{n} / \mathrm{dt} \in \boldsymbol{C}\left(\mathrm{I}, \ell^{\mathrm{p}}\right)$ can be obtained following the proof for scalar valued functions in calculus books (e.g., Stewart $\left[19\right.$, p. 88]). The description of $\boldsymbol{C}^{1}\left(\mathrm{I}, \ell^{\mathrm{p}}\right)$ follows from Theorem 2.6.

If at $t_{1} \in \mathrm{I}, \boldsymbol{n}(\mathrm{t})$ has an infinite number of derivatives and equals it's Taylor series, $\boldsymbol{n}(\mathrm{t})=\sum_{\mathrm{k}=0}^{\infty} \frac{\boldsymbol{n}^{(\mathrm{k})}\left(\mathrm{t}_{1}\right)}{\mathrm{k} !}\left(\mathrm{t}-\mathrm{t}_{1}\right)$ in a neighborhood of $t_{1}$, it is analytic at $t_{1}$. If it is analytic $\forall \mathrm{t} \in \mathrm{I}$, then $\boldsymbol{n}(\cdot) \in \mathscr{A}\left(\mathrm{I}, \ell^{\mathrm{p}}\right)$.

Theorem 2.11.

$$
\begin{aligned}
& \boldsymbol{C}^{\mathrm{1}}\left(\mathrm{I}, \ell^{\mathrm{p}}\right) \subseteq_{\mathrm{vs}} \boldsymbol{C}\left(\mathrm{I}, \ell^{\mathrm{p}}\right), \\
& \boldsymbol{C}^{1}\left(\mathrm{I}, \ell^{\mathrm{p}}\right) \subseteq_{\mathrm{vs}} \boldsymbol{C}_{\mathrm{cw}}^{1}\left(\mathrm{I}, \ell^{\mathrm{p}}\right) \subseteq_{\mathrm{vs}} \boldsymbol{C}_{\mathrm{cw}}^{1}\left(\mathrm{I}, \mathbf{R}^{\infty}\right), \\
& \boldsymbol{C}^{1}\left(\ell^{\mathrm{p}}, \ell^{\mathrm{p}}\right) \subseteq_{\mathrm{vs}} \boldsymbol{C}_{\mathrm{cw}}^{1}\left(\ell^{\mathrm{p}}, \ell^{\mathrm{p}}\right) \subseteq_{\mathrm{vs}} \boldsymbol{C}_{\mathrm{cw}}^{1}\left(\ell^{\mathrm{p}}, \mathbf{R}^{\infty}\right), \\
& \boldsymbol{C}^{1}\left(\mathrm{I} \times \ell^{\mathrm{p}}, \ell^{\mathrm{p}}\right) \subseteq_{\mathrm{vs}} \boldsymbol{C}_{\mathrm{cw}}^{1}\left(\mathrm{I} \times \ell^{\mathrm{p}}, \ell^{\mathrm{p}}\right) \subseteq_{\mathrm{vs}} \boldsymbol{C}_{\mathrm{cw}}^{1}\left(\mathrm{I} \times \ell^{\mathrm{p}}, \mathbf{R}^{\infty}\right), \\
& \mathscr{A}\left(\mathrm{I}, \ell^{\mathrm{p}}\right) \subseteq_{\mathrm{vs}} \mathscr{A}_{\mathrm{cw}}\left(\mathrm{I}, \ell^{\mathrm{p}}\right) \subseteq_{\mathrm{vs}} \mathscr{A}_{\mathrm{cw}}\left(\mathrm{I}, \mathbf{R}^{\infty}\right)
\end{aligned}
$$

and

$$
\mathscr{A}\left(\mathrm{I}, \ell^{\mathrm{p}}\right) \subseteq_{\mathrm{vs}} \boldsymbol{C}^{1}\left(\mathrm{I}, \ell^{\mathrm{p}}\right) \subseteq_{\mathrm{vs}} \boldsymbol{C}\left(\mathrm{I}, \ell^{\mathrm{p}}\right) .
$$

Proof. The first containment follows from Theorem 2.10. The remaining proofs are straight forward and often similar to the proof of Theorem 2.4.

Theorem 2.12 (Fundamental Theorem of Calculus)

$$
\text { If } \boldsymbol{n}(\cdot) \in \boldsymbol{C}\left(\mathrm{I}, \ell^{\mathrm{p}}\right) \text {, then }
$$

$$
\boldsymbol{n}(\mathrm{t})=\frac{\mathrm{d}}{\mathrm{dt}} \int_{\mathrm{s}=\mathrm{t}_{0}}^{\mathrm{s}=\mathrm{t}} \boldsymbol{n}(\mathrm{s}) \mathrm{ds},
$$

If $\boldsymbol{n}(\cdot) \in \boldsymbol{C}\left(\mathrm{I}, \ell^{\mathrm{p}}\right)$, then

$$
\boldsymbol{n}(\mathrm{t})=\boldsymbol{n}\left(\mathrm{t}_{0}\right)+\int_{\mathrm{s}=\mathrm{t}_{0}}^{\mathrm{s}=\mathrm{t}} \frac{\mathrm{d} \boldsymbol{n}(\mathrm{s})}{\mathrm{ds}} \mathrm{ds} .
$$


Note that the indefinite integral requires an arbitrary constant vector.

\subsection{Kernels, State Spaces and $\Sigma$ Spaces}

In the analytic context with an analytic kernel, $\mathbf{K}(\cdot) \in \mathbf{M}_{\mathrm{AT}}\left(\mathrm{I}_{0}, \mathbf{R}^{\infty \times \infty}\right)$, Moseley [14] used the following procedure to solve DAP. He first established local uniqueness in $\mathscr{A}_{\mathrm{cw}}\left(\mathrm{I}_{0}, \mathbf{R}^{\infty}\right)$ by considering the Taylor series coefficients obtained from the initial conditions and the differential equation. However, he chose a smaller $\Sigma$ space containing only distributions where if $\boldsymbol{n}(\mathrm{t})$ is in the $\Sigma$ space, then

$\forall \mathrm{i} \in \mathbf{N}, \mathrm{f}_{\mathrm{i}}^{\mathrm{d}}(\cdot, \boldsymbol{n}(\cdot): \mathbf{K}) \in \mathscr{A}(\mathrm{I}, \mathbf{R})$. He then obtained the explicit formula (6) for the (analytic) solution when $\mathrm{A}(\mathrm{t})$ is analytic. He did not rigorously isolate the unknown so he established global existence by showing that the solution given by the formula (6) was in the $\Sigma$ space, checking the initial conditions (2), and then substituting the formula into (1). Since global existence holds, local uniqueness implies global uniqueness.

The problem of interest is to extend Moseley's results for the analytic context to the continuous context. The solution given by (6) remains the same except that we now only require $\mathrm{A}(\mathrm{t}) \in \mathrm{C}\left(\mathrm{I}_{0}, \mathbf{R}\right)$. Global existence may be obtained as before. However, local uniqueness is not as easy as it was in the analytic context. McLaughlin, Lamb, and McBride [13] provided local existence and uniqueness for a Continuum Agglomeration Model of linear fragmentation with coagulation as a perturbation using semigroup theory. Spouge [11] provided a local existence theorem in the physical case, but not uniqueness. The standard procedure in Brauer and Noel [20] for a finite dimensional system requires a Lipschitz condition on the right hand side to obtain local existence and local uniqueness. In this paper, we provide preliminaries for using a Lipschitz condition to prove uniqueness in the continuous context by giving equivalent problems in scalar and vector form for DAP with $\mathbf{K}(\mathrm{t})$ in a larger collection than $\mathbf{M}_{\mathrm{CT}}\left(\mathrm{I}_{0}, \mathbf{R}^{\infty \times \infty}\right)$.

$$
\text { Let } \boldsymbol{f}^{\mathrm{d}}(\mathrm{t}, \boldsymbol{n} ; \mathbf{K})=\left\{\mathrm{f}_{\mathrm{i}}^{\mathrm{d}}(\mathrm{t}, \boldsymbol{n} ; \mathbf{K})\right\}_{\mathrm{i}=1}^{\infty} \text {. If } \forall \mathrm{i} \in \mathbf{N},
$$

$\mathrm{f}_{\mathrm{i}}^{\mathrm{d}}(\mathrm{t}, \boldsymbol{n} ; \mathbf{K})$ converges $\forall(\mathrm{t}, \boldsymbol{n}) \in \mathrm{I}_{0} \times \mathbf{R}^{\infty}$, then

$\boldsymbol{f}^{\mathrm{d}}(\mathrm{t}, \boldsymbol{n} ; \mathbf{K})$ maps $\mathrm{I}_{0} \times \mathbf{R}^{\infty}$ to $\mathbf{R}^{\infty}$. We say that (the restriction of) $\boldsymbol{f}^{\mathrm{d}}(\mathrm{t}, \boldsymbol{n} ; \mathbf{K})$ (to $\left.\mathrm{I} \times \ell^{1}\right)$ is in

$\boldsymbol{C}_{\mathrm{cw}}\left(\mathrm{I} \times \ell^{1}, \mathbf{R}^{\infty}\right)$ if $\forall \mathrm{i} \in \mathbf{N}$, (the restriction of)

$\mathrm{f}_{\mathrm{i}}^{\mathrm{d}}(\mathrm{t}, \boldsymbol{n} ; \mathbf{K}) \quad$ (to $\left.\mathrm{I} \times \ell^{1}\right)$ is in $\boldsymbol{C}\left(\mathrm{I} \times \ell^{1}, \mathbf{R}\right)$ and write $f^{\mathrm{d}}(\cdot, ; \mathbf{K}) \in \mathrm{C}_{\mathrm{cw}}\left(\mathrm{I} \times \ell^{1}, \mathbf{R}^{\infty}\right)$. Furthermore, when

$\boldsymbol{n}(\cdot) \in \boldsymbol{C}\left(\mathrm{I}, \mathbf{R}^{\infty}\right)$, we write $\boldsymbol{f}^{\mathrm{d}}(\cdot, \boldsymbol{n}(\cdot) ; \mathbf{K})=\left\{\mathrm{f}_{\mathrm{i}}^{\mathrm{d}}(\cdot, \boldsymbol{n}(\cdot) ; \mathbf{K})\right\}_{\mathrm{i}=1}^{\infty} \in \boldsymbol{C}_{\mathrm{cw}}\left(\mathrm{I}, \mathbf{R}^{\infty}\right)$ if

$\forall \mathrm{i} \in \mathbf{N}, \mathrm{f}_{\mathrm{i}}^{\mathrm{d}}(\cdot, \mathrm{n}(\cdot) ; \mathbf{K}) \in \mathrm{C}(\mathrm{I}, \mathbf{R})$.

Theorem 2.13. If $\boldsymbol{f}^{\mathrm{d}}(\cdot, ; ; \mathbf{K}) \in \boldsymbol{C}_{\mathrm{cw}}\left(\mathrm{I} \times \ell^{1}, \mathbf{R}^{\infty}\right)$, and $\boldsymbol{n}(\cdot) \in \boldsymbol{C}\left(\mathrm{I}, \ell^{1}\right)$, then $\boldsymbol{f}^{\mathrm{d}}(\cdot, \boldsymbol{n}(\cdot) ; \mathbf{K}) \in \boldsymbol{C}_{\mathrm{cw}}\left(\mathrm{I}, \mathbf{R}^{\infty}\right)$.

Proof. Compositions of continuous functions (in $\ell^{1}$ ) are continuous so that if $\boldsymbol{f}^{\mathrm{d}}(\cdot, \cdot ; \mathbf{K}) \in \mathrm{C}\left(\mathrm{I} \times \ell^{1}, \mathbf{R}\right)$ and $\boldsymbol{n}(\cdot) \in \boldsymbol{C}\left(\mathrm{I}, \ell^{1}\right)$, then $\mathrm{f}_{\mathrm{i}}^{\mathrm{d}}(\cdot, \boldsymbol{n}(\cdot) ; \mathbf{K}) \in \mathrm{C}(\mathrm{I}, \mathbf{R})$. (See Corollary 2.2.)

In the continuous context we wish conditions on $\mathbf{K}(\cdot)$ so that $\boldsymbol{f}^{\mathrm{d}}(\cdot, ; ; \mathbf{K}) \in \boldsymbol{C}_{\mathrm{cw}}\left(\mathrm{I} \times \ell^{1}, \mathbf{R}^{\infty}\right)$. Then for $\boldsymbol{n}(\cdot)$ in (any subspace of) $\boldsymbol{C}\left(\mathrm{I}, \ell^{1}\right)$ we have $\boldsymbol{f}^{\mathrm{d}}(\cdot, \boldsymbol{n}(\cdot) ; \mathbf{K}) \in \boldsymbol{C}_{\mathrm{cw}}\left(\mathrm{I}, \mathbf{R}^{\infty}\right)$. Then the convergence and continuity condition on $\boldsymbol{f}^{\mathrm{d}}(\cdot, \boldsymbol{n}(\cdot) ; \mathbf{K})$ need not be explicitly stated for the $\Sigma$ space or as a condition for solution (except as required for interpreting (1)). We begin with three classes of kernels: $\mathbf{M}_{\mathrm{CT}}\left(\mathrm{I}_{0}, \mathbf{R}^{\infty \times \infty}\right)$,

$\mathbf{M}_{\mathrm{B}}\left(\mathrm{I}, \mathbf{R}^{\infty \times \infty}\right)=\left\{\mathbf{K}(\mathrm{t})=\left\{\mathrm{K}_{\mathrm{i}, \mathrm{j}}(\mathrm{t})\right\}_{\mathrm{i}, \mathrm{j}=1}^{\infty} \in \boldsymbol{C}_{\mathrm{CW}}\left(\mathrm{I}_{0}, \mathrm{R}^{\infty \times \infty}\right)\right.$ :

$\mathrm{K}_{\mathrm{i}, \mathrm{j}}(\mathrm{t})=\mathrm{B}_{\mathrm{i}, \mathrm{j}}=$ constant, so that $\exists \mathrm{M}_{\mathrm{Bmax}}$ such that for all, $\left.\mathrm{i}, \mathrm{j} \in \mathrm{N},\left|\mathrm{B}_{\mathrm{i}, \mathrm{j}}\right| \leq \mathrm{M}_{\mathrm{Bmax}}\right\}$

and

$\mathbf{M}_{\text {Ств }}\left(\mathrm{I}, \mathbf{R}^{\infty \times \infty}\right)=\left\{\mathbf{K}(\cdot)=\left\{\mathrm{B}_{\mathrm{i}, \mathrm{j}} \mathrm{A}(\cdot)\right\}_{\mathrm{i}, \mathrm{j}=1}^{\infty} \in \boldsymbol{C}_{\mathrm{CW}}\left(\mathrm{I}_{0}, \mathrm{R}^{\infty \times \infty}\right)\right.$

$\mathrm{A}(\cdot) \in \mathrm{C}\left(\mathrm{I}_{0}, \mathbf{R}\right)$ and $\left.\mathbf{K}_{1}(\cdot)=\left\{\mathrm{B}_{\mathrm{i}, \mathrm{j}}\right\}_{\mathrm{i}, \mathrm{j}=1}^{\infty} \in \mathbf{M}_{\mathrm{B}}\left(\mathrm{I}_{0}, \mathbf{R}^{\infty \times \infty}\right)\right\}$

Since $\mathbf{M}_{\mathrm{CT}}\left(\mathrm{I}, \mathbf{R}^{\infty \times \infty}\right) \subseteq \mathbf{M}_{\mathrm{CTB}}\left(\mathrm{I}, \mathbf{R}^{\infty \times \infty}\right)$ and $\mathbf{M}_{\mathrm{B}}\left(\mathrm{I}, \mathbf{R}^{\infty \times \infty}\right) \subseteq \mathbf{M}_{\mathrm{CTB}}\left(\mathrm{I}, \mathbf{R}^{\infty \times \infty}\right)$, if we can prove that for $\mathbf{K}(\cdot) \in \mathbf{M}_{\text {СТВ }}\left(\mathrm{I}, \mathbf{R}^{\infty \times \infty}\right)$, we have $\boldsymbol{f}^{\mathrm{d}}(\cdot, ; \mathbf{K}) \in \boldsymbol{C}_{\mathrm{cw}}\left(\mathrm{I} \times \ell^{1}, \mathbf{R}^{\infty}\right)$, then for all kernels in these three classes, if $\boldsymbol{n}(\cdot) \in \boldsymbol{C}\left(\mathrm{I}, \ell^{1}\right)$, we have $\boldsymbol{f}^{\mathrm{d}}(\cdot, \boldsymbol{n}(\cdot): \mathbf{K}) \in \boldsymbol{C}_{\mathrm{cw}}\left(\mathrm{I}, \mathbf{R}^{\infty}\right)$. However, for clarity, we proceed class by class.

$$
\text { If } \mathbf{K}(\cdot)=\left\{\mathrm{K}_{\mathrm{i}, \mathrm{j}}(\mathrm{t})\right\}_{\mathrm{i}, \mathrm{j}=1}^{\infty} \in \mathbf{M}_{\mathrm{CT}}\left(\mathrm{I}, \mathbf{R}^{\infty \times \infty}\right) \text { and }
$$

$\boldsymbol{n}=\left\{\mathrm{n}_{\mathrm{i}}\right\}_{\mathrm{i}=1}^{\infty} \in \ell^{1}$, then for all $\mathrm{i}, \mathrm{j} \in \mathbf{N}$ we have $\mathrm{K}_{\mathrm{i}, \mathrm{j}}(\mathrm{t})=\mathrm{A}(\mathrm{t})$ so that

$$
\mathrm{f}_{\mathrm{i}}^{\mathrm{d}}(\mathrm{t}, \boldsymbol{n} ; \mathbf{K})=\sum_{\mathrm{j}=1}^{\infty} \mathrm{K}_{\mathrm{i}, \mathrm{j}}(\mathrm{t}) \mathrm{n}_{\mathrm{j}}=\mathrm{A}(\mathrm{t}) \mathrm{M}_{0}(\boldsymbol{n})
$$

where $\mathrm{M}_{0}(\boldsymbol{n})=\sum_{\mathrm{j}=1}^{\infty} \mathrm{n}_{\mathrm{j}}$ is the zeroth moment of the sequence. In the physical context, $n_{i} \geq 0$ so that, 
$\mathrm{M}_{0}(\boldsymbol{n})$ is the total number of particles and $\mathrm{M}_{1}(\boldsymbol{n}) \Delta \mathrm{v} \rho$ is the total mass of the particles (which should not change) where $M_{1}(t)=\sum_{j=1}^{\infty} j n_{j}(t)$ is the first moment of the solution and $\rho$ is the mass density. Treat [12] suggested (as have others) on a physical basis, that these and other moments, possibly all moments, should exist (converge and be continuous). We will take our $\Sigma$ space as a subspace of $\boldsymbol{C}\left(\mathrm{I}, \ell^{1}\right) \subseteq \boldsymbol{C}_{\mathrm{cw}}\left(\mathrm{I}, \ell^{1}\right) \subseteq \boldsymbol{C}_{\mathrm{cw}}\left(\mathrm{I}, \mathbf{R}^{\infty}\right)$. Again, we view a solution as a time-varying infinite-dimensional "state vector" $\boldsymbol{n}(\mathrm{t})$.

Theorem 2.14. Let $\mathbf{K}(\cdot) \in \mathbf{M}_{\mathrm{CT}}\left(\mathrm{I}_{0}, \mathbf{R}^{\infty \times \infty}\right)$ so that $\forall \mathrm{i} \in \mathbf{N}, \quad \mathrm{f}_{\mathrm{i}}^{\mathrm{d}}(\mathrm{t}, \boldsymbol{n} ; \mathbf{K})=\mathrm{A}(\mathrm{t}) \mathrm{M}_{0}(\boldsymbol{n})$. If $\boldsymbol{n}=\left\{\mathrm{n}_{\mathrm{i}}\right\}_{\mathrm{i}=1}^{\infty} \in \ell^{1}$, then $\mathrm{M}_{0}(\boldsymbol{n})=\sum_{\mathrm{j}=1}^{\infty} \mathrm{n}_{\mathrm{j}}$ exists (converges absolutely) and $\mathrm{M}_{0}(\boldsymbol{n}) \in \mathrm{C}\left(\ell^{1}, \mathbf{R}\right)$. If $(\mathrm{t}, \boldsymbol{n}) \in \mathrm{I} \times \ell^{1}$, then $\mathrm{f}_{\mathrm{i}}^{\mathrm{d}}(\mathrm{t}, \boldsymbol{n} ; \mathbf{K})$ exists (converges absolutely) and $\boldsymbol{f}^{\mathrm{d}}(\cdot, ; \mathbf{K}) \in \boldsymbol{C}_{\mathrm{cw}}\left(\mathrm{I} \times \ell^{1}, \mathbf{R}^{\infty}\right)$. If $\boldsymbol{n}(\cdot) \in \mathbf{C}\left(\mathrm{I}, \ell^{1}\right)$, then $\mathrm{M}_{0}(\boldsymbol{n}(\cdot)) \in \mathrm{C}(\mathrm{I}, \mathbf{R})$ and $\boldsymbol{f}^{\mathrm{d}}(\cdot, \boldsymbol{n}(\cdot): \mathbf{K}) \in \boldsymbol{C}_{\mathrm{cw}}\left(\mathrm{I}, \mathbf{R}^{\infty}\right)$.

Proof. Let $\mathbf{K}(\cdot) \in \mathbf{M}_{\mathrm{CT}}\left(\mathrm{I}_{0}, \mathbf{R}^{\infty \times \infty}\right)$ so that $\forall \mathrm{i} \in \mathbf{N}$, $\mathrm{f}_{\mathrm{i}}^{\mathrm{d}}(\mathrm{t}, \boldsymbol{n} ; \mathbf{K})=\mathrm{A}(\mathrm{t}) \mathrm{M}_{0}(\boldsymbol{n})$. By Theorem 2.5, if $\boldsymbol{n} \in \ell^{1} \subseteq \mathbf{R}^{\infty}$, then $\mathrm{M}_{0}(\boldsymbol{n})=\sum_{\mathrm{j}=1}^{\infty} \mathrm{n}_{\mathrm{j}}$ exists (converges absolutely) and $\mathrm{M}_{0}(\boldsymbol{n})=\sum_{\mathrm{j}=1}^{\infty} \mathrm{n}_{\mathrm{j}} \in \mathrm{C}\left(\ell^{1}, \mathbf{R}\right)$. If $(\mathrm{t}, \boldsymbol{n}) \in \mathrm{I} \times \ell^{1}$, then $\left|\mathrm{M}_{0}(\boldsymbol{n})\right| \leq\|\boldsymbol{n}\|_{1}<\infty$ and $\left|\mathrm{f}_{\mathrm{i}}^{\mathrm{d}}(\mathrm{t}, \boldsymbol{n} ; \mathbf{K})\right| \leq|\mathrm{A}(\mathrm{t})|\left|\mathrm{M}_{0}(\boldsymbol{n})\right| \leq|\mathrm{A}(\mathrm{t})|\|\boldsymbol{n}\|_{1}<\infty$ so that $\mathrm{f}_{\mathrm{i}}^{\mathrm{d}}(\mathrm{t}, \boldsymbol{n} ; \mathbf{K})$ exists (converges absolutely). By Corollary 2.9, $\mathrm{f}_{\mathrm{i}}^{\mathrm{d}}(\mathrm{t}, \boldsymbol{n} ; \mathbf{K})=\mathrm{A}(\mathrm{t}) \mathrm{M}_{0}(\boldsymbol{n}) \in \mathrm{C}\left(\mathrm{I} \times \ell^{1}, \mathbf{R}\right)$. Now let $\boldsymbol{n}(\cdot) \in \boldsymbol{C}\left(\mathrm{I}, \ell^{1}\right)$. By Theorem $2.6\|\boldsymbol{n}(\cdot)\|_{1} \in \mathrm{C}(\mathrm{I}, \mathbf{R})$ so that $\|\boldsymbol{n}(\mathrm{t})\|_{1}$ exists (converges absolutely) $\forall \mathrm{t} \in \mathrm{I}$. Since $\left|\mathrm{M}_{0}(\boldsymbol{n}(\mathrm{t}))\right| \leq\|\boldsymbol{n}(\mathrm{t})\|_{1}<\infty$ and $\begin{aligned}\left|\mathrm{f}_{\mathrm{i}}^{\mathrm{d}}(\mathrm{t}, \boldsymbol{n}(\mathrm{t}) ; \mathbf{K}(\mathrm{t}))\right| & =|\mathrm{A}(\mathrm{t})|\left|\mathrm{M}_{0}(\boldsymbol{n}(\mathrm{t}))\right|, \quad \mathrm{M}_{0}(\boldsymbol{n}(\mathrm{t})) \text { and } \\ & \leq|\mathrm{A}(\mathrm{t})| \mid \boldsymbol{n}(\mathrm{t}) \|_{1}<\infty\end{aligned}$ $\mathrm{f}_{\mathrm{i}}^{\mathrm{d}}(\mathrm{t}, \boldsymbol{n}(\mathrm{t}) ; \mathbf{K}(\mathrm{t}))$ exist (converge absolutely) $\forall \mathrm{t} \in \mathrm{I}$. As compositions and products of continuous functions (in $\ell^{1}$ ) are continuous, $\mathrm{M}_{0}(\boldsymbol{n}(\mathrm{t}))$, and $\mathrm{f}_{\mathrm{i}}^{\mathrm{d}}(\mathrm{t}, \boldsymbol{n}(\mathrm{t}) ; \mathbf{K})=\mathrm{A}(\mathrm{t}) \mathrm{M}_{0}(\boldsymbol{n}(\mathrm{t}))$ are in $\mathrm{C}(\mathrm{I}, \mathbf{R})$.

Theorem 2.15. Let $\mathbf{K}(\cdot) \in \mathbf{M}_{\mathrm{B}}\left(\mathrm{I}_{0}, \mathbf{R}^{\infty \times \infty}\right)$. Then $\forall(\mathrm{t}, \boldsymbol{n}) \in \mathrm{I} \times \ell^{1}, \mathrm{f}_{\mathrm{i}}^{\mathrm{d}}(\mathrm{t}, \boldsymbol{n} ; \mathbf{K})$ exists (converges absolutely) and is in $\boldsymbol{C}\left(\mathrm{I} \times \ell^{1}, \mathbf{R}\right)$. If $\boldsymbol{n}(\cdot) \in \boldsymbol{C}\left(\mathrm{I}, \ell^{1}\right)$, then $\boldsymbol{f}^{\mathrm{d}}(\cdot, \boldsymbol{n}(\cdot): \mathbf{K}) \in \boldsymbol{C}_{\mathrm{cw}}\left(\mathrm{I}, \mathbf{R}^{\infty}\right)$.

Proof. Let $\mathbf{K}(\cdot)=\left\{\mathrm{B}_{\mathrm{i}, \mathrm{j}}\right\}_{\mathrm{i}, \mathrm{j}=1}^{\infty} \in \mathbf{M}_{\mathrm{B}}\left(\mathrm{I}_{0}, \mathbf{R}^{\infty \times \infty}\right)$. (Note that $\mathbf{K}(t)$ is a constant function of $t$ for this kernel.) Then $\exists \mathrm{M}_{\text {Bmax }}$ such that $\forall \mathrm{i}, \mathrm{j} \in \mathbf{N},\left|\mathrm{B}_{\mathrm{i}, \mathrm{j}}\right| \leq \mathrm{M}_{\mathrm{Bmax}}$. Let $(\mathrm{t}, \boldsymbol{n}) \in \mathrm{I} \times \ell^{1}$ and $\boldsymbol{n}=\left\{\mathrm{n}_{\mathrm{i}}\right\}_{\mathrm{i}=1}^{\infty}$. Then

$$
\begin{aligned}
\left|\mathrm{f}_{\mathrm{i}}^{\mathrm{d}}(\mathrm{t}, \boldsymbol{n} ; \mathbf{K})\right| & =\left|\sum_{\mathrm{j}=1}^{\infty} \mathrm{B}_{\mathrm{i}, \mathrm{j}} \mathrm{n}_{\mathrm{j}}\right| \\
& \leq \sum_{\mathrm{j}=1}^{\infty}\left|\mathrm{B}_{\mathrm{i}, \mathrm{j}}\right|\left|\mathrm{n}_{\mathrm{j}}\right| \leq \sum_{\mathrm{j}=1}^{\infty} \mathrm{M}_{\mathrm{Bmax}}\left|\mathrm{n}_{\mathrm{j}}\right| \\
& =\mathrm{M}_{\mathrm{Bmax}} \sum_{\mathrm{j}=1}^{\infty}\left|\mathrm{n}_{\mathrm{j}}\right|=\mathrm{M}_{\mathrm{Bmax}}\|\boldsymbol{n}\|_{1}<\infty
\end{aligned}
$$

so that $\boldsymbol{f}^{\mathrm{d}}(\mathrm{t}, \boldsymbol{n} ; \mathbf{K})$ exists (converges absolutely). Now let $\mathrm{f}_{\mathrm{i}}^{\mathrm{d}}(\boldsymbol{n})=\sum_{\mathrm{j}=1}^{\infty} \mathrm{B}_{\mathrm{i}, \mathrm{j}} \mathrm{n}_{\mathrm{j}}$ and $\boldsymbol{n}_{1}=\left\{\mathrm{n}_{\mathrm{i}}^{1}\right\}_{\mathrm{i}=1}^{\infty} \in \ell^{1}$. Then

$$
\begin{aligned}
\left|\mathrm{f}_{\mathrm{i}}^{\mathrm{d}}(\boldsymbol{n})-\mathrm{f}_{\mathrm{i}}^{\mathrm{d}}\left(\boldsymbol{n}_{1}\right)\right| & =\left|\sum_{\mathrm{j}=1}^{\infty} \mathrm{B}_{\mathrm{i}, \mathrm{j}} \mathrm{n}_{\mathrm{j}}-\sum_{\mathrm{j}=1}^{\infty} \mathrm{B}_{\mathrm{i}, \mathrm{j}} \mathrm{n}_{\mathrm{j}}^{1}\right| \\
& =\left|\sum_{\mathrm{j}=1}^{\infty} \mathrm{B}_{\mathrm{i}, \mathrm{j}}\left(\mathrm{n}_{\mathrm{j}}-\mathrm{n}_{\mathrm{j}}^{1}\right)\right| \leq \sum_{\mathrm{j}=1}^{\infty}\left|\mathrm{B}_{\mathrm{i}, \mathrm{j}}\right|\left|\mathrm{n}_{\mathrm{j}}-\mathrm{n}_{\mathrm{j}}^{1}\right| \\
& \leq \sum_{\mathrm{j}=1}^{\infty} \mathrm{M}_{\text {Bmax }}\left|\left(\mathrm{n}_{\mathrm{j}}-\mathrm{n}_{\mathrm{j}}^{1}\right)\right|=\mathrm{M}_{\mathrm{Bmax}}\left\|\boldsymbol{n}-\boldsymbol{n}_{1}\right\|_{1}
\end{aligned}
$$

Hence $\mathrm{f}_{\mathrm{i}}^{\mathrm{d}}(\boldsymbol{n})$ is Lipschitz continuous and hence in $\mathrm{C}\left(\ell^{1}, \mathbf{R}\right)$. Since $\mathrm{f}_{\mathrm{i}}^{\mathrm{d}}(\mathrm{t}, \boldsymbol{n} ; \mathbf{K})=\mathrm{f}_{\mathrm{i}}^{\mathrm{d}}(\boldsymbol{n})=\sum_{\mathrm{j}=1}^{\infty} \mathrm{B}_{\mathrm{i}, \mathrm{j}} \mathrm{n}_{\mathrm{j}}$ is a constant function of time, $\mathrm{f}_{\mathrm{i}}^{\mathrm{d}}(\cdot, ; ; \mathbf{K}) \in \mathrm{C}\left(\mathrm{I} \times \ell^{1}, \mathbf{R}\right)$. Hence $\boldsymbol{f}^{\mathrm{d}}(\cdot, ; ; \mathbf{K}) \in \mathrm{C}_{\mathrm{cw}}\left(\mathrm{I} \times \ell^{1}, \mathbf{R}^{\infty}\right)$. If $\boldsymbol{n}(\cdot) \in \boldsymbol{C}\left(\mathrm{I}, \ell^{1}\right)$ then $\mathrm{f}_{\mathrm{i}}^{\mathrm{d}}(\cdot, \boldsymbol{n}(\cdot): \mathbf{K}) \in \mathrm{C}(\mathrm{I}, \mathbf{R})$ and

$$
\boldsymbol{f}^{\mathrm{d}}(\cdot, \boldsymbol{n}(\cdot): \mathbf{K}) \in \mathrm{C}_{\mathrm{cw}}\left(\mathrm{I}, \mathbf{R}^{\infty}\right) \text {. }
$$

Theorem 2.16. Let $\mathbf{K}(\cdot) \in \mathbf{M}_{\text {Ств }}\left(\mathrm{I}_{0}, \mathbf{R}^{\infty \times \infty}\right)$. Then $\forall(\mathrm{t}, \boldsymbol{n}) \in \mathrm{I}_{0} \times \ell^{1}, \mathrm{f}_{\mathrm{i}}^{\mathrm{d}}(\mathrm{t}, \boldsymbol{n} ; \mathbf{K})$ exists (converges absolutely) and $\boldsymbol{f}(\cdot, ; ; \mathbf{K}) \in \boldsymbol{C}_{\mathrm{cw}}\left(\mathrm{I}_{0} \times \ell^{1}, \mathbf{R}^{\infty}\right)$. If $\boldsymbol{n}(\cdot) \in \boldsymbol{C}\left(\mathrm{I}, \ell^{1}\right)$, then $\boldsymbol{f}^{\mathrm{d}}(\cdot, \boldsymbol{n}(\cdot): \mathbf{K}) \in \boldsymbol{C}_{\mathrm{cw}}\left(\mathrm{I}, \mathbf{R}^{\infty}\right)$.

$$
\text { Proof. Let } \mathbf{K}(\mathrm{t})=\left\{\mathrm{A}(\mathrm{t}) \mathrm{B}_{\mathrm{i}, \mathrm{j}}(\mathrm{t})\right\}_{\mathrm{i}, \mathrm{j}=1}^{\infty} \in \mathbf{M}_{\text {СтB }}\left(\mathrm{I}_{0}, \mathbf{R}^{\infty \times \infty}\right)
$$
and $\mathbf{K}_{1}(\cdot)=\left\{\mathrm{B}_{\mathrm{i}, \mathrm{j}}(\mathrm{t})\right\}_{\mathrm{i}, \mathrm{j}=1}^{\infty} \in \mathbf{M}_{\mathrm{B}}\left(\mathrm{I}_{0}, \mathbf{R}^{\infty \times \infty}\right)$. Then

$$
\begin{aligned}
\mathrm{f}_{\mathrm{i}}^{\mathrm{d}}(\mathrm{t}, \boldsymbol{n} ; \mathbf{K}) & =\sum_{\mathrm{j}=1}^{\infty} \mathrm{A}(\mathrm{t}) \mathrm{B}_{\mathrm{i}, \mathrm{j}} \mathrm{n}_{\mathrm{j}} \\
& =\mathrm{A}(\mathrm{t}) \sum_{\mathrm{j}=1}^{\infty} \mathrm{B}_{\mathrm{i}, \mathrm{j}} \mathrm{n}_{\mathrm{j}}=\mathrm{A}(\mathrm{t}) \mathrm{f}_{\mathrm{i}}^{\mathrm{d}}\left(\mathrm{t}, \boldsymbol{n} ; \mathbf{K}_{1}\right)
\end{aligned}
$$

where $\mathrm{A}(\mathrm{t}) \in \mathrm{C}(\mathrm{I}, \mathbf{R})$ and 
$\mathrm{f}_{\mathrm{i}}^{\mathrm{d}}\left(\mathrm{t}, \boldsymbol{n} ; \mathbf{K}_{1}\right)=\sum_{\mathrm{j}=1}^{\infty} \mathrm{B}_{\mathrm{i}, \mathrm{j}} \mathrm{n}_{\mathrm{j}} \in \mathrm{C}\left(\mathrm{I} \times \ell^{1}, \mathbf{R}\right) \quad$ (by $\quad$ Theorem

2.15). By Corollary 2.9

$\mathrm{f}_{\mathrm{i}}^{\mathrm{d}}(\mathrm{t}, \boldsymbol{n} ; \mathbf{K})=\mathrm{A}(\mathrm{t}) \mathrm{f}_{\mathrm{i}}^{\mathrm{d}}\left(\mathrm{t}, \boldsymbol{n} ; \mathbf{K}_{1}\right) \in \mathrm{C}\left(\mathrm{I} \times \ell^{1}, \mathbf{R}\right)$. If

$\boldsymbol{n}(\cdot) \in \boldsymbol{C}\left(\mathrm{I}, \ell^{1}\right)$, then $\mathrm{f}_{\mathrm{i}}^{\mathrm{d}}(\cdot, \boldsymbol{n}(\cdot): \mathbf{K}) \in \boldsymbol{C}(\mathrm{I}, \mathbf{R})$.

\subsection{Weierstrass M-Test and Local Uniform Boundedness}

Let $\operatorname{Int}_{\mathrm{c}}(\mathrm{I})=\{\mathrm{J} \subseteq \mathrm{I}: \mathrm{J}$ is a closed finite interval $\}$ and $\operatorname{Int}_{\mathrm{c}}\left(\mathrm{t}_{1}, \mathrm{I}\right)=\left\{\mathrm{J} \in \operatorname{Int}_{\mathrm{c}}(\mathrm{I}): \mathrm{t}_{1} \in J\right\}$. For $J \in \operatorname{Int}_{\mathrm{c}}(\mathrm{I})$, let $\mathrm{C}(\mathrm{J}, \mathbf{R})=\{\mathrm{f}: \mathrm{J} \rightarrow \mathbf{R}: \mathrm{f}$ is continuous $\}$. We briefly review the Weierstrass M-test and succeeding theorems on absolute and uniform convergence (Kaplan [21, pp. 436-444]). This should be familiar to engineers and scientists. We then consider a fourth class of kernels. Let

$$
\begin{aligned}
& \mathbf{M}_{\mathrm{CTB}}\left(\mathrm{I}_{0}, \mathbf{R}^{\infty \times \infty}\right) \\
& =\left\{\mathbf{K}(\mathrm{t})=\left\{\mathrm{K}_{\mathrm{i}, \mathrm{j}}(\mathrm{t})\right\}_{\mathrm{i}, \mathrm{j}=1}^{\infty} \in \mathbf{C}_{\mathrm{CW}}\left(\mathrm{I}_{0}, \mathbf{R}^{\infty \times \infty}\right):\right.
\end{aligned}
$$

$\forall \mathrm{t}_{1} \in \mathrm{I}_{0}$ and $\mathrm{J} \in \operatorname{Int}_{\mathrm{c}}\left(\mathrm{t}_{1}, \mathrm{I}_{0}\right), \exists \mathrm{M}_{\mathrm{Kmax}}(\mathrm{J})$ such that

$\left.\forall \mathrm{i}, \mathrm{j} \in \mathbf{N}, \max _{\mathrm{t} \in \mathrm{J}} \mathrm{K}_{\mathrm{i}, \mathrm{j}}(\mathrm{t}) \leq \mathrm{M}_{\mathrm{Kmax}}(\mathrm{J})<\infty\right\}$

Note $\mathbf{M}_{\text {СТВ }}\left(\mathrm{I}, \mathbf{R}^{\infty \times \infty}\right) \subseteq \mathbf{M}_{\mathrm{CTBS}}\left(\mathrm{I}, \mathbf{R}^{\infty \times \infty}\right) \quad$ let $\mathrm{K}_{\mathrm{i}, \mathrm{j}}(\mathrm{t})=\mathrm{A}(\mathrm{t}) \mathrm{B}_{\mathrm{i}, \mathrm{j}}$ and $\left.\mathrm{M}_{\mathrm{Kmax}}(\mathrm{J})=\max _{\mathrm{t} \in \mathrm{J}} \mathrm{A}(\mathrm{t}) \mathrm{M}_{\mathrm{Bmax}}\right)$.

We say that $\mathbf{K}(\mathrm{t})$ is locally uniformly bounded in time and size.

Theorem 2.17 (Weierstrass M-Test Extended). Let

$\mathrm{t}_{1} \in \mathrm{I}, \boldsymbol{n}(\cdot)=\left\{\boldsymbol{n}_{\mathrm{i}}(\cdot)\right\}_{\mathrm{i}=1}^{\infty} \in \mathrm{C}_{\mathrm{cw}}\left(\mathrm{I}, \mathbf{R}^{\infty}\right)$ and

$\mathrm{M}_{0}(\boldsymbol{n}(\mathrm{t}))=\sum_{\mathrm{i}=1}^{\infty} \mathrm{n}_{\mathrm{i}}(\mathrm{t})$. Suppose

$\forall \mathrm{J} \in \operatorname{Int}_{\mathrm{c}}\left(\mathrm{t}_{1}, \mathrm{I}\right), \quad \exists\left\{\mathrm{M}_{\text {nmax }}(\mathrm{i}, \mathrm{J})\right\}_{\mathrm{i}=1}^{\infty}$ such that $\forall \mathrm{t} \in \mathrm{J}$, $\left|\mathrm{n}_{\mathrm{i}}(\mathrm{t})\right| \leq \mathrm{M}_{\mathrm{nmax}}(\mathrm{i}, \mathrm{J})$ and

$\sum_{i=1}^{\infty} M_{n \max }(i, J)=M_{n \max }(J)<\infty$, then

$\mathrm{M}_{0}(\boldsymbol{n}(\mathrm{t}))=\sum_{\mathrm{i}=1}^{\infty} \mathrm{n}_{\mathrm{i}}(\mathrm{t})$ and $\|\boldsymbol{n}(\mathrm{t})\|_{1}=\sum_{\mathrm{i}=1}^{\infty}\left|\mathrm{n}_{\mathrm{i}}(\mathrm{t})\right|$ exist

(converge absolutely $\forall \mathrm{t} \in \mathrm{J}$ and are uniformly convergent on $\mathrm{J}$ so that theyare in $\mathrm{C}(\mathrm{J}, \mathbf{R})$. Since $\mathrm{t}_{1}$ was arbitrary, $\forall \mathrm{t} \in \mathrm{I}, \boldsymbol{n}(\mathrm{t}) \in \ell^{1}$ so $\boldsymbol{n}(\mathrm{t}) \in \mathrm{C}_{\mathrm{cw}}\left(\mathrm{I}, \ell^{1}\right)$ and

$\mathrm{M}(\boldsymbol{n}(\mathrm{t}))$ and $\|\boldsymbol{n}(\mathrm{t})\|_{1}$ are in $\boldsymbol{C}(\mathrm{I}, \mathbf{R})$ so that

$\boldsymbol{n}(\cdot) \in \mathrm{C}\left(\mathrm{I}, \ell^{1}\right)$. If $\boldsymbol{n}(\cdot) \in \mathrm{C}_{\mathrm{cw}}^{1}\left(\mathrm{I}, \mathbf{R}^{\infty}\right)$ and

$\forall \mathrm{J} \in \operatorname{Int}_{\mathrm{c}}\left(\mathrm{t}_{1}, \mathrm{I}\right), \exists\left\{\mathrm{M}_{\mathrm{nmax}}^{1}(\mathrm{i}, \mathrm{J})\right\}_{\mathrm{i}=1}^{\infty}$ such that $\forall \mathrm{t} \in \mathrm{J}$, $\left|\frac{\mathrm{dn}_{\mathrm{i}}(\mathrm{t})}{\mathrm{dt}}\right| \leq \mathrm{M}_{\mathrm{nmax}}^{1}(\mathrm{i}, \mathrm{J})$ and

$\sum_{i=1}^{\infty} M_{n \max }(i, J)=M_{n \max }(J)<\infty$, then $\sum_{i=1}^{\infty} \frac{\mathrm{dn}_{\mathrm{i}}(\mathrm{t})}{\mathrm{dt}}$ and $\left\|\frac{\mathrm{d} \boldsymbol{n}(\mathrm{t})}{\mathrm{dt}}\right\|_{1}=\sum_{\mathrm{i}=1}^{\infty}\left|\frac{\mathrm{dn}_{\mathrm{i}}(\mathrm{t})}{\mathrm{dt}}\right|$ exist (converge absolutely)

$\forall \mathrm{t} \in \mathrm{J}$ and are uniformly convergent on $\mathbf{J}$ so that they are in $\mathrm{C}(\mathrm{J}, \mathbf{R})$. Since $\mathrm{t}_{1}$ was arbitrary, $\forall \mathrm{t} \in \mathrm{I}, \frac{\mathrm{d} \boldsymbol{n}(\mathrm{t})}{\mathrm{dt}} \in \ell^{1}$ so $\frac{\mathrm{d} \boldsymbol{n}(\mathrm{t})}{\mathrm{dt}} \in \mathrm{C}_{\mathrm{cw}}\left(\mathrm{I}, \ell^{1}\right)$ and $\sum_{\mathrm{i}=1}^{\infty} \frac{\mathrm{dn}_{\mathrm{i}}(\mathrm{t})}{\mathrm{dt}}$ and $\left\|\frac{\mathrm{d} \boldsymbol{n}(\mathrm{t})}{\mathrm{dt}}\right\|_{1}$ are in $\mathrm{C}(\mathrm{I}, \mathbf{R})$ so that $\boldsymbol{n}(\cdot) \in \mathrm{C}^{1}\left(\mathrm{I}, \ell^{1}\right)$. Also,

$$
\frac{\mathrm{dM}(\boldsymbol{n}(\mathrm{t}))}{\mathrm{dt}}=\sum_{\mathrm{i}=1}^{\infty} \frac{\mathrm{dn}_{\mathrm{i}}(\mathrm{t})}{\mathrm{dt}} \in \mathrm{C}(\mathrm{J}, \mathbf{R}) .
$$

For $\mathbf{K}(\cdot) \in \mathbf{M}_{\mathrm{CTBS}}\left(\mathrm{I}_{0}, \mathbf{R}^{\infty \times \infty}\right)$, to insure $\boldsymbol{f}^{\mathrm{d}}(\mathrm{t}, \boldsymbol{n}(\mathrm{t}) ; \mathbf{K}) \in \boldsymbol{C}_{\mathrm{cw}}\left(\mathrm{I}, \mathbf{R}^{\infty}\right)$, we will require $\boldsymbol{n}(\mathrm{t})=\left\{\mathrm{n}_{\mathrm{i}}(\mathrm{t})\right\}_{\mathrm{i}=1}^{\infty}$ to satisfy a stronger local uniform boundedness condition in time.

Definition 2.2. Let $\boldsymbol{n}(\mathrm{t})=\left\{\mathrm{n}_{\mathrm{i}}(\mathrm{t})\right\}_{\mathrm{i}=1}^{\infty} \in \boldsymbol{C}_{\mathrm{cw}}\left(\mathrm{I}, \mathbf{R}^{\infty}\right)$. Then $\mathbf{n}(\mathrm{t})$ is locally uniformly bounded at $\mathrm{t}_{1}$ if $\forall \mathrm{J} \in \operatorname{Int}_{\mathrm{c}}\left(\mathrm{t}_{1}, \mathrm{I}\right), \exists\left\{\mathrm{M}_{\mathrm{nmax}}^{1}(\mathrm{i}, \mathrm{J})\right\}_{\mathrm{i}=1}^{\infty}, \quad$ such that $\forall \mathrm{t} \in \mathrm{J}$, $\left|\mathrm{n}_{\mathrm{i}}(\mathrm{t})\right| \leq \mathrm{M}_{\mathrm{nmax}}(\mathrm{i}, \mathrm{J})$ and $\sum_{\mathrm{i}=1}^{\infty} \mathrm{M}_{\mathrm{nmax}}(\mathrm{i}, \mathrm{J})=\mathrm{M}_{\mathrm{n} \max }(\mathrm{J})<\infty$.

We say $\boldsymbol{n}(\mathrm{t})$ is locally uniformly bounded on $\mathrm{I}$ if it is locally uniformly bounded $\forall \mathrm{t} \in \mathrm{I}$.

Now let

$$
\begin{aligned}
\boldsymbol{C}_{\mathrm{LUB}}\left(\mathrm{I}, \mathbf{R}^{\infty}\right)= & \left\{\boldsymbol{n} \in \mathbf{C}_{\mathrm{cw}}\left(\mathrm{I}, \mathbf{R}^{\infty}\right): \boldsymbol{n}\right. \text { is locally uniformly } \\
& \text { bounded on I }\}
\end{aligned}
$$

$$
\begin{aligned}
\boldsymbol{C}_{\mathrm{LUB}}^{1}\left(\mathrm{I}, \mathbf{R}^{\infty}\right)= & \left\{\boldsymbol{n} \in \boldsymbol{C}_{\mathrm{CW}}^{1}\left(\mathrm{I}, \mathbf{R}^{\infty}\right): \mathrm{d} \boldsymbol{n} / \mathrm{dt}\right. \text { is locally } \\
& \text { uniformly bounded on I }\}
\end{aligned}
$$

and

$$
\begin{gathered}
\mathscr{A}_{\mathrm{LUB}}\left(\mathrm{I}, \mathbf{R}^{\infty}\right)=\left\{\boldsymbol{n} \in \mathscr{A}_{\mathrm{CW}}\left(\mathrm{I}, \mathbf{R}^{\infty}\right): \boldsymbol{n}\right. \text { is locally uniformly } \\
\text { bounded on I }\}
\end{gathered}
$$

Moseley (2007) used $\mathscr{A}_{\text {LUB }}\left(\mathrm{I}, \mathbf{R}^{\infty}\right)$ (which he denoted by $\left.\mathbf{D}_{\text {AUBS }}\left(\mathrm{I}, \mathbf{R}^{\infty}\right)\right)$ as the $\Sigma$ space in the analytic context. We have

$$
\boldsymbol{C}_{\mathrm{LUB}}^{1}\left(\mathrm{I}, \mathbf{R}^{\infty}\right) \subseteq_{\mathrm{vs}} \boldsymbol{C}_{\mathrm{LUB}}\left(\mathrm{I}, \mathbf{R}^{\infty}\right) \subseteq_{\mathrm{vs}} \boldsymbol{C}_{\mathrm{cw}}\left(\mathrm{I}, \mathbf{R}^{\infty}\right) .
$$


Example 2.3. Let $\boldsymbol{n}(\cdot)=\left\{\mathrm{n}_{\mathrm{i}}(\cdot)\right\}_{\mathrm{i}=1}^{\infty} \in \boldsymbol{C}\left(\mathrm{I}, \ell^{1}\right)$ with $n_{i}(t) \geq 0$ and $n_{i}(t)$ increasing. Now for $t_{1} \in I$, let $J=[a, b] \in \operatorname{Int}_{c}\left(t_{1}, I\right)$ and

$\mathrm{M}_{\text {nmax }}(\mathrm{i}, \mathrm{J})=\max _{\mathrm{t} \in \mathrm{J}} \mathrm{n}_{\mathrm{i}}(\mathrm{t})=\mathrm{n}_{\mathrm{i}}(\mathrm{b})$. Then

$\sum_{\mathrm{i}=1}^{\infty} \mathrm{M}_{\mathrm{nmax}}(\mathrm{i}, \mathrm{J})=\sum_{\mathrm{i}=1}^{\infty} \mathrm{n}_{\mathrm{i}}(\mathrm{b})=\|\boldsymbol{n}(\mathrm{t})\|<\infty$. Hence

$\boldsymbol{n}(\mathrm{t}) \in \boldsymbol{C}_{\text {LUB }}\left(\mathrm{I}, \mathbf{R}^{\infty}\right)$.

It can be shown (similar to Moseley [14] in the analytic context) that in the continuous (physical) context, $\boldsymbol{n}(\mathrm{t})=\left\{\mathrm{n}_{\mathrm{i}}^{\mathrm{A}}(\mathrm{t})\right\}_{\mathrm{i}=1}^{\infty}$ where $\mathrm{n}_{\mathrm{i}}^{\mathrm{A}}(\mathrm{t})$ is given by (1.6) is in $\boldsymbol{C}_{\mathrm{LUB}}^{1}\left(\mathrm{I}_{\mathrm{IV}}\left(\mathrm{I}_{0}, \mathrm{t}_{0}, \boldsymbol{n}_{0}, \mathrm{~A}(\mathrm{t})\right), \mathbf{R}^{\infty}\right)$ where $\left[\mathrm{t}_{0}, \infty\right) \subseteq \mathrm{I}_{\mathrm{IV}}\left(\mathrm{I}_{0}, \mathrm{t}_{0}, \boldsymbol{n}_{0}, \mathrm{~A}(\mathrm{t})\right) \subseteq \mathrm{I}_{0}$.

Theorem 2.18. Let

$\boldsymbol{n}(\cdot)=\left\{\mathrm{n}_{\mathrm{i}}(\cdot)\right\}_{\mathrm{i}=1}^{\infty} \in \boldsymbol{C}_{\mathrm{LUB}}\left(\mathrm{I}, \mathbf{R}^{\infty}\right) \subseteq \boldsymbol{C}_{\mathrm{cw}}\left(\mathrm{I}, \mathbf{R}^{\infty}\right)$. Then $\|\boldsymbol{n}(\cdot)\|_{1}=\sum_{\mathrm{i}=1}^{\infty}\left|\mathrm{n}_{\mathrm{i}}(\cdot)\right|$ and $\mathrm{M}_{0}(\boldsymbol{n}(\cdot))=\sum_{\mathrm{i}=1}^{\infty} \mathrm{n}_{\mathrm{i}}(\cdot)$ are in

$\mathrm{C}(\mathrm{I}, \mathbf{R})$ and $\boldsymbol{n}(\cdot) \in \boldsymbol{C}\left(\mathrm{I}, \ell^{1}\right)$. If $\boldsymbol{n}(\cdot) \in \boldsymbol{C}_{\mathrm{LUB}}^{1}\left(\mathrm{I}, \mathbf{R}^{\infty}\right)$ then $\boldsymbol{n}(\cdot) \in \boldsymbol{C}^{1}\left(\mathrm{I}, \ell^{1}\right), \mathrm{M}_{0}(\boldsymbol{n}(\cdot)) \in \mathrm{C}^{1}(\mathrm{I}, \mathbf{R})$ and

$\frac{\mathrm{dM}_{0}(\boldsymbol{n}(\mathrm{t}))}{\mathrm{dt}}=\sum_{\mathrm{j}=1}^{\infty} \frac{\mathrm{dn}_{\mathrm{j}}(\mathrm{t})}{\mathrm{dt}}$.

Proof. Let $\mathrm{t}_{1} \in \mathrm{I}$ and $\boldsymbol{n}(\cdot)=\left\{\mathrm{n}_{\mathrm{i}}(\cdot)\right\}_{\mathrm{i}=1}^{\infty} \in \boldsymbol{C}_{\mathrm{LUB}}\left(\mathrm{I}, \mathbf{R}^{\infty}\right)$. Then $\forall \mathrm{J} \in \operatorname{Int}_{\mathrm{c}}\left(\mathrm{t}_{1}, \mathrm{I}\right), \exists\left\{\mathrm{M}_{\text {nmax }}(\mathrm{i}, \mathrm{J})\right\}_{\mathrm{i}=1}^{\infty}$ such that

$\forall \mathrm{t} \in \mathrm{J},\left|\mathrm{n}_{\mathrm{i}}(\mathrm{t})\right| \leq \mathrm{M}_{\text {nmax }}(\mathrm{i}, \mathrm{J})$ and

$\sum_{\mathrm{i}=1}^{\infty} \mathrm{M}_{\mathrm{nmax}}(\mathrm{i}, \mathrm{J})=\mathrm{M}_{\text {nmax }}(\mathrm{J})<\infty$. Hence $\forall \mathrm{t} \in \mathrm{J}$,

$\boldsymbol{n}(\mathrm{t}) \in \ell^{1}$ so that $\boldsymbol{n}(\cdot) \in \boldsymbol{C}_{\mathrm{cw}}\left(\mathrm{J}, \ell^{1}\right)$. By Theorem 2.17, $\|\boldsymbol{n}(\mathrm{t})\|_{1}=\sum_{\mathrm{i}=1}^{\infty}\left|\mathrm{n}_{\mathrm{i}}(\mathrm{t})\right|$ and $\mathrm{M}_{0}(\boldsymbol{n}(\mathrm{t}))=\sum_{\mathrm{i}=1}^{\infty} \mathrm{n}_{\mathrm{i}}(\mathrm{t})$ are in

$\mathrm{C}(\mathrm{J}, \mathbf{R})$. Since $\mathrm{t}_{1}$ was arbitrary, $\|\boldsymbol{n}(\mathrm{t})\|_{1}$ and $\mathrm{M}_{0}(\boldsymbol{n}(\mathrm{t}))$ are in $\mathrm{C}(\mathrm{I}, \mathbf{R})$. Hence by Theorem 2.6, $\boldsymbol{n}(\mathrm{t}) \in \boldsymbol{C}\left(\mathrm{I}, \ell^{1}\right)$. If $\boldsymbol{n}(\mathrm{t}) \in \boldsymbol{C}_{\mathrm{LUB}}^{1}\left(\mathrm{I}, \mathbf{R}^{\infty}\right)$, then, again by Theorem 2.17, $\left\|\frac{\mathrm{d} \boldsymbol{n}(\mathrm{t})}{\mathrm{dt}}\right\|_{1}=\sum_{\mathrm{i}=1}^{\infty}\left|\frac{\mathrm{dn}_{\mathrm{i}}(\mathrm{t})}{\mathrm{dt}}\right| \in \mathrm{C}(\mathrm{I}, \mathbf{R})$ and

$\frac{\mathrm{dM}_{0}(\boldsymbol{n}(\mathrm{t}))}{\mathrm{dt}}=\sum_{\mathrm{i}=1}^{\infty} \frac{\mathrm{dn}_{\mathrm{i}}(\mathrm{t})}{\mathrm{dt}} \in \mathrm{C}(\mathrm{I}, \mathbf{R})$. Hence by Theorem 2.6, $\boldsymbol{n}(\mathrm{t}) \in \mathrm{C}^{1}\left(\mathrm{I}, \ell^{1}\right)$ and so

$$
\mathrm{d} \boldsymbol{n}(\mathrm{t}) / \mathrm{dt}=\lim _{\mathrm{h} \rightarrow 0}[\boldsymbol{n}(\mathrm{t}+\mathrm{h}) / \mathrm{h}]=\left\{\mathrm{dn}_{\mathrm{j}}(\mathrm{t}) / \mathrm{dt}\right\}_{\mathrm{j}=1}^{\infty} .
$$

Since the range of functions in $\boldsymbol{C}_{\mathrm{LUB}}\left(\mathrm{I}, \mathbf{R}^{\infty}\right)$ is contained in $\ell^{1}$, we have $\boldsymbol{C}_{\mathrm{LUB}}\left(\mathrm{I}, \mathbf{R}^{\infty}\right)=\boldsymbol{C}_{\mathrm{LUB}}\left(\mathrm{I}, \ell^{1}\right)$. Similarly, $\boldsymbol{C}_{\mathrm{LUB}}^{1}\left(\mathrm{I}, \mathbf{R}^{\infty}\right)=\boldsymbol{C}_{\mathrm{LUB}}^{1}\left(\mathrm{I}, \ell^{1}\right)$.

Corollary 2.19.

$$
\begin{aligned}
& \boldsymbol{C}_{\mathrm{LUB}}\left(\mathrm{I}, \mathbf{R}^{\infty}\right)=\boldsymbol{C}_{\mathrm{LUB}}\left(\mathrm{I}, \ell^{1}\right) \subseteq_{\mathrm{vs}} \boldsymbol{C}\left(\mathrm{I}, \ell^{1}\right) \\
& \subseteq_{\mathrm{vs}} \boldsymbol{C}_{\mathrm{cw}}\left(\mathrm{I}, \ell^{1}\right) \subseteq_{\mathrm{vs}} \boldsymbol{C}_{\mathrm{cw}}\left(\mathrm{I}, \mathbf{R}^{\infty}\right)
\end{aligned}
$$

Also,

$$
\begin{aligned}
& \boldsymbol{C}_{\mathrm{LUB}}^{1}\left(\mathrm{I}, \mathbf{R}^{\infty}\right)=\boldsymbol{C}_{\mathrm{LUB}}^{1}\left(\mathrm{I}, \ell^{1}\right) \subseteq_{\mathrm{vs}} \boldsymbol{C}^{1}\left(\mathrm{I}, \ell^{1}\right) . \\
& \subseteq_{\mathrm{vs}} \boldsymbol{C}_{\mathrm{cw}}^{1}\left(\mathrm{I}, \ell^{1}\right) \subseteq_{\mathrm{vs}} \boldsymbol{C}_{\mathrm{cw}}^{1}\left(\mathrm{I}, \mathbf{R}^{\infty}\right)
\end{aligned}
$$

Proof. By Theorem 2.18, $\mathbf{C}_{\mathrm{LUB}}\left(\mathrm{I}, \mathbf{R}^{\infty}\right) \subseteq \mathbf{C}\left(\mathrm{I}, \ell^{1}\right)$. Everything else is straight forward or follows in a manner similar to the proof of Theorem 2.4.

We show that if $\mathbf{K}(\cdot) \subseteq \mathbf{M}_{\text {СтвS }}\left(\mathrm{I}_{0}, \mathbf{R}^{\infty \times \infty}\right)$ and $\boldsymbol{n}(\cdot) \in \boldsymbol{C}_{\mathrm{LUB}}\left(\mathrm{I}, \mathbf{R}^{\infty}\right)$, then $\boldsymbol{f}^{\mathrm{d}}(\cdot, \boldsymbol{n}(\cdot) ; \mathbf{K}) \in \boldsymbol{C}\left(\mathrm{I}, \mathbf{R}^{\infty}\right)$. We use the local uniform boundedness of $\mathbf{K}(\cdot)$ and $\boldsymbol{n}(\cdot)$. Let

$$
\begin{aligned}
& \boldsymbol{C}_{\mathrm{cw}-}\left(\mathrm{I} \times \ell^{1}, \mathbf{R}^{\infty}\right) \\
& =\left\{\boldsymbol{f}(\cdot, \cdot) \in \mathscr{F}\left(\mathrm{I} \times \ell^{1}, \mathbf{R}^{\infty}\right):\right. \\
& \text { for fixed } \left.\boldsymbol{n} \in \ell^{1}, \boldsymbol{f}(\cdot, \boldsymbol{n}) \in \mathrm{C}_{\mathrm{cw}}\left(\mathrm{I}, \mathbf{R}^{\infty}\right)\right\}
\end{aligned}
$$

and

$$
\begin{aligned}
& \boldsymbol{C}_{\mathrm{cw}-}\left(\mathrm{I} \times \ell^{1}, \ell^{1}\right) \\
& =\left\{\boldsymbol{f}(\cdot, \cdot) \in \mathscr{F}\left(\mathrm{I} \times \ell^{1}, \mathbf{R}^{\infty}\right):\right. \\
& \text { for fixed } \left.\boldsymbol{n} \in \ell^{1}, \boldsymbol{f}(\cdot, \boldsymbol{n}) \in \mathrm{C}_{\mathrm{cw}}\left(\mathrm{I}, \ell^{1}\right)\right\}
\end{aligned}
$$

Then $\boldsymbol{C}_{\mathrm{cw}-}\left(\mathrm{I} \times \ell^{1}, \mathbf{R}^{\infty}\right)$ and $\mathbf{C}_{\mathrm{cw}-}\left(\mathrm{I} \times \ell^{1}, \ell^{1}\right)$ are vector spaces and

$$
\begin{aligned}
& \boldsymbol{C}\left(\mathrm{I} \times \ell^{1}, \ell^{1}\right) \subseteq_{\mathrm{vs}} \boldsymbol{C}_{\mathrm{cw}}\left(\mathrm{I} \times \ell^{1}, \ell^{1}\right) \\
& \subseteq_{\mathrm{vs}} \boldsymbol{C}_{\mathrm{cw}-}\left(\mathrm{I} \times \ell^{1}, \ell^{1}\right) \subseteq_{\mathrm{vs}} \boldsymbol{C}_{\mathrm{cw}-}\left(\mathrm{I} \times \ell^{1}, \mathbf{R}^{\infty}\right)
\end{aligned}
$$

\section{Theorem 2.20. Let}

$\mathbf{K}(\cdot)=\left\{\mathrm{K}_{\mathrm{i}, \mathrm{j}}(\cdot)\right\}_{\mathrm{i}, \mathrm{j}=1}^{\infty} \subseteq \mathbf{M}_{\text {CTBS }}\left(\mathrm{I}_{0}, \mathbf{R}^{\infty \times \infty}\right)$. For $\mathrm{i} \in \mathbf{N}$, and $(\mathrm{t}, \boldsymbol{n}) \in \mathrm{I} \times \ell^{1}, \mathrm{f}_{\mathrm{i}}^{\mathrm{d}}(\mathrm{t}, \boldsymbol{n} ; \mathbf{K})$ exists (converges absolutely) and $\boldsymbol{f}^{\mathrm{d}}(\cdot, ; ; \mathbf{K}) \in \boldsymbol{C}_{\mathrm{cw}-}\left(\mathrm{I} \times \ell^{1}, \mathbf{R}^{\infty}\right)$. If $\boldsymbol{n}(\cdot) \in \boldsymbol{C}_{\mathrm{LUB}}\left(\mathrm{I}, \mathbf{R}^{\infty}\right)$, then $\boldsymbol{f}^{\mathrm{d}}(\cdot, \boldsymbol{n}(\cdot) ; \mathbf{K}) \in \boldsymbol{C}_{\mathrm{cW}}\left(\mathrm{I}, \mathbf{R}^{\infty}\right)$.

Proof. Let $\mathbf{K}(\cdot)=\left\{\mathrm{K}_{\mathrm{i}, \mathrm{j}}(\cdot)\right\}_{\mathrm{i}, \mathrm{j}=1}^{\infty} \subseteq \mathbf{M}_{\mathrm{CTBS}}\left(\mathrm{I}_{0}, \mathbf{R}^{\infty \times \infty}\right)$. Then $\forall \mathrm{t}_{1} \in \mathrm{I}_{0}$, and $\mathrm{J} \in \operatorname{Int}_{\mathrm{c}}\left(\mathrm{t}_{1}, \mathrm{I}\right), \exists \mathrm{M}_{\mathrm{Kmax}}(\mathrm{J})$ such that for all $i, j \in \mathbf{N}$ and $t \in J,\left|K_{i, j}(t)\right| \leq M_{K \max }(J)<\infty$. Let 
$\mathrm{i} \in \mathbf{N} \quad$ and $\quad(\mathrm{t}, \boldsymbol{n}) \in \mathrm{J} \times \ell^{1} \quad$ where $\quad \boldsymbol{n}=\left\{\mathrm{n}_{\mathrm{i}}\right\}_{\mathrm{i}=1}^{\infty} . \quad$ Then

$$
\begin{aligned}
& \left|\mathrm{f}_{\mathrm{i}}^{\mathrm{d}}(\mathrm{t}, \boldsymbol{n} ; \mathbf{K})\right|=\left|\sum_{\mathrm{j}=1}^{\infty} \mathrm{K}_{\mathrm{i}, \mathrm{j}}(\mathrm{t}) \mathrm{n}_{\mathrm{j}}\right| \leq \sum_{\mathrm{j}=1}^{\infty}\left|\mathrm{K}_{\mathrm{i}, \mathrm{j}}(\mathrm{t})\right|\left|\mathrm{n}_{\mathrm{j}}\right| \\
& \leq \mathrm{M}_{\mathrm{Kmax}}(\mathrm{J}) \sum_{\mathrm{j}=1}^{\infty}\left|\mathrm{n}_{\mathrm{j}}\right|=\mathrm{M}_{\mathrm{Kmax}}(\mathrm{J})\|\boldsymbol{n}\|_{1}<\infty \\
& \left|\mathrm{f}_{\mathrm{i}}^{\mathrm{d}}(\mathrm{t}, \boldsymbol{n} ; \mathbf{K})\right|=\left|\sum_{\mathrm{j}=1}^{\infty} \mathrm{K}_{\mathrm{i}, \mathrm{j}}(\mathrm{t}) \mathrm{n}_{\mathrm{j}}\right| \leq \sum_{\mathrm{j}=1}^{\infty}\left|\mathrm{K}_{\mathrm{i}, \mathrm{j}}(\mathrm{t})\right|\left|\mathrm{n}_{\mathrm{j}}\right| \\
& \leq \mathrm{M}_{\mathrm{Kmax}}(\mathrm{J}) \sum_{\mathrm{j}=1}^{\infty}\left|\mathrm{n}_{\mathrm{j}}\right|=\mathrm{M}_{\mathrm{Kmax}}(\mathrm{J})\|\boldsymbol{n}\|_{1}<\infty
\end{aligned}
$$

so that $\boldsymbol{f}^{\mathrm{d}}(\mathrm{t}, \boldsymbol{n} ; \mathbf{K})$ exists (converges absolutely for $\left.(\mathrm{t}, \boldsymbol{n}) \in \mathrm{J} \times \ell^{1}\right)$. Since $\mathrm{t}_{1}$ was arbitrary $\mathrm{f}_{\mathrm{i}}^{\mathrm{d}}(\mathrm{t}, \boldsymbol{n} ; \mathbf{K})$ exists for $(\mathrm{t}, \boldsymbol{n}) \in \mathrm{I} \times \ell^{1}$. Also, since

$\left|\mathrm{K}_{\mathrm{i}, \mathrm{j}}(\mathrm{t}) \mathrm{n}_{\mathrm{j}}\right| \leq \mathrm{M}_{\mathrm{Kmax}}\left|\mathrm{n}_{\mathrm{j}}\right|$ and

$\sum_{\mathrm{j}=1}^{\infty} \mathrm{M}_{\mathrm{Kmax}}\left|\mathrm{n}_{\mathrm{j}}\right|=\mathrm{M}_{\mathrm{Kmax}} \sum_{\mathrm{j}=1}^{\infty}\left|\mathrm{n}_{\mathrm{j}}\right|=\mathrm{M}_{\mathrm{Kmax}}\|\boldsymbol{n}\|_{1}<\infty$, by Theorem 2.17 we have that $\forall \mathrm{i} \in \mathbf{N}$ and fixed $\boldsymbol{n} \in \ell^{1}$, $\mathrm{f}_{\mathrm{i}}^{\mathrm{d}}(\cdot, \boldsymbol{n} ; \mathbf{K}) \in \mathrm{C}(\mathrm{I}, \mathbf{R})$. Hence

$\boldsymbol{f}^{\mathrm{d}}(\cdot, ; \mathbf{K}) \in \boldsymbol{C}_{\mathrm{cw}-}\left(\mathrm{I} \times \ell^{1}, \mathbf{R}^{\infty}\right)$. However, we do not have $\boldsymbol{f}^{\mathrm{d}}(\cdot, ; \mathbf{K}) \in \boldsymbol{C}_{\mathrm{cw}-}\left(\mathrm{I} \times \ell^{1}, \mathbf{R}^{\infty}\right)$. We may (or may not) be able to prove this with a further extension of the Weirstrauss M-test. Instead we let

$\boldsymbol{n}(\cdot)=\left\{\mathrm{n}_{\mathrm{j}}(\cdot)\right\}_{\mathrm{j}=1}^{\infty} \in \boldsymbol{C}_{\mathrm{LUB}}\left(\mathrm{I}, \mathbf{R}^{\infty}\right)$. Then for $\mathrm{t}_{1} \in \mathrm{I}$ and $\mathrm{J} \in$

$\operatorname{Int}_{\mathrm{c}}\left(\mathrm{t}_{1}, \mathrm{I}\right)$, not only do we have $\mathrm{M}_{\mathrm{Kmax}}(\mathrm{J})$ such that for all $\mathrm{i}, \mathrm{j} \in \mathbf{N}$ and $\mathrm{t} \in \mathrm{J},\left|\mathrm{K}_{\mathrm{i}, \mathrm{j}}(\mathrm{t})\right| \leq \mathrm{M}_{\mathrm{Kmax}}(\mathrm{J})<\infty$. but also $\left\{M_{n \max }(j, J)\right\}_{j=1}^{\infty}$ such that

$\forall \mathrm{t} \in \mathrm{J},\left|\mathrm{n}_{\mathrm{j}}(\mathrm{t})\right| \leq \mathrm{M}_{\text {nmax }}(\mathrm{j}, \mathrm{J})$ and

$\sum_{\mathrm{j}=1}^{\infty} \mathrm{M}_{\mathrm{nmax}}(\mathrm{j}, \mathrm{J})=\mathrm{M}_{\mathrm{nmax}}(\mathrm{J})<\infty$. Then

$$
\begin{aligned}
& \left|\mathrm{K}_{\mathrm{i}, \mathrm{j}}(\mathrm{t}) \mathrm{n}_{\mathrm{j}}(\mathrm{t})\right| \leq\left|\mathrm{K}_{\mathrm{i}, \mathrm{j}}(\mathrm{t})\right|\left|\mathrm{n}_{\mathrm{j}}(\mathrm{t})\right| \leq \mathrm{M}_{\mathrm{Kmax}}(\mathrm{J})\left|\mathrm{n}_{\mathrm{j}}(\mathrm{t})\right| \\
& \leq \mathrm{M}_{\mathrm{Kmax}}(\mathrm{J}) \mathrm{M}_{\mathrm{nmax}}(\mathrm{j}, \mathrm{J})
\end{aligned}
$$

and

$$
\begin{aligned}
& \sum_{j=1}^{\infty} M_{K \max }(J) M_{n \max }(j, J)=M_{K \max }(J) \sum_{j=1}^{\infty} M_{n \max }(j, J) \\
& =M_{\text {Kmax }}(J) M_{n \max }(J)<\infty
\end{aligned}
$$

Hence by Theorem 2.17, $\mathrm{f}_{\mathrm{i}}^{\mathrm{d}}(\cdot, \boldsymbol{n}(\cdot) ; \mathbf{K}) \in \mathrm{C}(\mathrm{I}, \mathbf{R})$. Hence $\boldsymbol{f}^{\mathrm{d}}(\cdot, \boldsymbol{n}(\cdot) ; \mathbf{K}) \in \boldsymbol{C}_{\mathrm{cw}}\left(\mathrm{I}, \mathbf{R}^{\infty}\right)$.

Thus if $\mathbf{K}(\cdot) \in \mathbf{M}_{\text {CтвS }}\left(\mathrm{I}_{0}, \mathbf{R}^{\infty \times \infty}\right)$ and we choose a subspace of $\boldsymbol{C}_{\mathrm{LUB}}\left(\mathrm{I}, \mathbf{R}^{\infty}\right)$ as our $\Sigma$ space, we obviate the need to explicitly require $\boldsymbol{f}^{\mathrm{d}}(\cdot, \boldsymbol{n}(\cdot) ; \mathbf{K}) \in \boldsymbol{C}_{\mathrm{cw}}\left(\mathrm{I}, \mathbf{R}^{\infty}\right)$ as a condition for $\boldsymbol{n}(\cdot)$ to be a solution (except to interpret (1.1)) or as a specific condition for the $\Sigma$ space.

\subsection{Equivalent Vector Problems}

Recall that if $\mathrm{f}_{\mathrm{i}}^{\mathrm{d}}(\mathrm{t}, \boldsymbol{n} ; \mathbf{K})$ converges $\forall(\mathrm{t}, \boldsymbol{n}) \in \mathrm{I}_{0} \times \mathbf{R}^{\infty}$ the functions $\mathrm{f}_{\mathrm{i}}^{1}(\mathrm{t}, \boldsymbol{n} ; \mathbf{K}), \mathrm{f}_{\mathrm{i}}^{2}(\mathrm{t}, \boldsymbol{n} ; \mathbf{K})$, and $\mathrm{f}_{\mathrm{i}}(\mathrm{t}, \boldsymbol{n} ; \mathbf{K})$ all map $\mathrm{I}_{0} \times \mathbf{R}^{\infty}$ to $\mathbf{R}$ and that

$\boldsymbol{f}^{\mathrm{d}}(\mathrm{t}, \boldsymbol{n} ; \mathbf{K})=\left\{\mathrm{f}_{\mathrm{i}}^{\mathrm{d}}(\mathrm{t}, \boldsymbol{n} ; \mathbf{K})\right\}_{\mathrm{i}=1}^{\infty}$ maps $\mathrm{I}_{0} \times \mathbf{R}^{\infty}$ to $\mathbf{R}$. Now let $\boldsymbol{f}^{1}(\mathrm{t}, \boldsymbol{n} ; \mathbf{K})=\left\{\mathrm{f}_{\mathrm{i}}^{1}(\mathrm{t}, \boldsymbol{n} ; \mathbf{K})\right\}_{\mathrm{i}=1}^{\infty}$,

$\boldsymbol{f}^{2}(\mathrm{t}, \boldsymbol{n} ; \mathbf{K})=\left\{\mathrm{f}_{\mathrm{i}}^{2}(\mathrm{t}, \boldsymbol{n} ; \mathbf{K})\right\}_{\mathrm{i}=1}^{\infty}$, and

$\boldsymbol{f}(\mathrm{t}, \boldsymbol{n} ; \mathbf{K})=\left\{\mathrm{f}_{\mathrm{i}}(\mathrm{t}, \boldsymbol{n} ; \mathbf{K})\right\}_{\mathrm{i}=1}^{\infty}$. These three functions map $\mathrm{I}_{0} \times \mathbf{R}^{\infty}$ to $\mathbf{R}$. As with $\boldsymbol{f}^{\mathrm{d}}(\mathrm{t}, \boldsymbol{n} ; \mathbf{K})$, the only explicit dependence on $\mathrm{t}$ is through $\mathbf{K}(\mathrm{t})$. If $\mathbf{K}(\cdot) \in \boldsymbol{C}_{\mathrm{cw}}\left(\mathrm{I}_{0}, \mathbf{R}^{\infty \times \infty}\right)$ and $\boldsymbol{f}^{\mathrm{d}}(\cdot, ; \mathbf{K}) \in \boldsymbol{C}_{\mathrm{cw}}\left(\mathrm{I} \times \ell^{1}, \mathbf{R}^{\infty}\right)$, then $\boldsymbol{f}^{1}(\cdot, ; ; \mathbf{K})$, $\boldsymbol{f}^{2}(\cdot, ; \mathbf{K})$, and $\boldsymbol{f}(\cdot, \cdot ; \mathbf{K})$ are all in $\boldsymbol{C}_{\mathrm{cw}}\left(\mathrm{I} \times \ell^{1}, \mathbf{R}^{\infty}\right)$ (see Theorem 2.1). Now let $\mathbf{K}(\cdot) \in \mathbf{M}_{\text {Ств }}\left(\mathrm{I}, \mathbf{R}^{\infty \times \infty}\right)$ Then by Theorem $2.16, f^{\mathrm{d}}(\cdot, ; \mathbf{K}) \in \boldsymbol{C}_{\mathrm{cw}}\left(\mathrm{I} \times \ell^{1}, \mathbf{R}^{\infty}\right)$. If we can show that $(\mathrm{t}, \boldsymbol{n}) \in \mathrm{I}_{0} \times \ell^{1}$ implies $\boldsymbol{f}^{1}(\mathrm{t}, \boldsymbol{n} ; \mathbf{K})$, $\boldsymbol{f}^{2}(\mathrm{t}, \boldsymbol{n} ; \mathbf{K})$, and $\boldsymbol{f}(\mathrm{t}, \boldsymbol{n} ; \mathbf{K})$ are in $\ell^{1}$, then these functions can be thought of as functions from $I_{0} \times \ell^{1}$ to $\ell^{1}$ instead of from $I_{0} \times \mathbf{R}^{\infty}$ to $\mathbf{R}$. We indeed show that if we restrict $\boldsymbol{f}^{\mathrm{d}}(\mathrm{t}, \boldsymbol{n} ; \mathbf{K})$ to $\mathrm{I}_{0} \times \ell^{1}$, then the restrictions of $\boldsymbol{f}^{1}(\mathrm{t}, \boldsymbol{n} ; \mathbf{K}), \boldsymbol{f}^{2}(\mathrm{t}, \boldsymbol{n} ; \mathbf{K})$, and $\boldsymbol{f}(\mathrm{t}, \boldsymbol{n} ; \mathbf{K})$ to $\mathrm{I}_{0} \times \ell^{1}$ all map to $\ell^{1}$ so these functions are all in

$$
\begin{aligned}
\boldsymbol{C}_{\mathrm{cw}}\left(\mathrm{I} \times \ell^{1}, \ell^{1}\right) . \text { Let } \\
\boldsymbol{C}_{\mathrm{cw}+}\left(\mathrm{I} \times \ell^{1}, \ell^{1}\right) \\
\left\{\boldsymbol{f}(\cdot, \cdot) \in \boldsymbol{C}_{\mathrm{cw}}\left(\mathrm{I} \times \ell^{1}, \ell^{1}\right): \text { for fixed } \boldsymbol{n} \in \ell^{1},\right. \\
\left.\|\boldsymbol{f}(\cdot, \boldsymbol{n})\|_{1} \in \mathrm{C}(\mathrm{I}, \mathbf{R})\right\}
\end{aligned}
$$

Then $\boldsymbol{C}_{\mathrm{cw}}\left(\mathrm{I} \times \ell^{1}, \ell^{1}\right)$ is a vector space. We show that if $\boldsymbol{f}(\cdot, \cdot ; \mathbf{K}) \in \boldsymbol{C}_{\mathrm{cw}}\left(\mathrm{I} \times \ell^{1}, \mathbf{R}^{\infty}\right)$, then $\boldsymbol{f}^{1}(\cdot, \cdot ; \mathbf{K}), \boldsymbol{f}^{2}(\cdot, ; \mathbf{K})$, and $\boldsymbol{f}(\cdot, \cdot ; \mathbf{K})$ are all in $\mathbf{C}_{\mathrm{cw}+}\left(\mathrm{I} \times \ell^{1}, \ell^{1}\right)$. We have

$$
\begin{aligned}
& \boldsymbol{C}\left(\mathrm{I} \times \ell^{1}, \ell^{1}\right) \subseteq_{\mathrm{vs}} \boldsymbol{C}_{\mathrm{cw}+}\left(\mathrm{I} \times \ell^{1}, \ell^{1}\right) \subseteq_{\mathrm{vs}} \boldsymbol{C}_{\mathrm{cw}}\left(\mathrm{I} \times \ell^{1}, \ell^{1}\right) \\
& \subseteq_{\mathrm{vs}} \boldsymbol{C}_{\mathrm{cw}-}\left(\mathrm{I} \times \ell^{1}, \ell^{1}\right) \subseteq_{\mathrm{vs}} \boldsymbol{C}_{\mathrm{cw}-}\left(\mathrm{I} \times \ell^{1}, \mathbf{R}^{\infty}\right)
\end{aligned}
$$

Theorem 2.21. Let $\mathbf{K}(\cdot) \in \boldsymbol{C}_{\mathrm{CTBS}}\left(\mathrm{I}_{0}, \mathbf{R}^{\infty \times \infty}\right)$. Then, for $(\mathrm{t}, \mathbf{n}) \in \mathrm{I}_{0} \times \ell^{1}$ the images $\boldsymbol{f}^{1}(\mathrm{t}, \boldsymbol{n} ; \mathbf{K}), \boldsymbol{f}^{2}(\mathrm{t}, \boldsymbol{n} ; \mathbf{K})$, 
and $\boldsymbol{f}(\mathrm{t}, \boldsymbol{n} ; \mathbf{K})$ are all in $\ell^{1}$. Also,

$\boldsymbol{f}^{\mathrm{d}}(\cdot, \cdot ; \mathbf{K}) \in \boldsymbol{C}_{\mathrm{cw}-}\left(\mathrm{I}_{0} \times \ell^{1}, \mathbf{R}^{\infty}\right)$,

$\boldsymbol{f}^{1}(\cdot, ; \mathbf{K}) \in \boldsymbol{C}_{\mathrm{cw}+}\left(\mathrm{I}_{0} \times \ell^{1}, \ell^{1}\right)$, and

$\boldsymbol{f}^{2}(\cdot, ; \mathbf{K}), \boldsymbol{f}(\cdot, ; \mathbf{K}) \in \boldsymbol{C}_{\mathrm{cw}-}\left(\mathrm{I}_{0} \times \ell^{1}, \ell^{1}\right)$. If

$\mathbf{K}(\cdot) \in \mathbf{M}_{\text {СТВ }}\left(\mathrm{I}, \mathbf{R}^{\infty \times \infty}\right)$, the

$\boldsymbol{f}^{\mathrm{d}}(\cdot, ; \mathbf{K}) \in \boldsymbol{C}_{\mathrm{cw}}\left(\mathrm{I}_{0} \times \ell^{1}, \mathbf{R}^{\infty}\right)$, and $\boldsymbol{f}^{1}(\cdot, ; \mathbf{K})$,

$\boldsymbol{f}^{2}(\cdot, ; \mathbf{K})$, and $\boldsymbol{f}(\cdot, ; \mathbf{K})$ are all in $\boldsymbol{C}_{\mathrm{cw}+}\left(\mathrm{I}_{0} \times \ell^{1}, \ell^{1}\right)$.

Proof. Let $\mathrm{t}_{1} \in \mathrm{I}_{0}$ and $\mathbf{K}(\cdot) \in \mathbf{M}_{\text {СтBS }}\left(\mathrm{I}_{0}, \mathbf{R}^{\infty \times \infty}\right)$. Then $\forall \mathrm{J} \in \operatorname{Int}_{\mathrm{c}}\left(\mathrm{t}_{1}, \mathrm{I}_{0}\right), \exists \mathrm{M}_{\mathrm{Kmax}}(\mathrm{J})$ such that $\forall \mathrm{i}, \mathrm{j}\left|\mathrm{K}_{\mathrm{i}, \mathrm{j}}\right| \leq \mathrm{M}_{\mathrm{Kmax}}(\mathrm{J})$. Hence for $(\mathrm{t}, \boldsymbol{n}) \in \mathrm{J} \times \ell^{1}$ where $\boldsymbol{n}=\left\{\mathrm{n}_{\mathrm{i}}\right\}_{\mathrm{i}=1}^{\infty}$, from (2.12) we have

$\left|\mathrm{f}_{\mathrm{i}}^{\mathrm{d}}(\mathrm{t}, \boldsymbol{n} ; \mathbf{K})\right| \leq \mathrm{M}_{\mathrm{Kmax}}(\mathrm{J})\|\boldsymbol{n}\|_{1}<\infty$ so that

$$
\left|\mathrm{f}_{\mathrm{i}}^{2}(\mathrm{t}, \boldsymbol{n} ; \mathbf{K})\right| \leq\left|\mathrm{n}_{\mathrm{i}}\right|\left|\mathrm{f}_{\mathrm{i}}^{\mathrm{d}}(\mathrm{t}, \boldsymbol{n} ; \mathbf{K})\right| \leq\left|\mathrm{n}_{\mathrm{i}}\right| \mathrm{M}_{\mathrm{Kmax}}(\mathrm{J})\|\boldsymbol{n}\|^{1}
$$

and

$$
\begin{aligned}
& \left\|\boldsymbol{f}^{2}(\mathrm{t}, \boldsymbol{n} ; \mathbf{K})\right\|_{1} \\
& =\sum_{\mathrm{i}=1}^{\infty}\left|\mathrm{f}_{\mathrm{i}}^{2}(\mathrm{t}, \boldsymbol{n} ; \mathbf{K})\right|=\sum_{\mathrm{i}=1}^{\infty}\left|\mathrm{n}_{\mathrm{i}} \mathrm{f}_{\mathrm{i}}^{\mathrm{d}}(\mathrm{t}, \boldsymbol{n} ; \mathbf{K})\right| \\
& \leq \sum_{\mathrm{i}=1}^{\infty}\left|\mathrm{n}_{\mathrm{i}}\right| \mathrm{M}_{\mathrm{Kmax}}(\mathrm{J})\|\boldsymbol{n}\|_{1}=\mathrm{M}_{\mathrm{Kmax}}(\mathrm{J})\|\boldsymbol{n}\| \sum_{\mathrm{i}=1}^{\infty}\left|\mathrm{n}_{\mathrm{i}}\right| \\
& =\mathrm{M}_{\mathrm{Kmax}}(\mathrm{J})\left(\|\boldsymbol{n}\|_{1}\right)^{2}<\infty
\end{aligned}
$$

Since $\mathrm{t}_{1}$ was arbitrary, $\forall(\mathrm{t}, \boldsymbol{n}) \in \mathrm{I}_{0} \times \ell^{1}, \boldsymbol{f}^{2}(\mathrm{t}, \boldsymbol{n} ; \mathbf{K})$ is in $\ell^{1}$. Furthermore, since

$\left|\mathrm{f}_{\mathrm{i}}^{2}(\mathrm{t}, \boldsymbol{n} ; \mathbf{K})\right|=\left|\mathrm{n}_{\mathrm{i}} \mathrm{f}_{\mathrm{i}}^{\mathrm{d}}(\mathrm{t}, \boldsymbol{n} ; \mathbf{K})\right| \leq\left|\mathrm{n}_{\mathrm{i}}\right| \mathrm{M}_{\text {Kmax }}(\mathrm{J})\|\boldsymbol{n}\|_{1}$ and $\sum_{\mathrm{i}=1}^{\infty}\left|\mathrm{n}_{\mathrm{i}}\right| \mathrm{M}_{\mathrm{Kmax}}(\mathrm{J})\|\boldsymbol{n}\|_{1}=\mathrm{M}_{\mathrm{Kmax}}(\mathrm{J})\left(\|\boldsymbol{n}\|_{1}\right)^{2}<\infty$, by Theorem 2.17, for fixed $\boldsymbol{n}=\left\{\mathrm{n}_{\mathrm{i}}\right\}_{\mathrm{i}=1}^{\infty} \in \ell^{1}$,

$$
\begin{gathered}
\left\|\boldsymbol{f}^{2}(\cdot, \boldsymbol{n} ; \mathbf{K})\right\|_{1}=\sum_{\mathrm{i}=1}^{\infty}\left|\mathrm{f}_{\mathrm{i}}^{2}(\cdot, \boldsymbol{n} ; \mathbf{K})\right| \\
=\sum_{\mathrm{i}=1}^{\infty}\left|\mathrm{n}_{\mathrm{i}} \mathrm{f}_{\mathrm{i}}^{\mathrm{d}}(\cdot, \boldsymbol{n} ; \mathbf{K})\right| \in \mathrm{C}\left(\mathrm{I}_{0}, \ell^{1}\right)
\end{gathered} .
$$

Hence $\boldsymbol{f}^{2}(\cdot, ; \mathrm{K}) \in \mathrm{C}_{\mathrm{cw}-}\left(\mathrm{I}_{0} \times \ell^{1}, \ell^{1}\right)$.

By Theorem 2.1, $\boldsymbol{f}^{2}(\cdot, ; ; \mathbf{K}) \in \boldsymbol{C}_{\mathrm{cw}-}\left(\mathrm{I}_{0} \times \ell^{1}, \ell^{1}\right)$. Also, since

$$
\begin{aligned}
\left|f_{i}^{1}(t, \boldsymbol{n} ; \mathbf{K})\right| & =\frac{1}{2}\left|\sum_{j=i}^{i-1} K_{i-j, j}(t) n_{j} n_{i-j}\right| \\
& \leq \frac{1}{2} \sum_{j=i}^{i-1}\left|K_{i-j, j}(t)\right|\left|n_{j}\right|\left|n_{i-j}\right|
\end{aligned}
$$

we have

$$
\begin{aligned}
\left\|\boldsymbol{f}^{1}(\mathrm{t}, \boldsymbol{n} ; \mathbf{K})\right\|_{1} & =\sum_{\mathrm{i}=1}^{\infty}\left|\mathrm{f}_{\mathrm{i}}^{1}(\mathrm{t}, \boldsymbol{n} ; \mathbf{K})\right| \\
& =\frac{1}{2} \sum_{\mathrm{i}=1}^{\infty} \sum_{\mathrm{j}=\mathrm{i}}^{\mathrm{i}-1}\left|\mathrm{~K}_{\mathrm{i}-\mathrm{j}, \mathrm{j}}(\mathrm{t})\right|\left|\mathrm{n}_{\mathrm{j}}\right|\left|\mathrm{n}_{\mathrm{i}-\mathrm{j}}\right| \\
& =\frac{1}{2} \sum_{\mathrm{i}=1}^{\infty} \sum_{\mathrm{j}=\mathrm{i}}^{\infty}\left|\mathrm{K}_{\mathrm{i}, \mathrm{j}}(\mathrm{t})\right|\left|\mathrm{n}_{\mathrm{j}}\right|\left|\mathrm{n}_{\mathrm{i}}\right| \\
& \leq \frac{1}{2} \sum_{\mathrm{i}=1}^{\infty} \sum_{\mathrm{j}=\mathrm{i}}^{\infty} \mathrm{M}_{\mathrm{Kmax}}(\mathrm{J})\left|\mathrm{n}_{\mathrm{i}}\right|\left|\mathrm{n}_{\mathrm{j}}\right| \\
& =\frac{1}{2} \mathrm{M}_{\text {Kmax }}(\mathrm{J}) \sum_{\mathrm{i}=1}^{\infty}\left|\mathrm{n}_{\mathrm{i}}\right| \sum_{\mathrm{j}=\mathrm{i}}^{\infty}\left|\mathrm{n}_{\mathrm{j}}\right| \\
& \leq \frac{1}{2} \mathrm{M}_{\mathrm{Kmax}}(\mathrm{J})\left(\|\boldsymbol{n}\|_{1}\right)^{2}<\infty
\end{aligned}
$$

where we have used (7). Hence

$\boldsymbol{f}^{1}(\cdot, ; \mathbf{K}) \in \boldsymbol{C}_{\mathrm{cw}}\left(\mathrm{I}_{0} \times \ell^{1}, \ell^{1}\right)$. Since

$$
\begin{aligned}
\left|\mathrm{f}_{\mathrm{i}}^{1}(\mathrm{t}, \boldsymbol{n} ; \mathbf{K})\right| & =\frac{1}{2}\left|\sum_{\mathrm{j}=\mathrm{i}}^{\mathrm{i}-1} \mathrm{~K}_{\mathrm{i}-\mathrm{j}, \mathrm{j}}(\mathrm{t}) \mathrm{n}_{\mathrm{j}} \mathrm{n}_{\mathrm{i}-\mathrm{j}}\right| \\
& \leq \frac{1}{2} \sum_{\mathrm{j}=\mathrm{i}}^{\mathrm{i}-1}\left|\mathrm{~K}_{\mathrm{i}-\mathrm{j}, \mathrm{j}}(\mathrm{t})\right|\left|\mathrm{n}_{\mathrm{j}}\right|\left|\mathrm{n}_{\mathrm{i}-\mathrm{j}}\right|
\end{aligned}
$$

and

$$
\begin{aligned}
\left\|\boldsymbol{f}^{1}(\mathrm{t}, \boldsymbol{n} ; \mathbf{K})\right\|_{1} & =\sum_{\mathrm{i}=1}^{\infty}\left|\mathrm{f}_{\mathrm{i}}^{1}(\mathrm{t}, \boldsymbol{n} ; \mathbf{K})\right| \\
& =\frac{1}{2} \sum_{\mathrm{i}=1}^{\infty} \sum_{\mathrm{j}=\mathrm{i}}^{\mathrm{i}-1}\left|\mathrm{~K}_{\mathrm{i}-\mathrm{j}, \mathrm{j}}(\mathrm{t})\right|\left|\mathrm{n}_{\mathrm{j}}\right|\left|\mathrm{n}_{\mathrm{i}-\mathrm{j}}\right| \\
& =\frac{1}{2} \sum_{\mathrm{i}=1}^{\infty} \sum_{\mathrm{j}=\mathrm{i}}^{\infty}\left|\mathrm{K}_{\mathrm{i}-\mathrm{j}, \mathrm{j}}(\mathrm{t})\right|\left|\mathrm{n}_{\mathrm{j}}\right|\left|\mathrm{n}_{\mathrm{i}}\right| \\
& \leq \frac{1}{2} \sum_{\mathrm{i}=1}^{\infty} \sum_{\mathrm{j}=\mathrm{i}}^{\infty} \mathrm{M}_{\mathrm{Kmax}}(\mathrm{J})\left|\mathrm{n}_{\mathrm{i}}\right|\left|\mathrm{n}_{\mathrm{j}}\right| \\
& ==\frac{1}{2} \mathrm{M}_{\mathrm{Kmax}}(\mathrm{J}) \sum_{\mathrm{i}=1}^{\infty}\left|\mathrm{n}_{\mathrm{i}}\right| \sum_{\mathrm{j}=\mathrm{i}}^{\infty}\left|\mathrm{n}_{\mathrm{j}}\right| \\
& \leq \frac{1}{2} \mathrm{M}_{\mathrm{Kmax}}(\mathrm{J})\left(\|\boldsymbol{n}\|_{1}\right)^{2}<\infty
\end{aligned}
$$

we have for fixed $\mathbf{n}$,

$\left\|\boldsymbol{f}^{1}(\cdot, \boldsymbol{n} ; \mathbf{K})\right\|_{1}=\sum_{\mathrm{i}=1}^{\infty}\left|\mathrm{f}_{\mathrm{i}}^{1}(\cdot, \boldsymbol{n} ; \mathbf{K})\right| \in \mathrm{C}\left(\mathrm{I}_{0}, \ell^{1}\right)$. Hence

$\boldsymbol{f}^{1}(\cdot, \cdot ; \mathbf{K}) \in \boldsymbol{C}_{\mathrm{cw}+}\left(\mathrm{I}_{0} \times \ell^{1}, \ell^{1}\right)$. Since $\boldsymbol{C}_{\mathrm{cw}-}\left(\mathrm{I} \times \ell^{1}, \ell^{1}\right)$ is a vector space (note

$\begin{aligned}\|\boldsymbol{f}(\mathrm{t}, \boldsymbol{n} ; \mathbf{K})\|_{1} & \left.\leq\left\|\boldsymbol{f}^{1}(\mathrm{t}, \boldsymbol{n} ; \mathbf{K})\right\|_{1}+\left\|\boldsymbol{f}^{2}(\mathrm{t}, \boldsymbol{n} ; \mathbf{K})\right\|_{1}\right), \\ & \leq \frac{3}{2} \mathrm{M}_{\mathrm{Kmax}}(\mathrm{J})\left(\|\boldsymbol{n}\|_{1}\right)^{2}<\infty\end{aligned}$

we have that $\boldsymbol{f}(\cdot, ; \mathbf{K}) \in \boldsymbol{C}_{\mathrm{cw}-}\left(\mathrm{I}_{0} \times \ell^{1}, \ell^{1}\right)$.

Now let $\mathbf{K}(\cdot) \in \boldsymbol{C}_{\text {Ств }}\left(\mathrm{I}_{0}, \mathbf{R}^{\infty \times \infty}\right)$. Then by Theorem 
2.16, $\boldsymbol{f}^{\mathrm{d}}(\cdot, ; \mathbf{K}) \in \boldsymbol{C}_{\mathrm{cw}}\left(\mathrm{I}_{0} \times \ell^{1}, \mathbf{R}^{\infty}\right)$. By using Theorem 2.1 and above, $\boldsymbol{f}^{1}(\cdot, ; \mathbf{K}), \boldsymbol{f}^{2}(\cdot, ; \mathbf{K})$ and $\boldsymbol{f}(\cdot, ; \mathbf{K})$ are in $\boldsymbol{C}_{\mathrm{cw}+}\left(\mathrm{I}_{0} \times \ell^{1}, \ell^{1}\right)$

Unfortunately, we have not proved that $\boldsymbol{f}(\cdot, ; \mathbf{K}) \in \boldsymbol{C}\left(\mathrm{I}_{0} \times \ell^{1}, \ell^{1}\right)$. However, assuming $\boldsymbol{f}(\cdot, ; \mathbf{K}) \in \boldsymbol{C}\left(\mathrm{I}_{0} \times \ell^{1}, \ell^{1}\right)$ we consider the Vector Problem (VP):

Vector ODE,

$$
\frac{\mathrm{d} \boldsymbol{n}}{\mathrm{dt}}=\boldsymbol{f}(\mathrm{t}, \boldsymbol{n} ; \mathbf{K}), \mathrm{t} \in \mathrm{I}_{0}=\left(\mathrm{t}_{0-}, \mathrm{t}_{0}, \mathrm{t}_{0+}\right)
$$

IVP IC

$$
\boldsymbol{n}\left(\mathrm{t}_{0}\right)=\boldsymbol{n}_{0}=\left\{\mathrm{n}_{\mathrm{i}}^{0}\right\}_{\mathrm{i}=1}^{\infty}, \mathrm{t} \in \mathrm{I}_{0}=\left(\mathrm{t}_{0-}, \mathrm{t}_{0}, \mathrm{t}_{0+}\right)
$$

where the derivative and equality are in $\ell^{1}$. That is, we now require the derivative to be defined with respect to the norm topology,

$\mathrm{d} \boldsymbol{n}(\mathrm{t}) / \mathrm{dt}=\lim _{\mathrm{h} \rightarrow 0}[\boldsymbol{n}(\mathrm{t}+\mathrm{h})-\boldsymbol{n}(\mathrm{t})] / \mathrm{h}=\left\{\mathrm{dn}_{\mathrm{i}}(\mathrm{t}) / \mathrm{dt}\right\}_{\mathrm{i}=1}^{\infty}$ in $\ell^{1}$, and equality as equality in $\ell^{1}$. For VP, we take our $\Sigma$ space as $\boldsymbol{C}^{1}\left(\mathrm{I}, \ell^{1}\right) \subseteq_{\mathrm{vs}} \boldsymbol{C}\left(\mathrm{I}, \ell^{1}\right)$.

For $\boldsymbol{f}(\cdot, ; \mathbf{K}) \in \boldsymbol{C}\left(\mathrm{I}_{0} \times \ell^{1}, \ell^{1}\right)$ we now show that $\mathrm{VP}$ is equivalent to

$$
\boldsymbol{n}(\mathrm{t})=\boldsymbol{n}_{0}+\int_{\mathrm{t}_{0}}^{\mathrm{t}} \boldsymbol{f}(\mathrm{s}, \boldsymbol{n}(\mathrm{s}) ; \mathbf{K}) \mathrm{ds}
$$

where for $\boldsymbol{n}=\left\{\mathrm{n}_{\mathrm{i}}(\mathrm{t})\right\}_{i=1}^{\infty} \in \boldsymbol{C}^{1}\left(\mathrm{I}, \ell^{1}\right)$ (the $\Sigma$ space) to be a solution of (21), we require $\forall i \in \mathbf{N}$, that (12) holds; that is, integration is componentwise. Equality is in $\ell^{1}$. We refer to this problem as the Integral Vector Problem (IVP)

Theorem 2.22. The distribution $\boldsymbol{n}(\mathrm{t})=\left\{\mathrm{n}_{\mathrm{i}}(\mathrm{t})\right\}_{i=1}^{\infty}$ is a solution of VP in $C^{1}\left(\mathrm{I}, \ell^{1}\right)$ if and only if it is a solution of IVP in $\boldsymbol{C}^{1}\left(\mathrm{I}, \ell^{1}\right)$.

Proof. For both problems we have chosen the $\Sigma$ space to be $\boldsymbol{C}^{1}\left(\mathrm{I}, \ell^{1}\right)$. Now assume that $\boldsymbol{n}(\mathrm{t})=\left\{\mathrm{n}_{\mathrm{i}}(\mathrm{t})\right\}_{i=1}^{\infty}$ is a solution of VP so that (19) and (20) are satisfied, and the right hand side of (19) is in $\boldsymbol{C}\left(\mathrm{I}, \ell^{1}\right)$. We may integrate from $t_{0}$ to $t$ using (17) to obtain the vector equation

$$
\begin{aligned}
\boldsymbol{n}(\mathrm{t}) & =\boldsymbol{n}\left(\mathrm{t}_{0}\right)+\int_{\mathrm{s}=\mathrm{t}_{0}}^{\mathrm{s}=\mathrm{t}} \frac{\mathrm{d} \boldsymbol{n}(\mathrm{s})}{\mathrm{ds}} \mathrm{ds} \\
& =\boldsymbol{c}+\int_{\mathrm{t}_{0}}^{\mathrm{t}} \boldsymbol{f}(\mathrm{s}, \boldsymbol{n}(\mathrm{s}) ; \mathbf{K}) \mathrm{ds}
\end{aligned}
$$

Applying the initial condition we obtain (21). Now assume that $\boldsymbol{n}(\cdot)$ is a solution of (21). Then substitute $\mathrm{t}=\mathrm{t}_{0}$ to obtain (20). Since $\boldsymbol{f}(\mathrm{t}, \boldsymbol{n}(\mathrm{t}) ; \mathbf{K}) \in \mathrm{C}\left(\mathrm{I}, \mathbf{R}^{\infty}\right) \subseteq \mathrm{C}_{\mathrm{CW}}\left(\mathrm{I}, \mathbf{R}^{\infty}\right)$, and $\boldsymbol{n}(\mathrm{t})=\boldsymbol{n}_{0}+\int_{\mathrm{t}_{0}}^{\mathrm{t}} \boldsymbol{f}(\mathrm{s}, \boldsymbol{n}(\mathrm{s}) ; \mathbf{K}) \mathrm{ds} \in \boldsymbol{C}\left(\mathrm{I}, \ell^{1}\right)$, differentiating (componentwise) we have that $\mathrm{d} \boldsymbol{n} / \mathrm{dt}=\left\{\mathrm{dn}_{\mathrm{i}}(\mathrm{t}) / \mathrm{dt}\right\}_{\mathrm{i}=1}^{\infty}$ and that (19) holds.

Theorem 2.23. If $\mathbf{K}(\cdot) \in \mathrm{M}_{\text {СтВ }}\left(\mathrm{I}_{0}, \mathbf{R}^{\infty \times \infty}\right)$, then $\boldsymbol{f}^{\mathrm{d}}(\cdot, ; \mathbf{K}) \in \boldsymbol{C}_{\mathrm{cw}}\left(\mathrm{I} \times \ell^{1}, \mathbf{R}^{\infty}\right)$ and $\boldsymbol{f}(\cdot, \cdot ; \mathbf{K}) \in \boldsymbol{C}_{\mathrm{cw}+}\left(\mathrm{I} \times \ell^{1}, \ell^{1}\right)$. If $\boldsymbol{n}(\cdot) \in \boldsymbol{C}\left(\mathrm{I}, \ell^{1}\right)$, then $\boldsymbol{f}^{\mathrm{d}}(\cdot, \boldsymbol{n}(\cdot) ; \mathbf{K}) \in \boldsymbol{C}_{\mathrm{cw}}\left(\mathrm{I}, \mathbf{R}^{\infty}\right)$ and $\boldsymbol{f}(\cdot, \boldsymbol{n}(\cdot) ; \mathbf{K}) \in \mathrm{C}_{\mathrm{CW}}\left(\mathrm{I}, \ell^{1}\right)$. On the other hand, if $\mathbf{K} \in \mathrm{M}_{\text {СТВS }}\left(\mathrm{I}_{0}, \mathbf{R}^{\infty \times \infty}\right)$, then $\boldsymbol{f}^{\mathrm{d}}(\cdot, ; \mathbf{K}) \in \boldsymbol{C}_{\mathrm{cw}-}\left(\mathrm{I} \times \ell^{1}, \mathbf{R}^{\infty}\right)$ and $\boldsymbol{f}(\cdot, ; \mathbf{K}) \in \boldsymbol{C}_{\mathrm{cw}-}\left(\mathrm{I} \times \ell^{1}, \ell^{1}\right)$. If, in addition, $\boldsymbol{n}(\cdot) \in \boldsymbol{C}_{\mathrm{LUB}}\left(\mathrm{I}, \ell^{1}\right)$, then $\boldsymbol{f}^{\mathrm{d}}(\cdot, \boldsymbol{n}(\cdot) ; \mathbf{K}) \in \mathrm{C}_{\mathrm{cw}}\left(\mathrm{I}, \mathbf{R}^{\infty}\right)$ and $\boldsymbol{f}(\cdot, \boldsymbol{n}(\cdot) ; \mathbf{K}) \in \boldsymbol{C}_{\mathrm{CW}}\left(\mathrm{I}, \ell^{1}\right)$.

Proof. If $\mathbf{K} \in \mathrm{M}_{\text {Ств }}\left(\mathrm{I}_{0}, \mathbf{R}^{\infty \times \infty}\right)$, then by Theorem 2.16, $\boldsymbol{f}^{\mathrm{d}}(\cdot, ; \mathbf{K}) \in \boldsymbol{C}_{\mathrm{cw}}\left(\mathrm{I} \times \ell^{1}, \mathbf{R}^{\infty}\right)$. By Theorem 2.21, $\boldsymbol{f}(\cdot, \cdot ; \mathbf{K}) \in \boldsymbol{C}_{\mathrm{cw}+}\left(\mathrm{I} \times \ell^{1}, \ell^{1}\right)$. If $\boldsymbol{n}(\cdot) \in \boldsymbol{C}\left(\mathrm{I}, \ell^{1}\right)$, then $\mathrm{f}_{\mathrm{i}}^{\mathrm{d}}(\cdot, \boldsymbol{n}(\cdot) ; \mathbf{K}) \in \mathrm{C}_{\mathrm{cw}}\left(\mathrm{I}, \mathbf{R}^{\infty}\right)$ and $\boldsymbol{f}(\cdot, \boldsymbol{n}(\cdot) ; \mathbf{K}) \in \boldsymbol{C}_{\mathrm{cw}}\left(\mathrm{I}, \ell^{1}\right)$. Now let $\mathbf{K}(\cdot) \in \mathrm{M}_{\text {СтвS }}\left(\mathrm{I}_{0}, \mathbf{R}^{\infty \times \infty}\right)$. Then by Theorem 2.21, $\boldsymbol{f}^{\mathrm{d}}(\cdot, ; \mathbf{K}) \in \boldsymbol{C}_{\mathrm{cw}-}\left(\mathrm{I} \times \ell^{1}, \mathbf{R}^{\infty}\right)$ and $\boldsymbol{f}(\cdot, ; \mathbf{K}) \in \boldsymbol{C}_{\mathrm{cw}-}\left(\mathrm{I} \times \ell^{1}, \ell^{1}\right)$. If, in addition, $\boldsymbol{n}(\cdot) \in \boldsymbol{C}_{\mathrm{LUB}}\left(\mathrm{I}, \ell^{1}\right)$, then $\boldsymbol{f}^{\mathrm{d}}(\cdot, \boldsymbol{n}(\cdot) ; \mathbf{K}) \in \boldsymbol{C}_{\mathrm{cw}}\left(\mathrm{I}, \mathbf{R}^{\infty}\right)$ and $\boldsymbol{f}(\cdot, \boldsymbol{n}(\cdot) ; \mathbf{K}) \in \boldsymbol{C}_{\mathrm{CW}}\left(\mathrm{I}, \ell^{1}\right)$.

To define VDAP in the continuous context, we would like $\boldsymbol{f}^{\mathrm{d}}(\cdot, ; \mathbf{K}) \in \mathrm{C}_{\mathrm{cw}}\left(\mathrm{I} \times \ell^{1}, \mathbf{R}^{\infty}\right)$ and $\boldsymbol{f}(\cdot, ; \mathbf{K}) \in \boldsymbol{C}\left(\mathrm{I} \times \ell^{1}, \ell^{1}\right)$. Then for $\boldsymbol{n}(\cdot) \in \boldsymbol{C}\left(\mathrm{I}, \ell^{1}\right)$, we would have $\boldsymbol{f}^{\mathrm{d}}(\cdot, \boldsymbol{n}(\cdot) ; \mathbf{K}) \in \boldsymbol{C}_{\mathrm{cw}}\left(\mathrm{I}, \mathbf{R}^{\infty}\right)$ and $\boldsymbol{f}(\cdot, \boldsymbol{n}(\cdot) ; \mathbf{K}) \in \boldsymbol{C}\left(\mathrm{I}, \ell^{1}\right)$. When $\mathbf{K}(\cdot) \in \mathbf{M}_{\text {Ств }}\left(\mathrm{I}_{0}, \mathbf{R}^{\infty \times \infty}\right)$, we do have $\boldsymbol{f}^{\mathrm{d}}(\cdot, \cdot ; \mathbf{K}) \in \boldsymbol{C}_{\mathrm{cw}}\left(\mathrm{I} \times \ell^{1}, \mathbf{R}^{\infty}\right)$, but have only shown that $\boldsymbol{f}(\cdot, ; \mathbf{K}) \in \boldsymbol{C}_{\mathrm{cw}+}\left(\mathrm{I} \times \ell^{1}, \ell^{1}\right)$ so that for $\boldsymbol{n}(\cdot) \in \mathrm{C}\left(\mathrm{I}, \ell^{1}\right)$, we have $\boldsymbol{f}^{\mathrm{d}}(\cdot, \boldsymbol{n}(\cdot) ; \mathbf{K}) \in \mathrm{C}_{\mathrm{cw}}\left(\mathrm{I}, \mathbf{R}^{\infty}\right)$ and $\boldsymbol{f}(\cdot, \boldsymbol{n}(\cdot) ; \mathbf{K}) \in \boldsymbol{C}_{\mathrm{cw}}\left(\mathrm{I}, \ell^{1}\right)$. We refer to this problem with $\Sigma$ space $\boldsymbol{C}^{1}\left(\mathrm{I}, \ell^{1}\right)$ as VDAP1. When 
$\mathbf{K}(\cdot) \in \mathbf{M}_{\text {СТВ }}\left(\mathrm{I}_{0}, \mathbf{R}^{\infty \times \infty}\right)$, we settle for

$\boldsymbol{f}^{\mathrm{d}}(\cdot, ; \mathbf{K}) \in \boldsymbol{C}_{\mathrm{cw}-}\left(\mathrm{I} \times \ell^{1}, \mathbf{R}^{\infty}\right)$ and

$\boldsymbol{f}(\cdot, ; \mathbf{K}) \in \boldsymbol{C}_{\mathrm{cw}-}\left(\mathrm{I} \times \ell^{1}, \ell^{1}\right)$ so that if $\boldsymbol{n}(\cdot) \in \boldsymbol{C}_{\mathrm{LUB}}\left(\mathrm{I}, \ell^{1}\right)$,

then $\boldsymbol{f}^{\mathrm{d}}(\cdot, \boldsymbol{n}(\cdot) ; \mathbf{K}) \in \boldsymbol{C}_{\mathrm{cw}}\left(\mathrm{I}, \mathbf{R}^{\infty}\right)$ and

$\boldsymbol{f}(\cdot, \boldsymbol{n}(\cdot) ; \mathbf{K}) \in \boldsymbol{C}_{\mathrm{cw}}\left(\mathrm{I}, \ell^{1}\right)$. We refer to this problem with

$\Sigma$ space $\boldsymbol{C}_{\mathrm{LUB}}^{1}\left(\mathrm{I}, \ell^{1}\right)$ as VDAP2. As

$\boldsymbol{C}_{\mathrm{LUB}}^{1}\left(\mathrm{I}, \mathbf{R}^{\infty}\right)=\boldsymbol{C}_{\mathrm{LUB}}^{1}\left(\mathrm{I}, \ell^{1}\right) \subseteq_{\mathrm{vs}} \boldsymbol{C}^{1}\left(\mathrm{I}, \ell^{1}\right)$

$\subseteq_{\mathrm{vs}} \boldsymbol{C}_{\mathrm{cw}}^{1}\left(\mathrm{I}, \ell^{1}\right) \subseteq_{\mathrm{vs}} \boldsymbol{C}_{\mathrm{cw}}^{1}\left(\mathrm{I}, \mathbf{R}^{\infty}\right)$, if we take

$\boldsymbol{C}_{\mathrm{LUB}}^{1}\left(\mathrm{I}, \mathbf{R}^{\infty}\right)=\boldsymbol{C}_{\mathrm{LUB}}^{1}\left(\mathrm{I}, \ell^{1}\right)$ as our $\Sigma$ space for SDAP,

ISDAP, and VDAP1or VDAP2, then they are all equivalent if they have the same problem parameters

$\left(\mathrm{I}_{0}, \mathrm{t}_{0}, \boldsymbol{n}_{0}, \mathbf{K}(\mathrm{t})\right)$.

\section{Summary and Future Work}

For the time-varying kernel $\left(\mathrm{K}_{\mathrm{i}, \mathrm{j}}(\mathrm{t})=\mathrm{A}(\mathrm{t})\right)$ in the analytic context, the problem parameters are

$\left(\mathrm{I}_{0}, \mathrm{t}_{0}, \mathrm{n}_{0}, \mathrm{~A}(\mathrm{t})\right) \in \mathrm{Int}_{\mathrm{o}} \times \mathrm{I}_{0} \times \ell^{1} \times \mathscr{A}\left(\mathrm{I}_{0}, \mathbf{R}\right)$. For this pro-

blem, Moseley [14] used the following problem solving procedure. He first established local uniqueness in

$\mathscr{A}_{\text {cw }}\left(\mathrm{I}_{0}, \mathbf{R}^{\infty}\right)$. However, he chose the smaller $\Sigma$ space $\mathscr{A}_{\text {LUB }}\left(\mathrm{I}, \mathbf{R}^{\infty}\right)$ containing only distributions where (for a time-varying kernel) if $\mathbf{n}(\mathrm{t})$ is in $\mathscr{A}_{\mathrm{LUB}}\left(\mathrm{I}, \mathbf{R}^{\infty}\right)$, then

the depletion coefficients $\boldsymbol{f}^{\mathrm{d}}(\mathrm{t}, \boldsymbol{n} ; \mathbf{K})=\left\{\mathrm{f}_{\mathrm{i}}^{\mathrm{d}}(\mathrm{t}, \boldsymbol{n} ; \mathbf{K})\right\}_{\mathrm{i}=1}^{\infty}$ are in $\mathscr{A}_{\mathrm{cw}}\left(\mathrm{I}_{0}, \mathbf{R}^{\infty}\right)$, He then obtained the explicit formula (6) for the (analytic) solution. He did not rigorously isolate the unknown so he established global existence by showing that the solution given by the formula (6) was in the $\Sigma$ space, checking the initial conditions, and then substituting the formula into (1). Since global existence holds, local uniqueness in the analytic context implies global uniqueness.

If we choose $C_{\mathrm{LUB}}^{1}\left(\mathrm{I}, \mathbf{R}^{\infty}\right)$ as our $\Sigma$ space, then SDAP, ISDAP, VDAP1, and IVDAP2 are all equivalent in the continuous context if they have the same problem parameters $\left(\mathrm{I}_{0}, \mathrm{t}_{0}, \boldsymbol{n}_{0}, \mathbf{K}(\mathrm{t})\right)$. If

$\mathbf{K}(\cdot) \in \mathbf{M}_{\text {СтBS }}\left(\mathrm{I}_{0}, \mathbf{R}^{\infty \times \infty}\right)$ and $\boldsymbol{n}(\cdot) \in \boldsymbol{C}_{\mathrm{LUB}}\left(\mathrm{I}, \mathbf{R}^{\infty}\right)$, we have $\boldsymbol{f}^{\mathrm{d}}(\cdot, \boldsymbol{n}(\cdot) ; \mathbf{K}) \in \boldsymbol{C}_{\mathrm{cw}}\left(\mathrm{I}, \mathbf{R}^{\infty}\right)$, so that we need not specify this condition separately. For the time varying kernel, the solution given by (6) is in $\boldsymbol{C}_{\mathrm{LUB}}^{1}\left(\mathrm{I}, \mathbf{R}^{\infty}\right)$, where $\mathrm{A}(\mathrm{t}) \in \mathrm{C}(\mathrm{I}, \mathbf{R})$ in the continuous context. However, we have not shown (local) uniqueness in the con- tinuous context. To do this we have (at least) four choices:

1) Provide a rigorous derivation of (6) that provides (existence and) uniqueness.

2) Develop and use a Lipschitz condition for: $\mathrm{f}_{\mathrm{i}}(\mathrm{t}, \boldsymbol{n} ; \mathbf{K})$ in the scalar problems SDAP and ISDAP.

3) Extend the (existence and) uniqueness results for FAP in the continuous context to obtain a unique sequential solution to DAP.

4) Develop and use a Lipschitz condition for $\boldsymbol{f}(\mathrm{t}, \boldsymbol{n} ; \mathbf{K})$ in the vector problems VDAP1 and VDAP2.

We have provided preliminaries for the development of a Lipschitz condition for VDAP1 and VDAP2. However, all four alternatives appear to be worthwhile.

\section{REFERENCES}

[1] W. M. Goldberger, "Collection of Fly Ash in a Self-Agglomerating Fluidized Bed Coal Burner," Proceedings of the ASME Annual Meeting, American Society of Mechanical Engineers, Pittsburg, 1967, 16 pp.

[2] J. H. Siegell, "Defluidization Phenomena in Fluidized Beds of Sticky Particles at High Temperatures," Ph.D. Thesis, City University of New York, New York, 1976.

[3] R. L. Drake, "A General Mathematics Survey of the Coagulation Equation," In: G. M. Hidy and J. R. Brock, Eds., Topics in Current Aerosol Research, Pergamon Press, New York, 1972.

[4] M. Von Smoluchowski, "Versuch Einer Mathematichen Theorie der Koagulationskinetik Kollider Lösungen," Zeitschrift fuer Physikalische Chemie, Vol. 92, No. 2, 1917, pp. 129-168.

[5] H. Müller, "Zur Allgemeinen Theorie Ser Raschen Koagulation," Kolloidchemische Beihefte, Vol. 27, No. 6-12, 1928, pp. 223-250.

[6] D. Morganstern, "Analytical Studies Related to the Maxwell-Boltzmann Equation," Journal of Rational Mechanics and Analysis, Vol. 4, No. 5, 1955, pp. 533-555.

[7] Z. A. Melzack, "A Scalar Transport Equation," Transactions of the American Mathematical Society, Vol. 85, No. 2, 1957, pp. 547-560. doi:10.1090/S0002-9947-1957-0087880-6

[8] J. B. McLeod, "On a Finite Set of Nonlinear Differential Equations (II)," Quarterly Journal of Mathematics, Vol. 13, No. 1, 1962, pp. 193-205. doi:10.1093/qmath/13.1.193

[9] A. Marcus, "Unpublished Notes," Rand Corporation, Santa Monica, 1965.

[10] W. H. White, "A Global Existence Theorem for Smoluchowski's Coagulation Equations," Proceedings of the American Mathematical Society, Vol. 80, No. 2, 1980, pp. 273-276.

[11] J. L. Spouge, "An Existence Theorem for the Discrete Coagulation-Fragmentation Equations," Mathematical Proceedings of the Cambridge Philosophical Society, Vol. 96, No. 2, 1984, pp. 351-357.

doi:10.1017/S0305004100062253 
[12] R. P. Treat, "An Exact Solution of the Discrete Smoluchowski Equation and Its Correspondence to the Solution in the Continuous Equation," Journal of Physics A: Mathematical and General, Vol. 23, No. 13, 1990, pp. 30033016. doi:10.1088/0305-4470/23/13/035

[13] D. J. McLaughlin, W. Lamb and A. C. McBride, "An Existence and Uniqueness Result for a Coagulation and Multi-Fragmentation Equation," SIAM Journal on Mathematical Analysis, Vol. 28, No. 5, 1997, pp 1173-1190. doi: $10.1137 / \mathrm{S} 0036141095291713$

[14] J. L. Moseley, "The Discrete Agglomeration Model with Time Varying Kernel," Nonlinear Analysis: Real World Applications, Vol. 8, No. 2, 2007, pp. 405-423. doi:10.1016/j.nonrwa.2005.12.001

[15] J. L. Moseley, "The Discrete Agglomeration Model: The Fundamental Agglomeration Problem with a Time-Varying Kernel," Far East Journal of Applied Mathematics,
Vol. 47, No. 1, 2010, pp. 17-34.

[16] R. H. Martin, "Nonlinear Operators and Differential Equations in Banach Spaces," John Wiley \& Sons, New York, 1976

[17] A.W. Naylor and G. R. Sell, "Linear Operator Theory in Engineering and Science," Holt Rinehart ND Winston, Inc., New York, 1971.

[18] R. G. Bartle, "The Elements of Real Analysis," John Wiley \& Sons, New York, 1976.

[19] J. Stewart, "Essential Calculus, Early Transcendentals," Thomson Brooks/Cole, Independence, 2007

[20] F. Brauer and J. A. Nohel, "The Qualitative Theory of Ordinary Differential Equations," W. A. Benjamin, Inc., New York, 1969

[21] W. Kaplan, “Advanced Calculus," Addison-Wesley Publishing Company, Redwood City, 1991. 